\author{
UNIVERSIDADE DE SÃO PAULO \\ FFCLRP - DEPARTAMENTO DE BIOLOGIA \\ PROGRAMA DE PÓS-GRADUAÇÃO EM ENTOMOLOGIA
}

The mating communication of stingless bees

(Hymenoptera: Apidae, Meliponini)

\title{
A comunicação do processo reprodutivo em abelhas sem ferrão (Hymenoptera: Apidae, Meliponini)
}

Lucas Garcia von Zuben

Tese apresentada à Faculdade de Filosofia, Ciências e Letras de Ribeirão Preto da USP, como parte das exigências para a obtenção do título de Doutor em Ciências. Área: ENTOMOLOGIA 
The mating communication of stingless bees

(Hymenoptera: Apidae, Meliponini)

\section{A comunicação do processo reprodutivo em abelhas sem ferrão (Hymenoptera: Apidae, Meliponini)}

Tese apresentada à Faculdade de Filosofia, Ciências e Letras de Ribeirão Preto da Universidade de São Paulo, como parte das exigências para a obtenção do título de Doutor em Ciências. Área: Entomologia Orientador: Prof. Dr. Fábio Santos do Nascimento 
Autorizo a reprodução e divulgação total ou parcial deste trabalho, por qualquer meio convencional ou eletrônico, para fins de estudo e pesquisa, desde que citada a fonte.

Von Zuben, Lucas Garcia

The mating communication of stingless bees (Hymenoptera: Apidae, Meliponini) / A comunicação do processo reprodutivo em abelhas sem ferrão (Hymenoptera: Apidae, Meliponini). Ribeirão Preto, 2017.

106 p. : il. ; $30 \mathrm{~cm}$

Tese de doutorado, apresentada à Faculdade de Filosofia Ciências e Letras de Ribeirão Preto/USP. Área de concentração: Entomologia.

Orientador: Nascimento, Fábio Santos do.

1. Scaptotrigona depilis. 2. Sex pheromones. 3. Mating behavior. 4. Social insects. 5. Drone aggregations. 


\section{AGRADECIMENTOS}

À Universidade de São Paulo, Faculdade de Filosofia, Ciências e Letras de Ribeirão Preto e ao Programa de Pós-Graduação em Entomologia pela oportunidade concedida.

Ao Conselho Nacional de Desenvolvimento Científico e Tecnológico e à Coordenação de Aperfeiçoamento de Pessoal de Nível Superior (CAPES) pelo financiamento da pesquisa.

Ao Prof. Dr. Fábio Santos do Nascimento pela orientação, apoio, incentivo e confiança depositados, fundamentais para a realização deste estudo.

Special thanks to Prof. Christoph Grueter for all the supervision given during the whole study. His contribution was fundamental for the development of this $\mathrm{PhD}$. He was always very dedicated and patient to discuss, teach, and follow the project development. I am very grateful for all the discussions, ideas and valuable comments and suggestions in the preliminary versions of this thesis. He also kindly received me for internship in his laboratory at the University of Lausanne, greatly contributing to my academic formation.

Special thanks to Francisca Serges for all the friendship and nice discussions, which directly and indirectly contributed to improve my work. I am also very grateful for the kind reception offered during my stay in Lausanne.

To prof. Laurent Keller for receiving me in his group at the University of Lausanne and for the support given during the development of the internship.

Aos indivíduos de Scaptotrigona depilis pelo sacrifício involuntário indispensável à realização desta pesquisa.

Aos meus pais, Adriana e Marcos, e aos meus irmãos, Mari, Vitor, Carol e Dante, por serem parte de mim. Em especial à minha querida Carolinda, pela revisão e formatação final da tese.

À Rafa, meu amor, pelo carinho, compreensão, parceria e apoio durante todo o doutorado, especialmente na reta final. Muito obrigado por ser essa mulher incrível e por compartilhar a vida comigo.

À Decoy por permitir realizar os experimentos de olfatometria no seu laboratório e aos parceiros dessa empreitada, James e Túlio, pela compreensão e apoio durante todo o desenvolvimento deste trabalho. 
Aos meus amigos Ganso, Charales, Ingrid e Aline por revisarem o texto e pelos comentários e sugestões valiosíssimos.

Às secretárias do Programa de pós-graduação em Entomologia, Renata e Vera, pela atenção, competência e presteza de sempre.

A todos os colegas de laboratório por terem participado direta ou indiretamente na realização deste trabalho e, especialmente, ao Dr. Sidnei Mateus, que sempre ofereceu importante ajuda durante todo o doutorado;

À Azia, minha primeira orientanda, pela amizade, compreensão e apoio oferecido.

Aos amigos que de diferentes maneiras me ajudaram durante esses anos de convivência em Ribeirão Preto, especialmente àqueles da Kalakuta e os agregados. 
"Like a star rising from the dark and meeting other star that flashes up for a moment only to disappear again in the dark, so man and woman meet each other. They are gliding along together. They light up in love, a briefflame - and disappear again in different directions" Edvard Munch 


\section{RESUMO}

Von Zuben, L. G. A comunicação do processo reprodutivo em abelhas sem ferrão (Hymenoptera: Apidae, Meliponini). 2017. 106f. Tese (Doutorado em Ciências). Faculdade de Filosofia, Ciências e Letras de Ribeirão Preto, Universidade de São Paulo, Ribeirão Preto, 2017.

O processo reprodutivo é de extrema importância para os organismos vivos, é através dele que os indivíduos transmitem as informações contidas em seus genes para as próximas gerações. Para que qualquer indivíduo seja bem-sucedido nesse processo, o primeiro desafio a ser superado é encontrar um parceiro sexual. Para cumprir essa tarefa, machos e fêmeas comunicam sua presença utilizando uma variedade de canais sensoriais. Nas abelhas sociais, o encontro entre machos e fêmeas é um processo complexo e resultado de um refinado sistema de comunicação, mediado principalmente por sinais químicos. Embora Meliponini seja o maior e mais diverso grupo de abelhas sociais, existem poucas informações sobre a comunicação sexual desses insetos. Um fenômeno comum nesse grupo de abelhas é a formação de grandes agregados de machos nas proximidades de colônias que possuem uma rainha virgem. No entanto, os sinais envolvidos na atração dos machos e na formação desses agregados são pouco conhecidos. Desse modo, este trabalho objetivou investigar os fatores envolvidos na comunicação sexual de Meliponini. Para explorar esse problema, nós realizamos uma revisão sobre a biologia reprodutiva dessas abelhas (cap. 1), testamos o papel das forrageiras na atração de machos (cap.2), identificamos os compostos presentes nas marcas depositadas por machos nas agregações (cap.3) e investigamos os fatores relacionados à escolha dos machos por uma determinada colônia (cap. 4). Os resultados obtidos apontam que as forrageiras têm um papel central na atração dos machos e que os machos depositam ativamente seus hidrocarbonetos cuticulares nos locais de agregação. Além disso, foi possível identificar que a atratividade de uma colônia está relacionada com a sua biomassa. Assim, esses resultados contribuem para ampliar nosso conhecimento sobre o processo reprodutivo em abelhas sem ferrão e mostram que a comunicação sexual desse grupo de insetos é um processo tão complexo quanto fascinante que envolve machos, rainhas e operárias.

Palavras-chave: Scaptotrigona depilis; feromônios sexuais; comportamento de cópula; insetos sociais; agregações de machos. 


\begin{abstract}
Von Zuben, L. G. The mating communication of stingless bees (Hymenoptera: Apidae, Meliponini). 2017. PhD thesis. Faculdade de Filosofia, Ciências e Letras de Ribeirão Preto, Universidade de São Paulo, Ribeirão Preto, 2017.

Reproduction is the utmost important process for living organisms since it is through this process that individuals can transmit their genetic information to the next generation. To be successful in this process, the first challenge individuals need to overcome is finding a sexual partner. To accomplish this task, males and females communicate their presence using several sensorial modalities. In highly eusocial bees, this complex process is the outcome of a precise chemical communication system. Stingless bees (Meliponini) represents the most species-rich group of eusocial bees and although a lot of information related to the group can be found in the literature, very little is known about their mating communication. A common phenomenon in this group of social bees is the formation of large male aggregations in front of nests during reproductive events. However, the factors involved in the formation of such male aggregation are poorly understood. Therefore, the aim of this study was to investigate the mating communication of stingless bees. To explore this problem, we reviewed the mating biology of the bees (chapter 1), tested the role of foragers in the attraction of males (chapter 2), identified the compounds that drones deposit at the aggregation site (chapter 3) and investigated the factors related to the differential attraction of males to colonies (chapter 4). Our results suggest that foragers have a central role in the long-range attraction of males and that males actively deposit their cuticular hydrocarbons at the aggregation site. Furthermore, we observed that the number of attracted males increased with the weight of colonies, showing that the attractiveness of colonies is related to their biomass. Thus, these results contribute to improve our knowledge about the reproductive process of stingless bees and show that the sexual communication of these bees is as complex as fascinating and involves males, queens and workers.
\end{abstract}

Key words: Scaptotrigona depilis; sex pheromones; mating behavior; social insects; drone aggregations. 


\section{SUMÁRIO}

General Introduction.............................................................................................................9

CHAPTER 1 - Stingless bees mating biology .........................................................................11

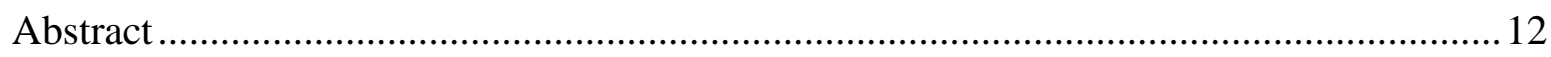

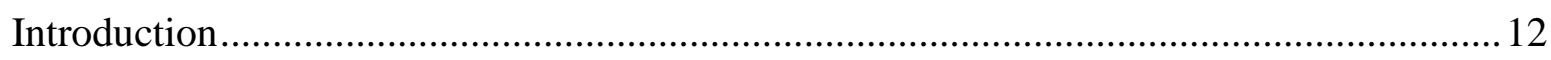

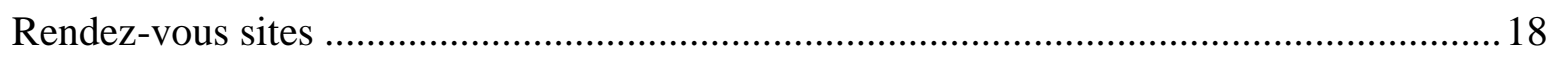

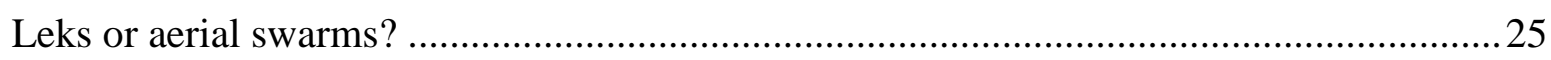

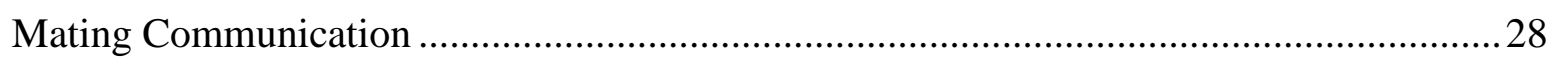

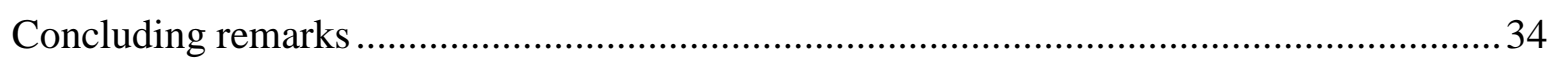

CHAPTER 2 - Nuptial messengers: the role of workers for male attraction in the stingless bee Scaptotrigona depilis ........................................................................................35

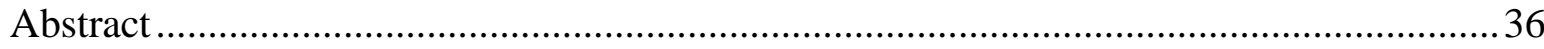

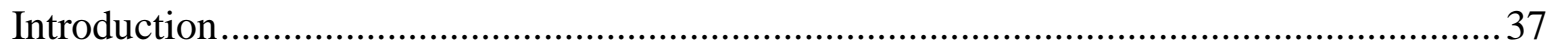

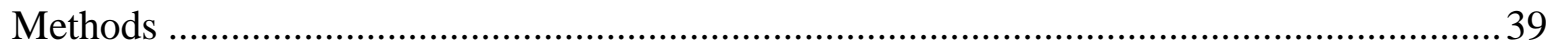

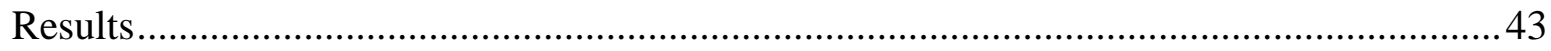

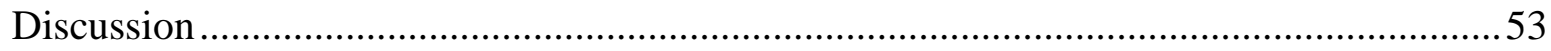

CHAPTER 3 - The aggregation pheromone of males ...........................................................59

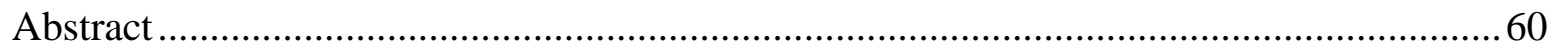

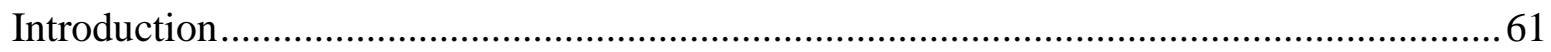

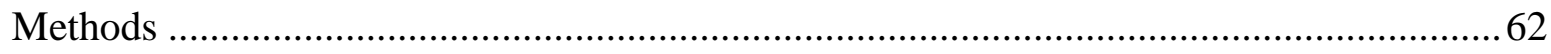

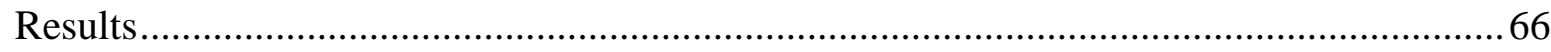

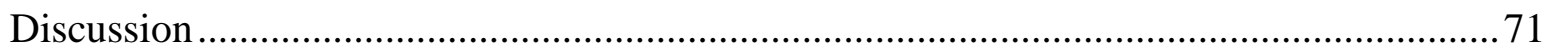

CHAPTER 4 - Differential attraction of males: symmetry breaking or

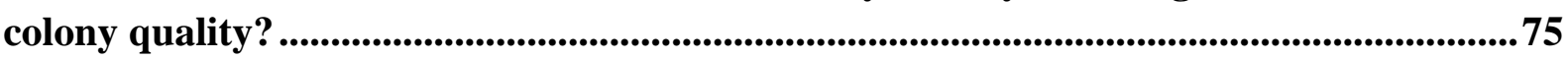

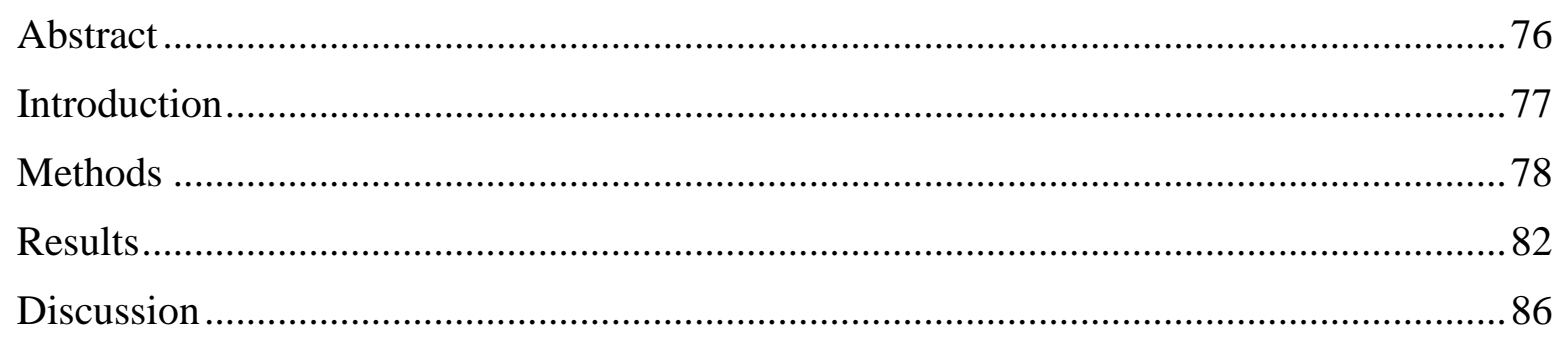

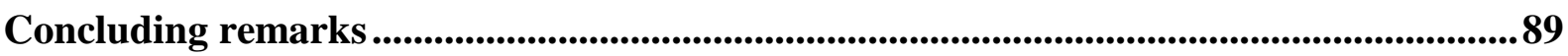

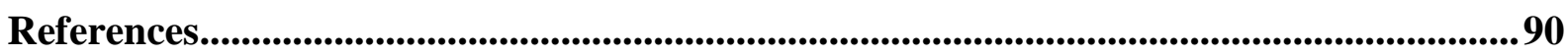

Appendix ..........................................................................................................................................99

Appendix 1 - Project developed during the internship at the University of Lausanne

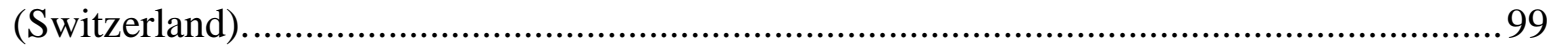




\section{General Introduction}

For centuries, researchers have studied the fascinating strategies that males and females employ to ensure their genetic contribution is passed down to further generations. Research indicates that multiple ecological variables affect the evolution of these sexual behaviors in complex ways. Mating is not a trivial activity and both males and females overcome several challenges to successfully reproduce. The first step of mating is the detection of a potential reproductive partner. To locate mates, animals may use a diversity of sensorial modes. This sexual communication increases the efficiency of mate finding and minimizes the costs of non-specific encounters. The study of location signaling by males and females in the context of reproduction is fundamental to a comprehensive understanding of the mating biology of any species.

In this study, we explored the mating communication of the diverse group of highly eusocial stingless bees. A common phenomenon found in this group of bees is the formation of large drone aggregations in front of nests during reproductive events. However, the mechanisms males use to find nests having virgin queens and successfully copulate are poorly understood. Therefore, the aim of this thesis was to better understand the components of the sexual communication in Meliponini. To do that, we used Scaptotrigona depilis as a model species. This species naturally occurs in our study site and is very resistant to manipulation. Moreover, it is possible to easily start the reproductive process in colonies of $S$. depilis by removing the old physogastric queen. In addition, species belonging to the same genus (i.e. S. mexicana and S. postica) had their mating biology investigated, which facilitates a comparative analysis.

In chapter 1, we reviewed the available information on stingless bee mating biology. We discussed the diversity of behavior found in this group of bees using a previously-established framework explaining the sexual behavior of other insects. The aim of this chapter was to 
establish the theoretical background of the whole study and contextualize the research conducted in subsequent chapters. In chapter 2, we examined how foraging activity affects male attendance levels during reproductive events. The available evidence suggests that queen produced compounds do not explain the massive attraction of males to stingless bee nests. Consequently, researchers have proposed that foragers could be the agents responsible for such attraction, but this hypothesis was never tested prior to this study. We combined behavioral test with chemical analyses to evaluate the effect of foraging activity on the attraction of males.

Previous studies have also shown that communication among males is fundamental for the formation of drone aggregations. Stingless bee males seem to mark the aggregation site with pheromones, but the identity and source of the compounds comprising these pheromone markings are still unknown. Therefore, in chapter 3, we collected drone marks at aggregation sites and identified the compounds that could potentially act as aggregating pheromones.

Finally, during our studies we observed a large variation in the number of males attracted to colonies, ranging from few to thousands of males. Thus, in chapter 4 we investigated the factors involved in the differential attraction of males to colonies. We tested whether this observation could be the result of an emergent property of the communication among males (the 'symmetry breaking' hypothesis) or if differences in the quality of colonies could explain such differences in the number of attracted males.

Besides the studies mentioned above, we also present in this thesis (appendix 1) the scientific project developed at the University of Lausanne (Lausanne, Switzerland), in cooperation with Prof. Laurent Keller and Prof. Christoph Grueter. This project aimed to investigate factors involved in the evolution of social information use in stingless bees. Thus, we developed an Agent-Based Model (ABM) to test the effect of competition on the foraging strategies of stingless bees. 
CHAPTER 1

Stingless bees mating biology 


\begin{abstract}
Mating is a key event for all sexual animals. Among the endless varieties of sexual behavior evolution has shaped, social insects stand out. Recently, the mating behavior of ants, honeybees and bumblebees was reviewed. However, the large and diverse group of stingless bees was far less explored. Most of the current knowledge about Meliponini mating biology is the result of anecdotal observations and only a few systematic studies have been done. Here we aimed to review the available data on the mating behavior of these group of bees, suggesting further investigation on the existing gaps. As the female's life cycle is similar across the whole group of bees, we give a special focus to male behavior. We describe their mate seeking strategies and try to classify their behavior. In particular, we highlight the differences between the two main patterns of male behavior found in this group of social bees. We also explore stingless bee sexual communication, discussing the signaling role of queens, males and workers. To make an evolutionary sense of the diversity found in Meliponini, we discuss their behavior based on the framework proposed for other bees and social insects.
\end{abstract}

\title{
Introduction
}

Mating is an essential event in the life of almost every sexual animal. It is the first step of the crucial moment when individuals transmit their genetic legacy to the next generation. Across time, evolution has shaped endless varieties of sexual behavior in males and females. Bright colors, beautiful songs, nuptial gifts and good perfumes are all used by animals to charm the opposite sex (Alcock 2013). However, behind this apparent cooperative process lies an important conflict that arises from the asymmetrical investment of males and females in reproduction. Females gametes are large, immobile and full of resources, while male gametes are small, mobile and carry little more than a piece of DNA (Parker et al. 1972). Additionally, 
females also often invest more in parental care (Davies et al. 2012). This leads to males having a greater potential rate of reproduction (Clutton-Brock and Parker 1992). Thus, male reproductive success increases with number of matings, while for females it does not increase beyond the first mating (Bateman 1948). The asymmetrical investment in reproduction by males and females has an impact on sexual behavior. Females will be a limiting factor for males' reproductive success and males are expected to compete for access to females. Generally, the behavior output of this conflict of interests is choosy females and competitive males.

Ecological factors are also essential to understand mating system patterns since they affect the capacity to defend and monopolize mates (Emlen and Oring 1977). According to Emlen and Oring (1977), the degree to which an individual of the low-investing sex can control access to the limiting sex is affected by certain environmental factors. These authors suggest that the spatiotemporal distribution of key resources and mates is particularly relevant to understand the evolution of mating systems. They also argue that the intensity of sexual selection and potential for polygamy increases with the potential for defending and monopolizing mates or resources.

Sexual behavior is, therefore, the result of a complex set of variables. Among the many different reproductive behaviors evolution has shaped, social hymenoptera stands out. Social behavior adds even more complexity to the already multifaceted mating process. These insects form colonies of up to 20 million individuals and have in common cooperative brood care and reproductive division of labor (Wilson et al. 1990; Hölldobler and Wilson 2009). In general, female social insects have similar life cycles, mating early in life and losing attractiveness soon after copulation (Boomsma et al. 2005; Paxton 2005). The observed pattern of mating system in social hymenoptera is monandrous females and polygynous males (Eickwort and Ginsberg 1980; Ayasse et al. 2001; Boomsma et al. 2005; Paxton 2005). 
Exceptions to this rule include the polyandrous honeybee females and the monogynous honeybee and stingless bee males (Boomsma et al. 2005). However, female multiple mating might be more widespread among social insects than previously suggested (Hughes et al. 2008; Baer 2014)

As part of the effort to understand mating in this fascinating group of insects, the mating biology of several social hymenoptera species was investigated. Recently, the mating biology of ants (Baer 2011), honeybees (Baer 2005) and bumblebees (Baer 2003) were reviewed. In contrast, the mating biology of stingless bees (Meliponini) has received far less attention. With more than 600 species, Meliponini is the largest and most diverse groups of social bees (Rasmussen and Cameron 2010). The high diversity of species within this group offers good opportunities to increase our understanding of the reproductive process not only of bees but also of other insects.

The stingless bee queens (i.e. the reproductive females), like almost all other female bees, become receptive early after emergence and lose attractiveness soon after copulation (Engels and Imperatriz-Fonseca, 1990). They mate only once in life (Peters et al. 1999; Strassmann 2001; Jaffé et al. 2014). New queens are constantly produced throughout the year (Engels and Imperatriz-Fonseca, 1990; Imperatriz-Fonseca and Zucchi 1995; Moo-Valle et al. 2001; Veen et al. 2004; Prato and Soares 2013). However, most of the queens produced are killed right after their emergence, having no chance to reproduce (Engels and Imperatriz-Fonseca, 1990; da Silva et al. 1972; Imperatriz-Fonseca and Zucchi 1995; Kärcher et al. 2013). In some species, they can hide in "refuge cells" (also called prison cells) and escape from death (Juliani 1962; Imperatriz-Fonseca and Zucchi 1995; Engels and Imperatriz-Fonseca, 1990; ). So, the first challenge stingless bee queens need to overcome is workers' resistance.

New queens can mate when there is a queen replacement, or when the colony is swarming to make a new daughter colony (Engels and Imperatriz-Fonseca, 1990). Accepted virgin queens 
remain some time inside the nest after emergence. During this period, workers feed and interact intensively with the future queen (Engels and Imperatriz-Fonseca, 1990; ImperatrizFonseca and Zucchi 1995). It does not take a long time until the queen is sexually mature and leaves to make her nuptial flight (Engels 1987; Engels et al. 1993). The time of the nuptial flight varies among species, taking from few minutes to more than one hour (da Silva et al. 1972; Nogueira-Ferreira and Soares 1998; van Veen and Sommeijer 2000; Sommeijer et al. 2003). After mating, she comes back to the nest, where she will remain until the end of her life. A few days after the nuptial flight, she starts oviposition (Engels and Imperatriz-Fonseca, 1990; Kerr et al. 1962; da Silva et al. 1972; van Veen and Sommeijer 2000; Van Veen and Sommeijer 2000).

Stingless bees' males differ from other male bees. They mate only once in life since they leave their genitalia inside the queen after copulation (Colonello and Hartfelder 2005). In Meliponini, many species produce several males over a short period of time, the so-called Male-Producing Period (Chinh et al. 2003; Velthuis et al. 2005; Chinh and Sommeijer 2005). This period does not occur at the same time for all colonies, so, at the population level, the availability of males is constant over the entire year (Chinh et al. 2003; Velthuis et al. 2005; Chinh and Sommeijer 2005). However, in some species like Tetragonisca angustula, the production of males is highly seasonal (Prato and Soares 2013).

After emergence, males soon leave their mother colony. They remain a few days (about 2-3 weeks) inside the nest, and after leaving they never come back (Van Veen et al. 1997; Velthuis et al. 2005). The activities of males outside the nests are poorly known (Velthuis et al. 2005). Males were observed feeding in flowers and at sleeping roosts along with other males (Kerr et al. 1962; Santos et al. 2014). But, certainly, the most conspicuous activity of stingless bee males is the formation of large reproductive aggregations (Michener 1946; Engels 1987; Roubik 1990; Sommeijer and Bruijn 1995; Nogueira-Ferreira and Soares 1998; 
van Veen and Sommeijer 2000; Cameron et al. 2004; Cortopassi-Laurino 2007; Galindo López and Kraus 2009; Boongird and Michener 2010; Boongird 2011; Bänziger and Khamyotchai 2014).

Drone aggregations can have hundreds or even thousands of males and can be located close (Michener 1946; Engels 1987; Roubik 1990; Nogueira-Ferreira and Soares 1998; Cameron et al. 2004; Cortopassi-Laurino 2007; Kraus et al. 2008; Galindo López and Kraus 2009; Boongird and Michener 2010; Boongird 2011; Bänziger and Khamyotchai 2014) or far (Sommeijer and Bruijn 1995; Sommeijer et al. 2004) from the nests. At these aggregations, males remain very close to each other, perching at specific locations (e.g. leaves) most of the time, but also flying periodically (Roubik 1990; Sommeijer and Bruijn 1995; Van Veen et al. 1997; van Veen and Sommeijer 2000; Sommeijer et al. 2004). While perching, males dehydrate nectar (Van Veen et al. 1997; Cortopassi-Laurino 2007).

In nest-associated aggregations, males arrive at the nest area in the morning and leave at the end of the afternoon, returning the next day to the same place (Roubik 1990; Van Veen et al. 1997; Nogueira-Ferreira and Soares 1998; Galindo López and Kraus 2009). They chemically mark their aggregation site, which probably facilitates nest finding the subsequent day (Galindo López and Kraus 2009; see also chapter 3). These aggregations initiate a few days before the nuptial flight and finish a few days after copulation (Kerr et al. 1962; NogueiraFerreira and Soares 1998). In some species, the whole mating process lasts about 13-15 days (Scaptotrigona mexicana: Galindo López and Kraus 2009). Males of an aggregation are not related to each other and come from several different colonies (Paxton 2000; Cameron et al. 2004; Kraus et al. 2008). It is suggested that such male diversity is related to a high male dispersal distance, which could help avoid inbreeding (Cameron et al. 2004; Kraus et al. 2008). 
Staying at an aggregation is a risky activity. Wasps, beetles and phorid flies predate Meliponini males at congregations (Brown 1997; Cortopassi-Laurino 2007; Koedam et al. 2009; Koedam et al. 2011). No aggression among drones occurs in nest-associated aggregations (Roubik 1990; Nogueira-Ferreira and Soares 1998), while agonistic interactions were already observed in non-nest associated aggregations (Sommeijer and Bruijn 1995; Sommeijer et al. 2004). Interaction with conspecific workers may occur (Sommeijer et al. 2004; Schorkopf 2016). Curiously, workers of non-related species were observed visiting aggregations and licking the leg of males (Kerr et al. 1962; LvZ, personal observation). Why workers visit male aggregations of unrelated species is unknown.

As soon as the virgin queen leaves the nest, males quickly fly after her (van Veen and Sommeijer 2000). When males successfully copulate, they leave their large genital capsule inside the queen, known as mating plug (Colonello and Hartfelder 2005). This structure is thought to prevent additional copulations (Colonello and Hartfelder 2005). After copulation, queens return to the colony and there they remove the mating plug (Engels and ImperatrizFonseca, 1990).

Most of the current knowledge about Meliponini mating biology is the result of anecdotal observations and only a few systematic studies have been done (see, for example, Galindo López and Kraus 2009 and Fierro et al. 2011). Here, we review the mating behavior of stingless bees. We bring together all the scattered data about the reproductive process of Meliponini. We focus on mating communication and pre-mating behavior of males. To make sense of the diversity of sexual behavior in this group we use the available frameworks, which were proposed for other bees and other social insects, to interpret and discuss the available data. Doing this, we hope to contribute to the investigation of the ecological factors and underlying mechanisms involved in the evolution of the mating biology of stingless bees. 


\section{Rendez-vous sites}

The place where mating occurs, the so-called rendez-vous site, is a key information to understand the reproductive behavior of bees (Alcock 1978; Eickwort and Ginsberg 1980; Paxton 2005). As the life cycle of females bees is fundamentally the same across the whole group, the observed differences in the reproductive behavior of these insects are attributed to different strategies employed by males to find and secure mates (Alcock 1978; Eickwort and Ginsberg 1980; Paxton 2005). The rendez-vous sites help to understand the evolutionary and ecological bases of male seeking tactics since these sites help to interpret the factors involved in the success of the strategies adopted by males.

The mating behavior of males varies greatly within the group of bees. The places they choose to find females can be grouped into three main categories: flowers, female emergence area and non-resource based landmarks (Alcock 1978; Eickwort and Ginsberg 1980; Paxton 2005). Flowers are the most common rendez-vous sites observed in solitary bees (Alcock 1978). Species like Nomadopsis puellae (Alcock 1980) and Anthidium maculosum (Alcock et al. 1977), just to name a few, are examples of bees that copulate on flowers. In these groups, males either wait on or patrol flowers, which are likely to be visited by receptive females (Alcock 1978; Eickwort and Ginsberg 1980). Shortly after females land on the flower to feed, males quickly copulate with them.

The next common rendez-vous site is female emergence area, which includes general nest area, nest entrance and nest interior (Alcock 1978; Eickwort and Ginsberg 1980; Paxton 2005). Males wait for females at their emergence sites and copulate with them right after their emergence, maximizing their reproductive success (Alcock 1978; Eickwort and Ginsberg 1980; Paxton 2005). The bees Amegilla dawsoni and Lasioglossum malachurum are examples of species having such rendez-vous sites (Ayasse et al. 1999; Simmons et al. 2003) 
The non-resource based rendez-vous sites are places that do not have any valuable resource for females, like hilltops (Alcock 1978; Eickwort and Ginsberg 1980; Paxton 2005). Usually, large groups of males aggregate in this non-resource based sites and copulate with females that are attracted to these places (Alcock 1978; Eickwort and Ginsberg 1980; Paxton 2005). These sites can also be located between nests and foraging areas where it is likely to find passing by females.

Non-resource based landmarks are the most common mating site found in social bees. Bumblebees, for example, have four different strategies of mate location, but the most common rendez-vous site is non-resource based landmarks (Goulson 2010). Bumblebee males patrol flight routes, which are topographical landmarks, such as conspicuous plants (Goulson 2010). Males mark different parts of these plants (e.g., flowers and stems) with secretions from their labial gland (Goulson 2010; Ayasse and Jarau 2014). Females, as well as conspecific males, are attracted to these pheromones (Goulson 2010; Ayasse and Jarau 2014).

Non-resource based sites are also the preferred mating place of honeybee males (Baer 2005; Paxton 2005). Males of Apis species form large congregations in specific geographic locations, the drone congregation areas (Baer 2005; Engels and Imperatriz-Fonseca, 1990). Virgin queens fly to these areas and males use olfactory and visual cues to locate arriving females (Slessor et al. 2005; Trhlin and Rajchard 2011). At these places, honeybee queens copulate with several males (Estoup et al. 1994; Oldroyd et al. 1997).

In the stingless bee group, two different types of rendez-vous sites can be found (Table 1 and Table 2). Males of species belonging to Melipona genus aggregate at non-resource based landmarks, similar to what is observed in honeybees (Sommeijer and Bruijn 1995; Sommeijer et al. 2004). Even though actual mating has never been observed at these places, the observation of virgin queens visiting and interacting with males at such sites strongly suggest that mating indeed occurs at these aggregation sites (Sommeijer and Bruijn 1995; Sommeijer et al. 2004). 
Drones of several other stingless bees species are often seen waiting for receptive females in large aggregations in front of their nests (Michener 1946; Engels 1987; Roubik 1990; Nogueira-Ferreira and Soares 1998; van Veen and Sommeijer 2000; Cameron et al. 2004; Cortopassi-Laurino 2007; Galindo López and Kraus 2009; Boongird and Michener 2010; Boongird 2011; Bänziger and Khamyotchai 2014). Usually, males wait until the virgin queen leaves the nest and as soon as she leaves, they fly after her (van Veen and Sommeijer 2000).

Table 1. Description of the two patterns of male behavior found in stingless bees.

\section{Male behavior}

Nest - associated aggregation

Non-nest-associated aggregation

\section{Description}

Drones congregate close to nest entrances and wait for the virgin queen nuptial flight

Drones congregate at non-resource based landmarks and mate with virgin queens that are attracted to such aggregations.

Less common, but also observed in some species, males in these large congregations do not wait for the virgin queen's nuptial flight, but instead, they mate with her inside the nest (Boongird and Michener 2010; Boongird 2011). Copulation in this species occurred at night (7:00-8:00 pm) (Boongird and Michener 2010). Not all drones can enter the nest, some of them are attacked and rejected by the guards (Boongird and Michener 2010). Selective permission for males may be involved with the resin they carry on their hind legs, since only males carrying this resource were allowed to enter (Boongird and Michener 2010). This hypothesis, however, was not tested. Although copulation happening inside the nest was so far only observed in few stingless bee species, it may be more common in the group. More 
detailed observation of drone aggregations and of the whole mating process are needed to elucidate how common is this strategy in Meliponini. Boongird and Michener (2010) provided a clue that can be useful to identify if males are using this tactic. They reported that this strategy was observed only in males that were morphologically similar to workers (isopodal males) and not observed in morphologically different males (anisopodal males). Even though these authors did not properly test the relationship between male morphology and strategy, this trait could be used as a starting point for further studies on males' reproductive behavior in stingless bees.

Exploring the ideas proposed by Emlen and Oring (1977), researchers have tried to explain the diversity of rendez-vous sites found in bees based on ecological factors (Alcock 1978; Paxton 2005). These authors proposed that the spatiotemporal distribution of receptive females affect the evolution of male strategies (see Table 3). Distribution of females in space ranges from very clumped to very dispersed. If females' emergence sites are clumped, males are expected to maximize their reproductive success by finding female emergence sites, since they would be able to control and mate with several different females (Alcock 1978; Paxton 2005). Likewise, if the time of female emergence is predictable, males would benefit from waiting at their nest and thus mating with them right after their emergence (Alcock 1978; Paxton 2005). Therefore, the expected rendez-vous sites in these cases are the female emergence area. But, if females are dispersed in space or if their time of emergence is unpredictable, finding the site of female's emergence can be too costly and therefore it might be more beneficial to wait in places where receptive females are more predictable (Alcock 1978; Paxton 2005). Consequently, flowers (resource based) or landmarks (non-resource based) are the expected rendez-vous sites in these cases. 
Table 2. Rendez-vous sites used by different stingless bees species.

\begin{tabular}{|c|c|c|}
\hline Species & Rendez-vous sites & References \\
\hline Heterotrigona apicalis & nest entrance & Boongird \& Michener 2010 \\
\hline Melipona fasciata & nest entrance & van Veen et al. 1997 \\
\hline Scaptotrigona mexicana & nest entrance & Kraus et al. 2008; Lopez \& Kraus 2009 \\
\hline Scaptotrigona postica & nest entrance & $\begin{array}{l}\text { Kerr et al. 1962; Engels 1987; Engels et al. 1993; } \\
\text { Koedam et al. 2009; Paxton } 2000\end{array}$ \\
\hline Scaura latitarsis & nest entrance & Nogueira-Ferreira \& Soares 1998 \\
\hline $\begin{array}{l}\text { Tetragonisca angustula (trigona } \\
\text { jaty) }\end{array}$ & nest entrance & $\begin{array}{l}\text { Michener 1946; Fierro et al. 2011; Kerr et al. 1962; } \\
\text { Nogueira-Ferreira \& Soares 1998; Van veen \& Sommeijer } \\
2000\end{array}$ \\
\hline Tetragonula fuscobalteata & $\begin{array}{l}\text { nest entrance / inside the } \\
\text { nest }\end{array}$ & Boongird \& Michener 2010 \\
\hline Tetragonula laeviceps (Smith) & nest entrance & Bazinger \& Khamyotchai 2014 \\
\hline Tetragonula pagdeni & $\begin{array}{l}\text { nest entrance / inside the } \\
\text { nest }\end{array}$ & Boongird \& Michener 2010 \\
\hline Trigona collina & nest entrance & Cameron et al. 2004; Boongird \& Michener 2010 \\
\hline Trigona dorsalis & nest entrance & Roubik 1990 \\
\hline Trigona fulviventris & nest entrance & Michener 1946;Nogueira-Ferreira \& Soares 1998; \\
\hline Trigona spinipes & nest entrance & Cortopassi-laurino (2007) \\
\hline
\end{tabular}




\begin{tabular}{lll}
\hline Species & Rendez-vous sites & References \\
\hline $\begin{array}{l}\text { Trigona testaceicornis } \\
\text { perilampoides }\end{array}$ & nest entrance & Michener 1946 \\
Nannotrigona testaceicornis & nest entrance & Nogueira-Ferreira \& Soares 1998 \\
Melipona favosa & $\begin{array}{l}\text { non-resource based } \\
\text { landmark }\end{array}$ & Sommeijer et al. 2004; Sommeijer \& de Bruijn, 1995 \\
Melipona beechei & non-resource based & \\
& landmark & Van veen \& Sommeijer 2000 \\
\hline
\end{tabular}

Table 3. Predicted association between spatiotemporal distribution of receptive females and rendez-vous sites (taken from Paxton 2005).

Female (nest) density Rendez-vous site

\section{High}

(aggregated)

Low

(dispersed)
Female emergence site

(nest, nest entrance, general nesting area)

Flowers (resource based) OR

Landmark, flyway (non-resource based) 
This framework is very logically plausible but also has some weaknesses, like the difficulty of measuring some variables (e.g. the spatial distribution of receptive females) (Alcock 1978; Paxton 2005). This makes the test and validation of these ideas a complicated task. Yet, this framework seems to explain the rendez-vous sites of several bee species (Alcock 1978; Eickwort and Ginsberg 1980; Ayasse et al. 2001; Paxton 2005). However, it is not sufficient to explain the mating sites found in stingless bees. The predicted association between rendezvous sites and the spatiotemporal distribution of receptive females do not fit with the observed mating sites of most stingless bee species. The distribution of stingless bee nests is, with few exceptions (e.g. Trigona collina), far from being clumped in space (Eltz et al. 2002; Eltz et al. 2003; Roubik 2006). Moreover, the emergence of receptive females (virgin queens) are highly unpredictable. Therefore, according to the proposed framework, stingless bee males should look for females at flowers or at non-resource based landmarks.

This prediction is true only for species belonging to Melipona genus, but not for most stingless bee species. Interestingly, the spatial distribution of nests and temporal patterns of female emergence are very similar between Melipona bees and other stingless bee species. This suggests that other ecological factors besides the spatiotemporal distribution of receptive females may be involved in the evolution of males' reproductive behavior. Further research aiming to elucidate these other ecological factors could help to better understand not only the evolutionary and ecological basis of the mating behavior of stingless bees, but of the whole group of bees. 


\section{Leks or aerial swarms?}

The classification of a mating behavior is an important step to understand its evolution. Allocating existing behaviors to predefined categories facilitates a comparative analysis. But, more importantly, it helps to interpret the forces of natural selection that might be involved in the mating behavior under analysis. So, here, we try to classify the behavior of stingless bee males.

Male aggregations for reproductive purpose occur in several animal groups and are relatively common in insects (Höglund and Alatalo 1995; Shelly and Whittier 1997). Such male groups are often classified as leks (Bradbury 1981; Höglund and Alatalo 1995; Shelly and Whittier 1997). According to Bradbury (1981), classical leks are male aggregations that meet the following four criteria: (i) there is absence of male parental care, with males contributing only with gametes; (ii) there is a mating arena to which females come and on which most mating occurs; (iii) the display sites of males are not associated with any valuable resource to females (e.g. food, nest sites, etc.), except the males themselves; (iv) the females have an opportunity for mate choice once she visits the arena. This definition of leks is controversial (Höglund and Alatalo 1995; Shelly and Whittier 1997). These criteria are too strict to account for all variation found in lek-like male aggregations and should rather be seen as continuous variables (Shelly and Whittier 1997). A detailed discussion about the controversy on the definition of leks is beyond the scope of this review (for a detailed discussion see Höglund and Alatalo 1995), but this term seems inappropriate to define some of the male aggregations found in insects (Shelly and Whittier 1997). The categories proposed by Shelly and Whittier (1997) explain better insect aggregations and help to understand the mechanisms underlying the evolution of male mating behavior in these animals. Hence, we will use these categories to classify the behavior of stingless bee males. 
Shelly and Whittier (1997) grouped insect male aggregations in two categories: substratebased aggregations and aerial aggregations. The first type consists of males aggregating at specific locations, where they spend most of their time perching or at least perching periodically. Mating is initiated on the substrate or in the air. The second type, the aerial swarms, consists of groups of males in continuous flight. In this case, mating is initiated in the air. These categories are useful because they help to highlight important differences between these two patterns of reproductive aggregations.

While males of substrate-based aggregations often aggressively defend territories against conspecific males, males in aerial swarms seldom have agonistic interactions or defend specific areas before female arrival (Shelly and Whittier 1997; Sivinski and Petersson 1997). Other remarkable difference is the opportunity for female choice in each type of aggregation. Courtship signals and female sampling are consistently absent in aerial swarms but are commonly seen in substrate-based aggregations (Shelly and Whittier 1997). These groups also have great differences regarding the number of males in the aggregation and the existence of long-range attraction of females by males. Substrate-based aggregations usually have fewer participants and males in these aggregations are also more likely to produce longrange attractive signals than males in aerial swarms (Shelly and Whittier 1997). In summary, the two types of aggregations can be distinguished by the presence of territoriality and courtship, number of males and production of long-range signals for female attraction. According to Shelly and Whittier (1997), only the mating systems having male aggression and courtship behavior should be considered leks, to not lose the original intention of the term. Therefore, substrate-based aggregations are more alike to what is traditionally called leks.

If we try to apply these categories to the male behavior of stingless bees, the available evidence suggest that the two patterns described by Shelly and Whittier (1997) are found in 
these bees. Nest-associated aggregations are very similar to aerial swarms (see Table 4). Male-male aggression has never been seen in such aggregations, male courtship is absent and females probably do not have any opportunity for mate choice (Roubik 1990; NogueiraFerreira and Soares 1998). The number of males at these aggregations is very large (more than 7000: Bänziger and Khamyotchai 2014) and as they are attracted to nests having a virgin queen, they probably do not produce long-range signals for female attraction. Non-nest associated aggregations are more closely related to substrate-based aggregations (Table 4). Agonistic interactions of males were already observed, as well as the long-range attraction of females (Sommeijer and Bruijn 1995; Sommeijer et al. 2004).

However, the behavior of stingless bee males does not perfectly fit these categories. Males in nest-associated aggregations are not in continuous flight as are males in more classical aerial swarms (see Sivinski and Petersson 1997). Instead, males aggregate at specific locations where they perch periodically. In the case of non-nest associated aggregations, available evidence is insufficient to say that males have and defend specific territories, or that they have any kind of courtship behavior, or that queens can choose their mate. Nevertheless, the categories proposed by Shelly and Whittier (1997) improve our understanding of the factors involved in the evolution of stingless bees mating systems. Using these categories to classify Meliponini male behavior show, for instance, that the two patterns of mating behavior found in stingless bees may have striking differences in male-male competition and in the opportunities for female choice. Additional and more detailed observations of male and female behavior in nest associated and non-nest associated aggregations are needed to deepen the knowledge about the selective forces involved in the evolution of stingless bees mating systems. 
Table 4. Comparison between substrate-based aggregations, aerial swarms and the two patterns of male strategies found in stingless bees.

\begin{tabular}{lcccc}
\hline \multicolumn{1}{c}{ Strategy } & $\begin{array}{c}\text { Male-Male } \\
\text { aggression }\end{array}$ & $\begin{array}{c}\text { Courtship } \\
\text { signals }\end{array}$ & Number of males & $\begin{array}{c}\text { Production of } \\
\text { long range signals }\end{array}$ \\
\hline $\begin{array}{l}\text { Substrate- } \\
\text { based } \\
\text { aggregation }\end{array}$ & $\checkmark$ & $\checkmark$ & low & $\checkmark$ \\
$\begin{array}{l}\text { Aerial swarms } \\
\text { Nest }\end{array}$ & $\mathrm{X}$ & $\mathrm{X}$ & high & $\mathrm{X}$ \\
$\begin{array}{l}\text { agsociated } \\
\text { aggregation }\end{array}$ & $\mathrm{X}$ & $\mathrm{X}$ & high & $\mathrm{X}$ \\
$\begin{array}{l}\text { Non-Nest } \\
\text { associated } \\
\text { aggregation }\end{array}$ & $\checkmark$ & $?$ & & $\checkmark$ \\
\hline
\end{tabular}

\section{Mating Communication}

The signals used by males and females to find each other are a very important aspect of mating behavior. Insects can use different sensorial modalities for mate attraction, including acoustic (Drosopoulos and Claridge 2006), visual (Lloyd 1997) and chemical signals (Ayasse et al. 2001). Chemical communication is the mechanism most often used by bees, as well as by most insects, to find mates (Eickwort and Ginsberg 1980; Ayasse et al. 2001). Chemical compounds, produced by males or females, that stimulate one or more behavioral responses in the opposite sex, bringing both sexes together for the purpose of mating, are called sex pheromones (Ayasse et al. 2001). These compounds can attract the mating partner from long distances, but can also act in a short range, stimulating courtship behavior and copulation (Ayasse et al. 2001). 
The diversity of mating behavior of bees is reflected in the diversity of their sex pheromones. The variation is expressed in the chemical properties of the compounds used (e.g. volatility) and in the emitter, i.e. if females or males (Ayasse et al. 2001). To interpret this variation in an evolutionary sense, Ayasse et al. (2001) proposed a functional classification of sex pheromones, that includes not only bees but also ants and wasps. They explored the framework proposed by Alcock (1978) and used the rendez-vous site to predict the mating communication (Table 5). They argued that density and distribution of receptive females shape chemical communication, similarly to what occurs with male mating seeking tactics, and that females, as the limiting sex, will assume the less risky and costly role in mating communication.

This framework predicts that when the mating site is the female emergence area, females will be the signaling sex (Ayasse et al. 2001). Female sex pheromones, in this case, usually have low volatility and are detected only over short distances (Ayasse et al. 2001). Hydrocarbons and isopentenyl esters are examples of compounds used by female bees (Ayasse et al. 1999; Simmons et al. 2003). The potentially high costs for females communicating their nest and oviposition sites, given that predators or parasites can eavesdrop on these signals, may explain this pattern (Ayasse et al. 2001). Furthermore, males can use other indications, like environmental cues, to locate receptive females over a long distance (Ayasse et al. 2001).

Otherwise, if mating occurs at non-resource based sites, males and females are expected to produce compounds with high volatility for long-range attraction (Ayasse et al. 2001). The 9ODA queen pheromone of Apis is an example of a compound having these properties (Ayasse et al. 2001). Male compounds in these cases are responsible for female attraction and swarm/lek formation, while female pheromones are used in male attraction (Ayasse et al. 2001). Under circumstances when the male is signaling to a female, the female gains an advantage by avoiding the costs of non-conspecific encounters and the possibility of choosing a mate (Ayasse 
et al. 2001). Finally, when mating occurs at resource-based landmarks (e.g. flowers) neither males or females are expected to communicate (Ayasse et al. 2001).

In summary, the framework predicts that females will be the major signaling sex when the rendez-vous site is the nesting area, while males will be the main emitters of pheromones in non-resource based landmarks. The available data on the chemical communication of solitary bees seems to support these predictions (Ayasse et al. 2001).

Table 5. Predicted signaling role during mating communication in relation to rendez-vous sites (adapted from Ayasse et al. 2001).

\section{Rendez-vous site}

Males as an antiaphrodisiac

Female emergence site (nest, nest entrance, general nesting area)

Flowers (resource based)

Landmark, flyway (nonresource based) in mate attraction (long distance/high volatility
None

\section{Females} signal lack of receptivity/ individual recognition (short distance/low volatility)

None

in mate attraction and in mating swarm/lek formation (long distance/high volatility)

The same seems to be true for social bees. Bumblebee males deposit pheromones from their labial glands on their patrolling routes, which are non-resource based landmarks (Goulson 2010; Ayasse and Jarau 2014). These pheromones belong to a variety of chemical classes and attract both males and females (Ayasse and Jarau 2014). In honeybees, males aggregating at non-resource based landmarks are attracted by the volatile queen pheromone 
(9-ODA) and also by the queen's abdominal and tergal gland extracts (Ayasse et al. 2001; Slessor et al. 2005; Trhlin and Rajchard 2011). Honeybee males produce compounds that attract conspecific males and are probably involved in the formation of the drone congregations (Brandstaetter et al. 2014), as the framework predicts. These compounds could also help virgin queens to find the drone congregations areas. But, as far as we know, the attraction of queens to these compounds have never been measured.

The lack of data about the sex pheromones of stingless bees limits the analysis of how well the mating communication of these bees fits these predictions. Only three species $-S$. mexicana, S. postica and T. angustula - have their sex pheromones analyzed. All these three species have the same rendez-vous sites, i.e. nest area. Below we organize the available information on Meliponini, indicating the possible roles of queens, males and workers in sexual communication.

Queens: Volatile compounds, such as 2-alcohols, were the most attractive to males in queens of S. mexicana and S. postica (Engels et al. 1997; Verdugo-Dardon et al. 2011) . Other less volatile compounds, like ketones, were also important in stimulating copulatory attempts in males of S. postica (Engels et al. 1997). In T. angustula an ester, isopropyl hexanoate, was the most attractive compound for males (Fierro et al. 2011). Queen-produced volatiles apparently contradict the low range/low volatility features of female's sex pheromone, expected of species mating close to the nesting area. However, these compounds may not be used in longrange signaling but only for short-range communication. Several lines of evidence suggest that virgin queens are either only partially or not at all responsible for long-range attraction of drones. For instance, Fierro et al. (2011) showed that attraction of males to queens decreases rapidly at relatively short distances. Additionally, during swarm events, males were seen aggregating in front of the new site before the arrival of the virgin queen (Michener 1946; Kerr et al. 1962; Nogueira-Ferreira and Soares 1998). 
It seems that two components of queen pheromones are important in stimulating the whole sequence of male mating behavior. One of the components, more volatile, probably attracts the males to queens and the other one, less volatile, may be responsible for triggering copulation (Engels et al. 1997; Fierro et al. 2011). Interestingly, a physogastric queen was also shown to attract males under artificial conditions (Sakagami, S. F. \& Laroca 1963; Campos and Melo 1990; Engels et al. 1993; Engels et al. 1997; Fierro et al. 2011), which indicates that at least one of the components used in mating communication is maintained after copulation and may be also used in queen-worker communication.

Males: Males were reported to be highly attractive to queens of M. favosa, but the compounds used to attract females were not identified (Sommeijer and Bruijn 1995; Sommeijer et al. 2004). This species has non-nest associated aggregations and these male-produced compounds may help queens to find the drone congregation sites (Sommeijer and Bruijn 1995; Sommeijer et al. 2004). S. mexicana males deposit pheromones mark the substrate where they aggregate which is important for short-range orientation of drones towards specific sites (Galindo López and Kraus 2009; see also chapter 3). These pheromone marks are probably comprised of males cuticular hydrocarbons, which the males deposit at the aggregation site (chapter 3). Drones also became attracted to other groups of drones in laboratory experiments (Galindo López and Kraus 2009). This male-male communication seems to be very important for the formation of congregations (Engels et al. 1990; Galindo López and Kraus 2009).

Workers: Stingless bee workers seems to play an important role in mating communications. S. depilis foragers seem to be responsible for the long-range attraction of drones since they significantly affect the capacity of colonies to attract males (see chapter 2). A forager based transmission of a sexual message may be one way to announce the presence of a virgin queen directly to males, reducing the risk of advertising the nest location to undesirable enemies. In 
addition, the signal transmitted by foragers may inform males about the quality of colonies since the number of attracted males increases with the biomass of colonies (chapter 4). Workers were also essential for the establishment of drone congregation sites in $M$. favosa (Sommeijer et al. 2004). They were highly attractive to males and were seen depositing resin and plant materials on the substrate where males aggregate (Sommeijer et al. 2004). Thus, worker-male communication during reproduction may be a common phenomenon in stingless bees.

Studies on Meliponini mating communication are scarce, but altogether the available information allows us to start identifying the short and long-range components of stingless bee sexual attraction. For nest-associated aggregation, the long-range component seems to involve foragers (chapter 2), while the short-range component includes the queen's sex pheromones, which attract males and trigger copulation (Engels et al. 1997; Fierro et al. 2011; Verdugo-Dardon et al. 2011). A short-range male-male communication also appears to be very important in the formation of aggregations (Galindo López and Kraus 2009). Another potential short-range communication may exist in species where mating occurs inside the nest. To enter the nest, males must pass the rigid surveillance of guards (Boongird and Michener 2010). To recognize and discriminate nestmates from others individuals, guards usually rely on cuticular hydrocarbons (Nunes et al. 2008). Likewise, cuticular hydrocarbons of males can be involved in male acceptance. The relationship of these compounds with other male traits can be a fruitful area of investigation. For non-nest associated aggregations, workers seem to be involved in the formation of drone congregation sites and male produced compounds appear to explain the long-range attraction of virgin queens to these areas (Sommeijer and Bruijn 1995; Sommeijer et al. 2004). Thus, sexual communication of stingless bees seems a complex process that involves interactions between queens, workers and males. The available data seem to confirm the predictions of the framework proposed by 
Ayasse et al. (2001; see Table 5). However, further studies are necessary to precisely identify the components of the sexual communication in stingless bees.

\section{Concluding remarks}

Stingless bees have a great variety of mating behaviors, which were so far poorly explored. These bees have two clear patterns of male mating behavior, which reveal striking differences in sexual communication, male-male competition and in the opportunities for female choice. Additionally, the existence of different male strategies among species having the same spatiotemporal distribution of receptive females offers good opportunities to better understand the factors involved in the evolution of male seeking behavior in bees. Stingless bees also have a fascinating mating communication system, that seems to involve males, queens and workers. Additional and detailed data on the behavior of males at congregations, especially in the less studied non-nest associated aggregations, will improve our understanding of the selective forces involved in each pattern of male behavior. The investigation of the species that mate inside the nest is also a promising area of study. The diversity of strategies adopted by stingless bee males makes these bees a good model for studying the mating biology of insects. Thus, the reproductive biology of this group of social bees is full of scientific treasures awaiting to be discovered. 


\section{CHAPTER 2}

Nuptial messengers: the role of workers for male attraction in the stingless bee Scaptotrigona depilis 


\section{Abstract}

Mate finding is a key event of the reproductive process. To find each other, males and females use a variety of sensorial modalities. Chemical compounds are the main channel used by hymenopterans for sexual communication. Males and females may produce sex pheromones, which can be used for long-range attraction or for short-range communication. In stingless bees, mating communication is poorly understood. Males are attracted to colonies during reproductive events, but the identity and the source of the compounds that they use to find nests are poorly understood. To explore this question, we investigated the role of forager activity during reproduction in the Neotropical species Scaptotrigona depilis. We combined behavioral experiments with chemical analyses to test the effect of foragers on male attraction. We evaluated the capacity of colonies to attract drones with and without forager activity by preventing some colonies from foraging. Furthermore, we investigated the differences in the chemical composition of foragers from attractive and from non-attractive colonies by analyzing their head and leg extracts. We found that colonies with foraging activity attracted on average 10 times more males than colonies without foraging. This result strongly suggests that foragers play an important role in male attraction. However, we did not find any qualitative or quantitative difference in the chemical composition of foragers from attractive and non-attractive colonies. This indicates that the putative worker signal is not a straightforward change in the composition of forager compounds. Our results suggest that the communication system of stingless bee reproduction is a complex process that involves interactions between queens, workers and males. 


\section{Introduction}

For many animals, mating is a complex event. First, individuals need to find a sexual partner. To locate the opposite sex, animals use visual, acoustic and chemical signals, which can be produced by females or males (Eickwort and Ginsberg 1980; Wyatt 2003; Grüter and Keller 2016; Leonhardt et al. 2016). This sexual communication increases the efficiency of mate finding and reduces the costs of non-specific encounters (Ayasse et al. 2001). Mating signals can also provide information regarding the kinship of sexual partners thereby helping individuals avoid inbreeding (Lihoreau et al. 2007). In Hymenoptera, as well as in most other insects, chemical signals are the main channel used for sexual communication (Ayasse et al. 2001). The sex pheromones can attract mates from a long distance, but can also act at a close range (Ayasse et al. 2001).

In corbiculate bees, the most common pattern of mating behavior is females moving to signaling males. In Euglossini (orchid bees), males collect compounds from orchid flowers and probably release them during courtship display (Eltz et al. 1999; Eltz et al. 2005). These fragrances may attract both conspecific males and females (Zimmermann et al. 2006). In bumble bees (Bombus) several different strategies of mate location have been found, but the most common mechanism is females being attracted to signaling males (Goulson 2010; Ayasse and Jarau 2014). Males mark leaves and branches along specific flying routes with secretions from their labial gland, which attract virgin queens in laboratory bioassays, but may also attract males (Goulson 2010; Ayasse and Jarau 2014). The flying routes are patrolled by males and can be shared by numerous males (Goulson 2010). Honey bee (Apis) queens also fly to sites where males are located, the so-called drone congregation areas (Koeniger et al. 2005; Paxton 2005; Trhlin and Rajchard 2011). It is not currently known what attracts females to these areas (Brandstaetter et al. 2014). Honeybee drones attract other drones in 
laboratory experiments, which suggests they produce cues that might be involved in the formation of congregations (Brandstaetter et al. 2014).

In contrast, stingless bees (Meliponini) show a different pattern of sexual communication: males are attracted to nests with virgin queens. This attraction results in the formation of drone aggregations that can contain hundreds or even thousands of drones waiting in front of the nests for the virgin queen nuptial flight (Michener 1946; Engels 1987; Roubik 1990; Kraus et al. 2008; Galindo López and Kraus 2009; Boongird and Michener 2010; Boongird 2011; Bänziger and Khamyotchai 2014). In this swarm of mostly unrelated males (Paxton 2000; Cameron et al. 2004; Kraus et al. 2008), only one will be able to successfully mate the virgin queen (Strassmann 2001; Jaffé et al. 2014). Drones start to arrive at nest entrances a few days before the nuptial flight and leave few days after mating (Kerr et al. 1962; Velthuis et al. 2005).

The attraction of males to nests during reproductive events suggests that colonies are emitting a strong sexual message, but the identity and the source of the compounds that males use to find nests are poorly understood. Researchers have proposed that three sources could explain this long-range male attraction: (i) sex pheromones emitted by virgin queens (Engels 1987), (ii) variation in the nest odor (Engels et al. 1993), or (iii) a sex pheromone spread by workers (Roubik 1990; Engels et al. 1990).

Approaches to understand the sexual communication of stingless bees have focused on the identification of virgin queen sex pheromones and their effects on male behavior. These studies have shown that virgin queens of different stingless bee species have compounds that are attractive to males (Engels et al. 1993; Engels et al. 1997; Fierro et al. 2011; VerdugoDardon et al. 2011). However, it remains unknown whether these attractants are used in the long-range attraction of males. Alternatively, queen signals might be used for short-range communication (e.g. after queens leave the nest for the nuptial flight). 
Several lines of evidence suggest that virgin queen signals are either only partially or not at all responsible for drone aggregations in front of stingless bee nests. For example, during the swarming process, male aggregations were seen at the new nest site after the arrival of workers, but before the virgin queen arrival (Michener 1946; Kerr et al. 1962; Nogueira-Ferreira and Soares 1998), suggesting that the attraction of males is independent of the presence of the virgin queen. Furthermore, the capacity of queens to attract males rapidly decreases even at relatively close range ( $<20 \mathrm{~m}$ from the queen) (Fierro et al. 2011). This raises the question whether males indeed rely mainly or partially on the virgin queen's sex pheromone to locate the nests.

To explore this question further, we tested the role of forager activity in male attraction. Foragers are the agents of a social insect colony that are in direct contact with the external environment and may be responsible for transmitting the sexual message to the environment (Roubik 1990). The aim of this study was to test the hypothesis that forager activity is responsible for the attraction of drones during reproduction. We combined behavioral experiments with chemical analyses to test this hypothesis. We first evaluated the capacity of colonies to attract drones with and without foraging activity and, second, investigated possible changes in the chemical composition of foragers from attractive and unattractive colonies by analyzing head and leg extracts.

\section{Methods}

Bees and study site

The study was performed in two different periods: during May and June (2014) and during April and May (2016) at the University of Sao Paulo campus in Ribeirão Preto, Brazil. A total of 28 colonies of Scaptotrigona depilis were used (14 in each period). Colonies were kept in 
wooden boxes during the experiments. S. depilis colonies are headed by one ovipositing queen, but one to several virgin queens are usually present in queenright colonies (Kerr et al. 1962).

\section{Behavioral test}

The aim of this test was to evaluate the effect of forager activity on colony attractiveness to males. To start the mating process and, consequently, attract males to colonies, we removed the physogastric queen from all nests on the same day. Colonies were divided into two groups. In control colonies $(N=7)$, foragers could forage freely, while in test colonies $(N=7)$ foragers were not allowed to leave the nest for foraging (Fig. 1). To prevent workers from foraging, we connected the nest entrance to a cage. Two sides of this cage were made of a net, which allowed airflow between the nest and the environment (Fig. 1). It is not uncommon that foragers gather near the nest exit, without being able to forage, e.g. during days with heavy rain during the rainy season. After physogastric queen removal, we counted the number of males each colony attracted during fourteen days. To count males, we took pictures of aggregations, which were close to nest entrances and later counted the total number of males using a standard image editing software. Counts were performed by two different researchers simultaneously to record the number of males at the same time of the day for both groups of colonies and to check for observer biases. After this fourteen-day period, we opened all colonies to check if they had physogastric and, therefore, mated queens. At this point, we opened the cages, releasing foragers from test colonies, and counted the number of males they attracted during the next six days. This test was carried out during May and June (2014). 


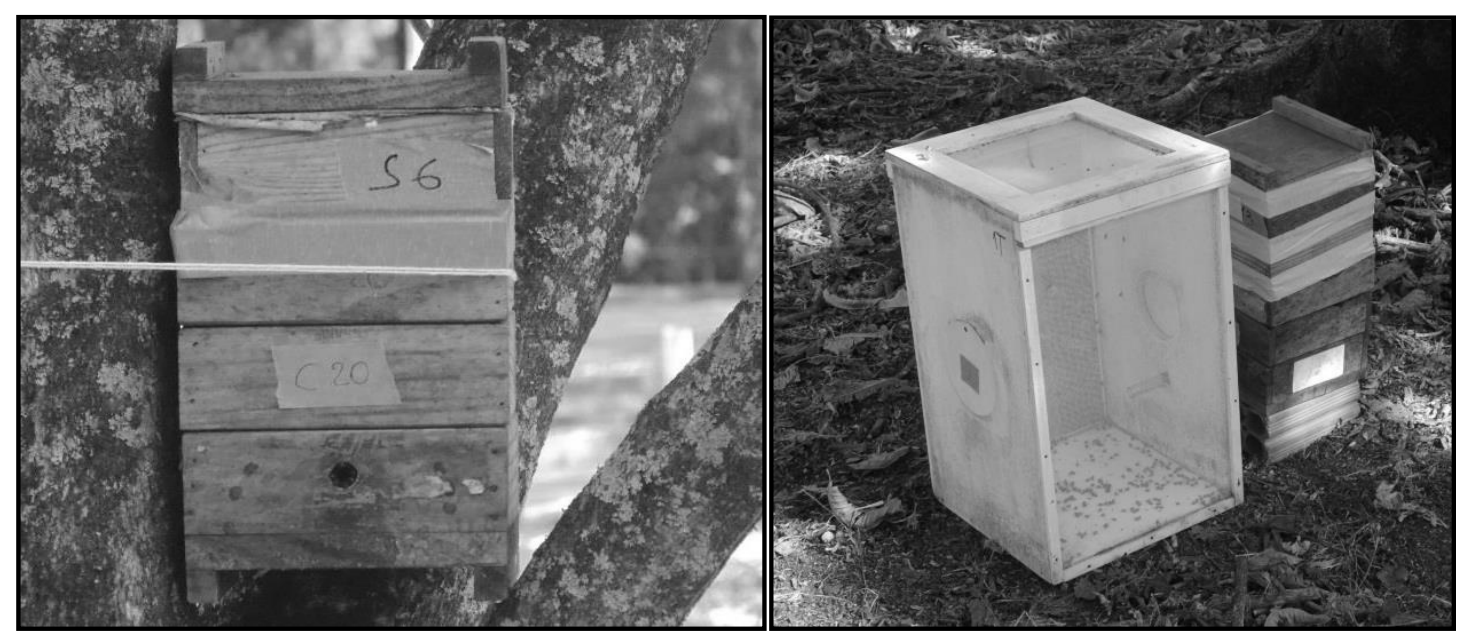

Figure 1. Experimental colonies of $S$. depilis. Left: control colonies, open to the field, allowing workers to forage freely; right: test colonies, connected to a cage, preventing foragers from foraging.

\section{Collection of foragers for chemical analysis}

To investigate if variation in the chemical profile of foragers following the removal of the queen could explain the attraction of males, returning foragers were collected for further chemical analysis. Half of the colonies $(\mathrm{N}=7)$ had their physogastric queen removed, while the other half $(\mathrm{N}=7)$ remained with their queen during the whole study. Colonies of both colony-groups had 10 foragers collected on the same day and at three different moments: (i) immediately before queen removal; (ii) five days after queen removal, which is at the peak of colonies' attractiveness; and (iii) after queens have mated and no male was observed in front of any colony. Collected foragers were immediately frozen. We also recorded the foraging traffic (i.e. number of foragers leaving during 1 minute) and the number of males each colony attracted (in the same way as described above) during eighteen days. These data were collected four times per day, two times in the morning (08:30-10:00 and 10:30-12:00) and two times in the afternoon (13:30-15:00 and 15:30-17:00). 
Preparation of cephalic and leg extracts

Cephalic extracts were prepared by macerating one forager head in $350 \mu \mathrm{L}$ of organic solvent (dichloromethane). Leg extracts were prepared by putting all six legs of a forager in $150 \mu \mathrm{L}$ of dichloromethane. Legs were left in the solvent for 24 hours at room temperature before being analyzed. Stingless bee legs contain several glands and some of them are important sources of pheromones used by foragers in recruitment communication (Cruz-Landim et al. 1998; Jarau et al. 2004a; Hrncir et al. 2004).

\section{Chemical Analysis}

Cephalic and leg extracts were analyzed using a GC-MS system (SHIMADZU, GCMSQP2010) equipped with a RTx-5 capillary column, using helium as the carrier gas at a constant flow rate of $1.0 \mathrm{~mL}$ min-1. $1 \mu \mathrm{L}$ of each sample was injected in the CG-MS system. All samples were injected in the splitless mode. The temperature protocol for the cephalic extracts was 40 to $290{ }^{\circ} \mathrm{C}$ at $12{ }^{\circ} \mathrm{C} / \mathrm{min}$, held at $290{ }^{\circ} \mathrm{C}$ for $20 \mathrm{~min}$. For the leg extracts, oven was programmed at 50 to $300{ }^{\circ} \mathrm{C}$ at $10{ }^{\circ} \mathrm{C} / \mathrm{min}$, held at $300{ }^{\circ} \mathrm{C}$ for $10 \mathrm{~min}$. For both group of extracts the injector inlet temperature was held at $250{ }^{\circ} \mathrm{C}$. The identification of compounds was made using their retention index, diagnostic ions and standard MS databases (NIST 2008).

\section{Statistical Analysis}

To analyze the effect of forager activity on the number of attracted males between test and control colonies we applied a generalized linear model (GLM), using maximum number of males observed per colony as a dependent variable and presence/absence of foragers as independent variable. To control for overdispersion, we did a quasi-Poisson GLM. To compare test colonies before and after releasing the foragers we applied a generalized linear 
mixed model (GLMM), using the same dependent and independent variable, as described above, and using colony as a random variable. To test for an effect of average foraging traffic on males' attraction we performed a Poisson GLM.

For the analyses of the chemical profile of foragers, absolute abundances of the chemical compounds were transformed according to Aitchison (1986) to decrease the dependence of compositional data. Overall comparison among groups was performed using PERMANOVA. To evaluate if specific compounds could be used as a cue for males to discriminate between attractive and unattractive colonies, we performed linear models in which the abundance of a given chemical compound was the dependent variable, status/day groups the independent variables, and colony the random factor. The models were posthoc corrected for multiple comparisons using general linear hypotheses test.

All statistical analysis was performed using R software version 3.3.2 (R Development Core Team, 2013), packages lme4 (GLM and GLMM models), vegan (PERMANOVA) and multicomp (multiple comparisons) were used for analysis.

\section{Results}

\section{General observations}

Males started to arrive at nest entrances two days after physogastric queen removal and peaked after five to six days (Fig. 2). After fifteen days, all queens had successfully mated. It took more than one month until no single male can be observed in front of colonies. Daily, males arrived in the morning (around 10:00 hrs.) and peaked early in the afternoon (14:0015:00 hrs.). Subsequently, the number of males steadily decreased and at 17:00-18:00 hrs. no male could be observed in front of colonies. 


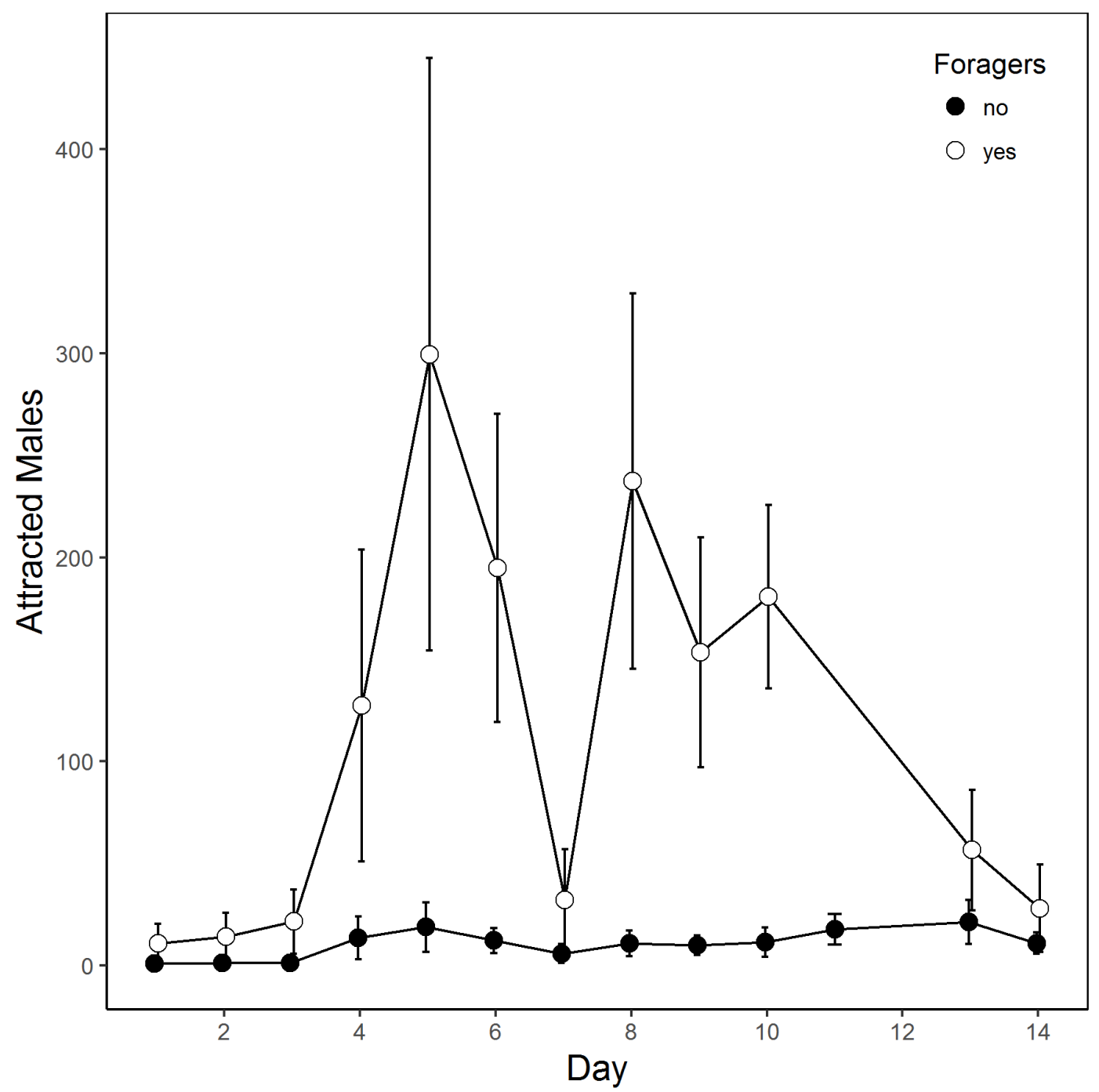

Figure 2. Mean $( \pm \mathrm{SE})$ of attracted males per experimental group during fourteen days.

The number of males attracted per colony varied between 20 and 880 males. This great variation was observed in both 2014 and 2016 (Fig. 3). Drones did not interact aggressively while in aggregations and jumping spiders (Salticidae) were seen preying drones. 


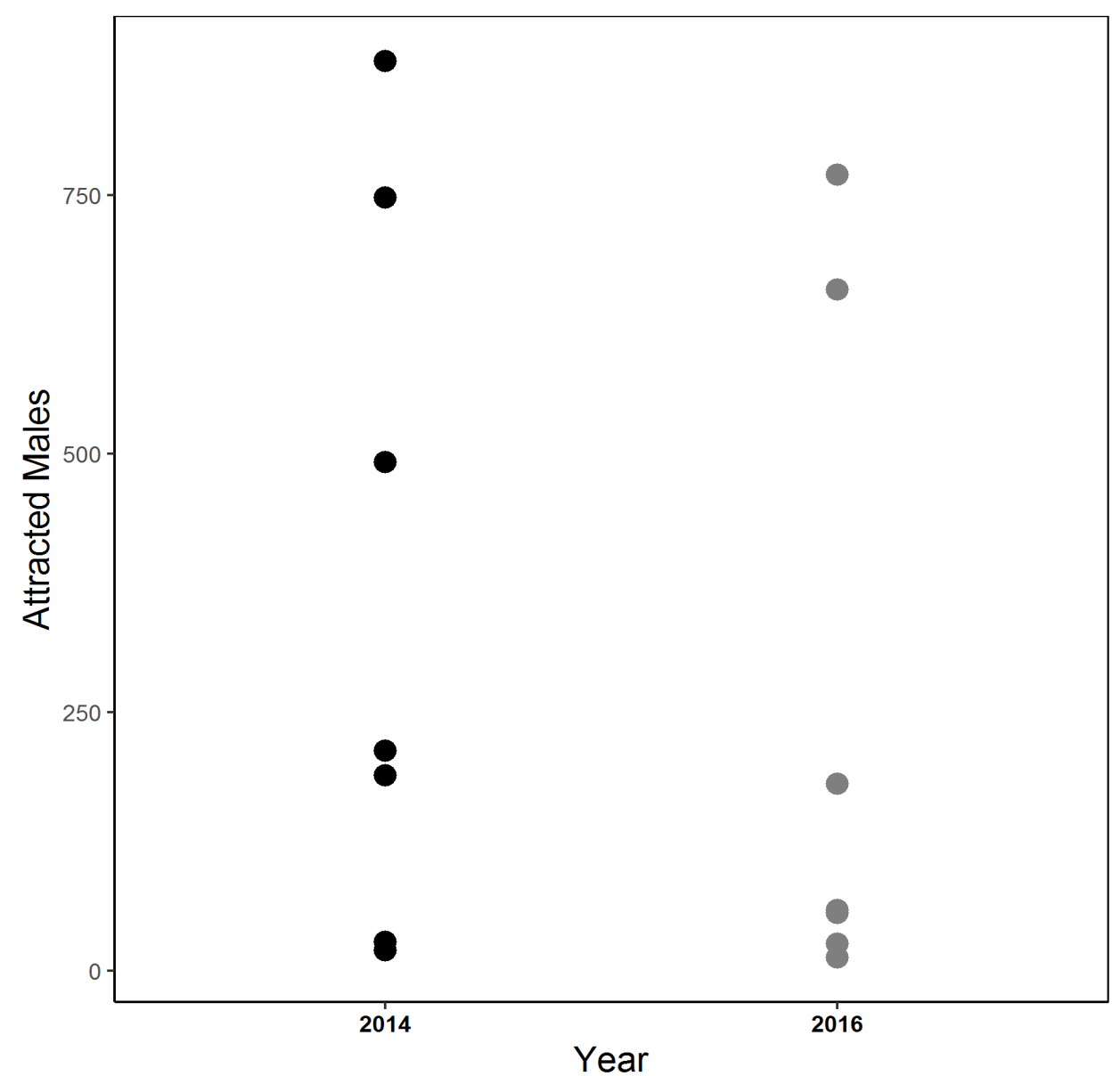

Figure 3. Distribution of attracted males among colonies during the two periods the reproductive process was entirely followed.

\section{Effect of forager activity on male attraction}

Forager activity had a significant effect on the number of males attracted to colonies (GLM, $t=$ 2.389, $p=0.03$; Fig. 4 and Fig. 5). The maximum number of males control colonies attracted (367.14 \pm 345.12 ; Mean $\pm \mathrm{SD}$; range: 20 to 880 ) was on average 10 times higher than in test colonies (35.66 \pm 29.54 ; Mean $\pm \mathrm{SD}$; range: 3 to 74 ). After 14 days, we opened the cages of the treatment colony group to allow foraging traffic. Subsequently, the maximum number of males attracted to test colonies increased significantly (GLMM, $z=23.72, p<0.001$; Fig. 6 and Fig. 7) from an average of $35.66 \pm 29.54$ to $241 \pm 245.86$ males, Mean \pm SD. We also tested whether 
foraging traffic predicted the number of males, but did not find a significant effect of foraging traffic on number of attracted males (GLM, $t=0.51, p=0.63$; Fig. 8).

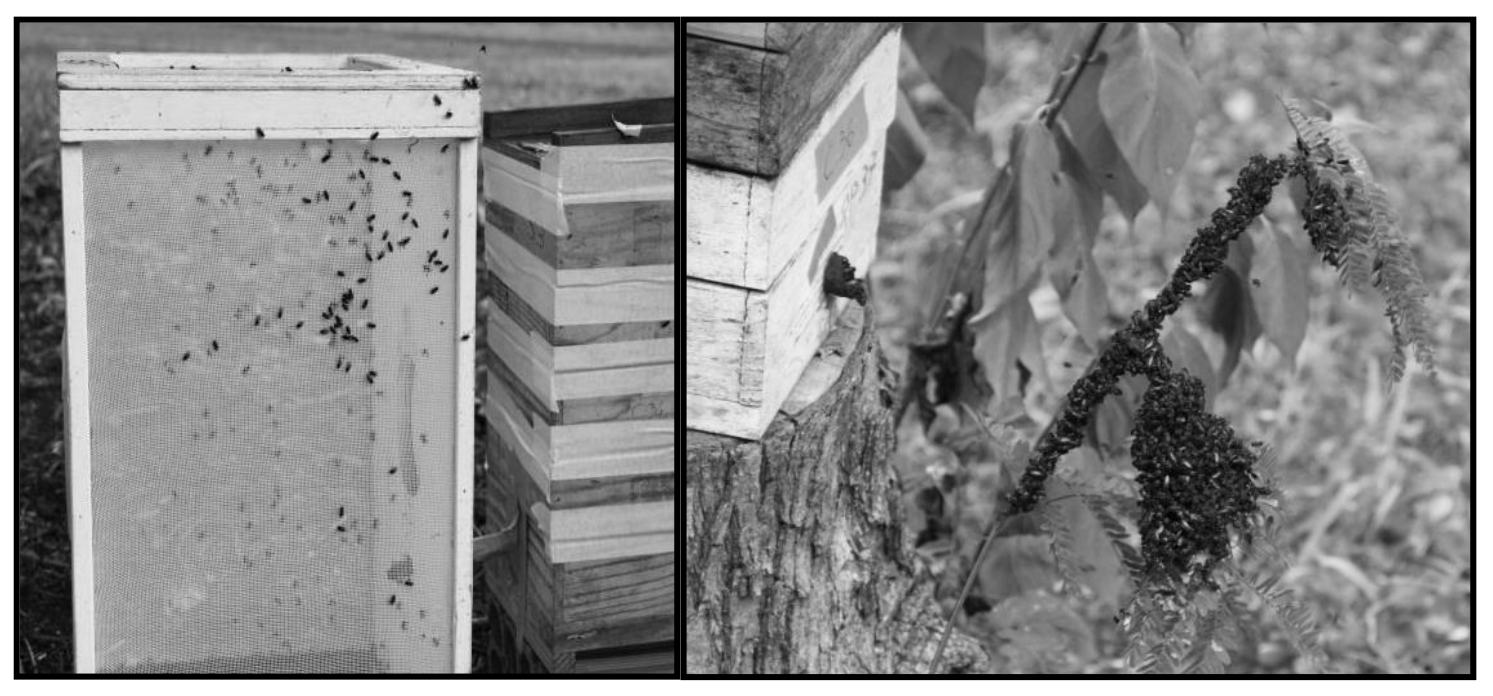

Figure 4. Number of males attracted to control colonies (right) and test colonies (left).

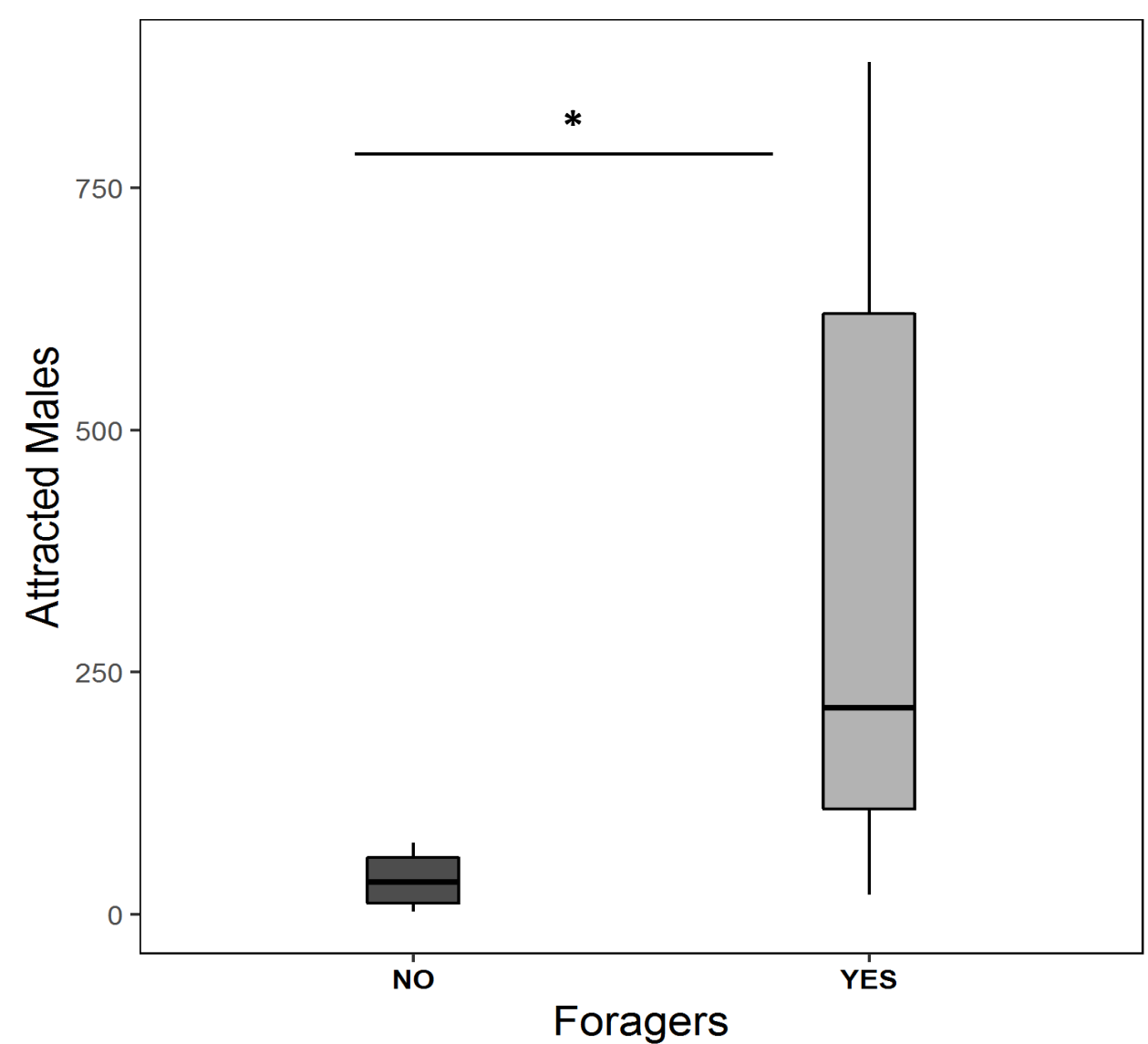

Figure 5. Box-and-whisker plots of the maximum number of males attracted by control colonies (with foraging activity) and test colonies (without foraging activity). ${ }^{*} \mathrm{p}=0.03$ (quasi-Poisson GLM). Box plots show the median, 25 and $75 \%$. Whiskers show all data. 


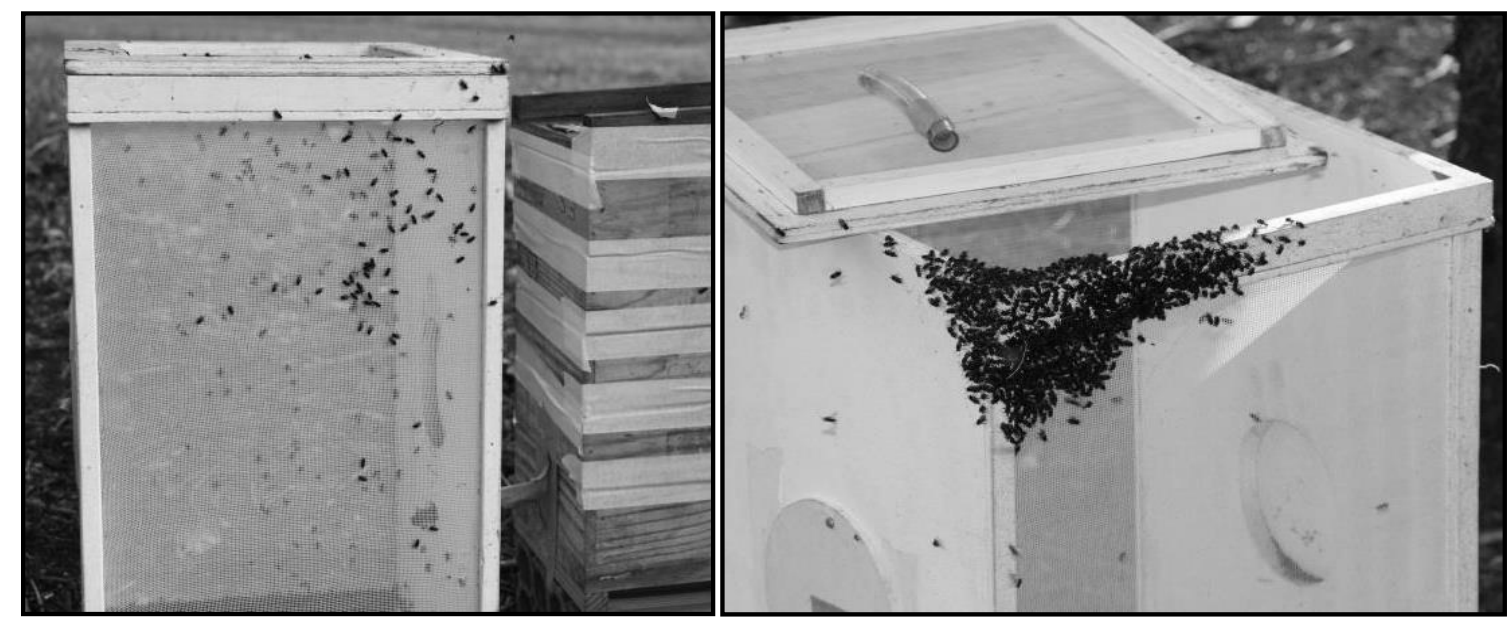

Figure 6. Males attracted to test colonies before (left) and after (right) allowing foragers to go the field.

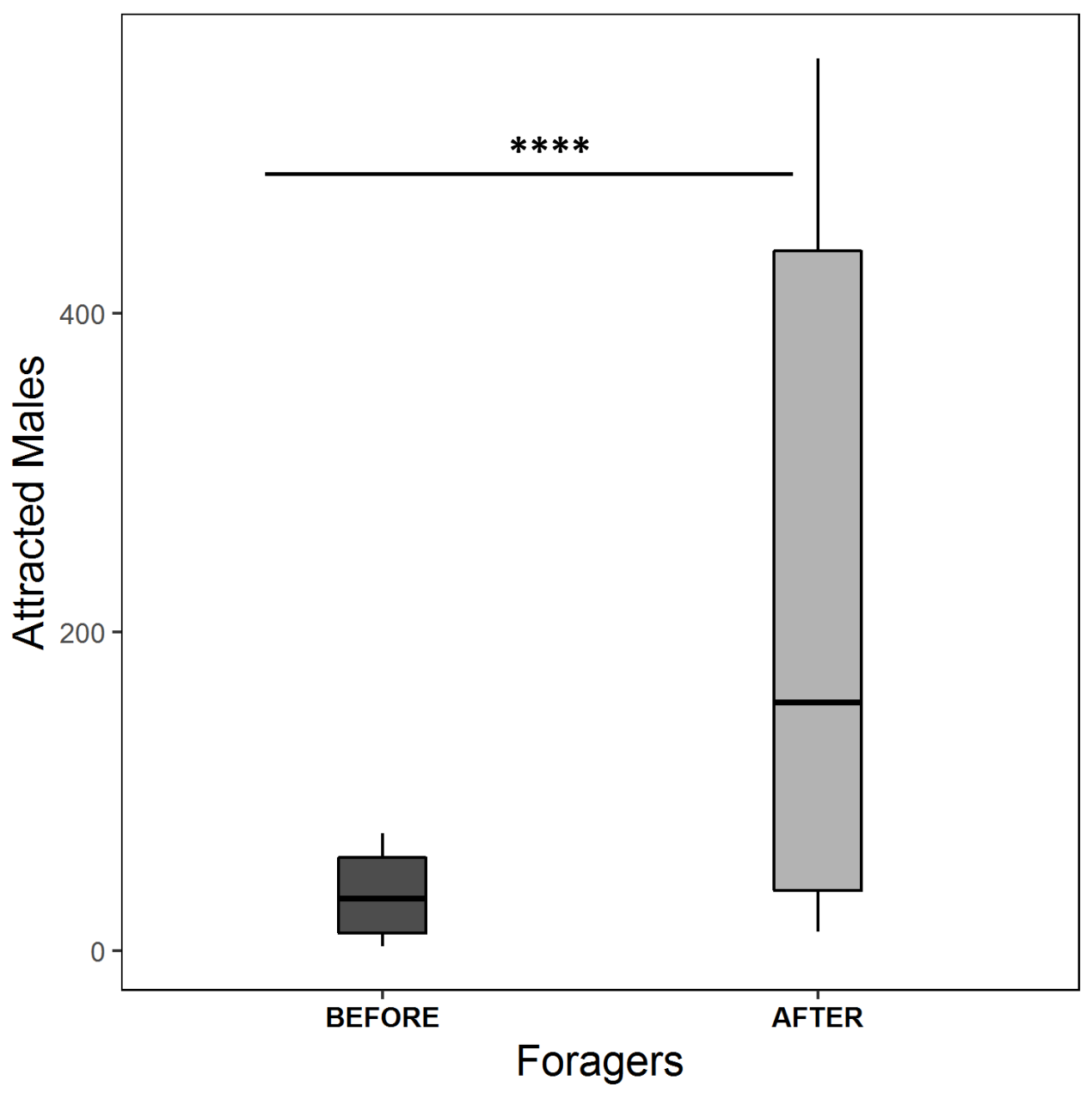

Figure 7. Box-and-whisker plots of the maximum number of males attracted by test colonies before and after releasing the foragers. $* * * \mathrm{p}<0.001$ (Poisson GLMM). Box plots show the median, 25 and 75 $\%$ percentiles. Whiskers show all data 


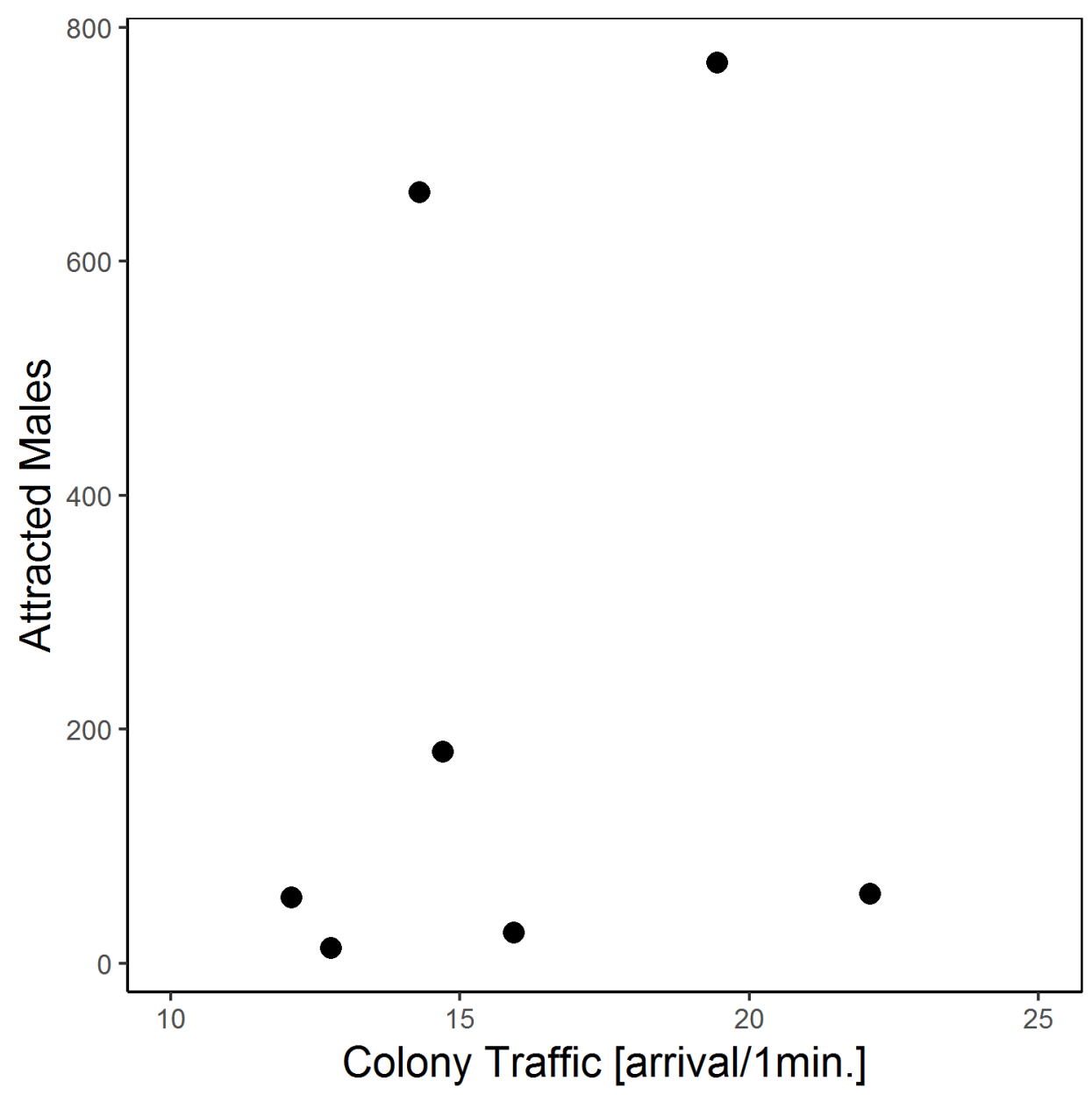

Figure 8. The relationship between colony traffic and number of attracted males

Chemical profile of leg and cephalic extracts

The chemical analyses of forager legs revealed a total of fourteen compounds (Table 7). The 9-Heptacosene and Pentacosane were the most abundant compounds in the leg extracts, comprising about $50 \%$ of the total extract content. A total of eleven compounds were found in the chemical analysis of cephalic extracts (Table 8). The extract comprised mainly alcohols and ketones, but 
one aldehyde was also found. The major compounds present in the heads of S. depilis foragers were 2-Tridecanone, Benzaldehyde and 2-heptanol, comprising about 30\%, 25\% and $15 \%$ of the total extract content, respectively (Table 8).

Statistical analysis of the chemical profile of head extracts showed no difference in the abundance of any individual compound of attractive (i.e. test colony, measurement 2) versus unattractive colonies. Compounds also did not significantly vary over time. Moreover, neither the status of the colony (PERMANOVA, $F=1.72, p=0.14$ ), nor time (PERMANOVA, $F=$ $1.16, p=0.30)$ influenced the overall chemical profile of head extracts.

Abundance of leg compounds did not differ significantly among attractive and unattractive colony (Table 7). Additionally, status of colonies had no significant effect on the overall chemical profile of leg extracts (PERMANOVA, $F=0.75, p=0.46$ ). In contrast, leg compounds varied in time (Table 6). The abundance of the compounds 2-Tridecanone, Pentacosane, 9- Hexacosane, 9-Heptacosene and 9-Nonacosene changed significantly over time in both test and control colonies. Differences in the abundances of compounds were found between measurement 1 and 3 and between measurement 2 and 3, while measurement 1 and 2 showed no significant differences (Table 6). Time also had a significant effect on the overall chemical profile of legs (PERMANOVA, $F=14.81, p<0.001$ ). 
Table 6. Significance levels of general linear hypothesis posthoc comparison test per treatment and measurement group. $* p<0.05 ; * * p<0.01 ; * * * p<0.001$.

\begin{tabular}{|c|c|c|c|}
\hline Compound & Pairwise comparison & adjusted $p$ val & \\
\hline 2-Tridecanone & measurement 2 test - measurement 3 test & 0.018 & $*$ \\
\hline 2-Tridecanone & measurement 1 test - measurement 3 test & $<0.0001$ & $* * *$ \\
\hline 2-Tridecanone & measurement 2 control - measurement 3 control & $<0.0001$ & $* * *$ \\
\hline 2-Tridecanone & measurement 1 control - measurement 3 control & $<0.0001$ & $* * *$ \\
\hline 2 -Pentadecanone & measurement 1 test - measurement 3 test & 0.007 & $* *$ \\
\hline 2 -Pentadecanone & measurement 2 control - measurement 3 control & 0.001 & $* *$ \\
\hline 2 -Pentadecanone & measurement 1 control - measurement 3 control & 0.0003 & $* * *$ \\
\hline Pentacosane & measurement 2 test - measurement 3 test & 0.018 & * \\
\hline Pentacosane & measurement 1 test - measurement 3 test & 0.001 & $* * *$ \\
\hline Pentacosane & measurement 2 control - measurement 3 control & 0.037 & $*$ \\
\hline Pentacosane & measurement 1 control - measurement 3 control & 0.0003 & $* * *$ \\
\hline 9-Hexacosene & measurement 2 control - measurement 3 control & 0.037 & $*$ \\
\hline 9-Heptacosene & measurement 2 test - measurement 3 test & 0.00003 & $* * *$ \\
\hline 9-Heptacosene & measurement 1 test - measurement 3 test & 0.001 & $* *$ \\
\hline 9-Heptacosene & measurement 2 control - measurement 3 control & 0.00001 & $* * *$ \\
\hline 9-Heptacosene & measurement 1 control - measurement 3 control & 0.00003 & $* * *$ \\
\hline 9-Nonacosene & measurement2test - measurement 3 test & 0.005 & $* *$ \\
\hline 9-Nonacosene & measurement 1 test - measurement 3 test & 0.007 & $* *$ \\
\hline 9-Nonacosene & measurement 2 control - measurement 3 control & 0.04 & $*$ \\
\hline
\end{tabular}


Table 7. Relative abundance of chemical compounds found in leg extracts of S. depilis foragers per day and group of colonies (Sd: Standard deviation; in bold are compounds that significantly differ among groups; double-bond position was assigned based on Engels et al. 1990)

\begin{tabular}{|c|c|c|c|c|c|c|c|c|c|c|c|c|c|c|c|c|c|c|}
\hline \multirow[b]{3}{*}{ Compound } & \multicolumn{6}{|c|}{ Measurement 1} & \multicolumn{6}{|c|}{ Measurement 2} & \multicolumn{6}{|c|}{ Measurement 3} \\
\hline & \multicolumn{3}{|c|}{ Control } & \multicolumn{3}{|c|}{ Test } & \multicolumn{3}{|c|}{ Control } & \multicolumn{3}{|c|}{ Test } & \multicolumn{3}{|c|}{ Control } & \multicolumn{3}{|c|}{ Test } \\
\hline & Mean & \pm & $\mathrm{Sd}$ & Mean & \pm & $\mathrm{Sd}$ & Mean & \pm & $\mathrm{Sd}$ & Mean & \pm & $\mathrm{Sd}$ & Mean & \pm & $\mathrm{Sd}$ & Mean & \pm & $\mathrm{Sd}$ \\
\hline Benzaldehyde & 2.99 & \pm & 2.24 & 2.01 & \pm & 0.76 & 3.11 & \pm & 3.62 & 2.83 & \pm & 2.62 & 6.05 & \pm & 4.54 & 5.52 & \pm & 6.11 \\
\hline 2-Tridecanone & 3.41 & \pm & 5.07 & 1.98 & \pm & 1.92 & 5.36 & \pm & 7.94 & 5.82 & \pm & 7.96 & 15.86 & \pm & 9.63 & 16.56 & \pm & 15.55 \\
\hline 2 -Pentadecanone & 1.79 & \pm & 2.12 & 1.08 & \pm & 1.12 & 2.04 & \pm & 2.77 & 2.14 & \pm & 2.55 & 4.08 & \pm & 2.97 & 3.92 & \pm & 3.40 \\
\hline Pentacosane & 20.32 & \pm & 4.45 & 19.00 & \pm & 5.99 & 16.77 & \pm & 4.39 & 15.56 & \pm & 4.15 & 12.63 & \pm & 5.11 & 11.51 & \pm & 6.99 \\
\hline 9-Hexacosene & 1.26 & \pm & 0.33 & 1.51 & \pm & 0.46 & 1.48 & \pm & 0.57 & 1.44 & \pm & 0.46 & 1.23 & \pm & 0.59 & 1.18 & \pm & 0.56 \\
\hline 9-Heptacosene & 28.27 & \pm & 7.65 & 26.99 & \pm & 5.68 & 29.81 & \pm & 8.31 & 29.04 & \pm & 8.48 & 19.36 & \pm & 5.30 & 18.25 & \pm & 8.44 \\
\hline Heptacosane & 11.40 & \pm & 3.05 & 11.15 & \pm & 3.50 & 10.84 & \pm & 3.22 & 12.05 & \pm & 4.60 & 12.67 & \pm & 3.96 & 10.84 & \pm & 4.96 \\
\hline 9-Nonacosene & 9.27 & \pm & 1.62 & 9.53 & \pm & 2.42 & 9.86 & \pm & 2.65 & 9.61 & \pm & 2.83 & 8.62 & \pm & 2.75 & 7.27 & \pm & 3.40 \\
\hline Nonacosane & 5.14 & \pm & 2.13 & 5.59 & \pm & 2.26 & 4.44 & \pm & 1.10 & 5.37 & \pm & 2.54 & 5.49 & \pm & 2.05 & 5.69 & \pm & 2.82 \\
\hline 9-Hentriacontene & 4.54 & \pm & 1.16 & 5.76 & \pm & 2.27 & 3.98 & \pm & 1.06 & 4.53 & \pm & 2.74 & 3.97 & \pm & 1.43 & 5.55 & \pm & 3.38 \\
\hline Hentriacontane & 1.46 & \pm & 0.78 & 1.70 & \pm & 0.82 & 1.30 & \pm & 1.00 & 1.19 & \pm & 1.12 & 1.12 & \pm & 0.43 & 2.24 & \pm & 2.14 \\
\hline not identified & 3.17 & \pm & 1.31 & 4.16 & \pm & 1.59 & 3.39 & \pm & 1.70 & 3.22 & \pm & 1.53 & 2.65 & \pm & 1.03 & 4.48 & \pm & 3.07 \\
\hline not identified & 4.92 & \pm & 2.31 & 5.54 & \pm & 3.01 & 5.32 & \pm & 3.16 & 4.88 & \pm & 2.74 & 3.65 & \pm & 1.97 & 4.33 & \pm & 2.81 \\
\hline not identified & 2.06 & \pm & 0.84 & 4.00 & \pm & 4.09 & 2.32 & \pm & 1.36 & 2.32 & \pm & 1.62 & 2.61 & \pm & 1.88 & 2.65 & \pm & 1.76 \\
\hline
\end{tabular}


Table 8. Relative abundance of chemical compounds found in head extracts of S. depilis foragers per day and group of colonies (Sd: Standard deviation; double-bond position was assigned based on Engels et al. 1990).

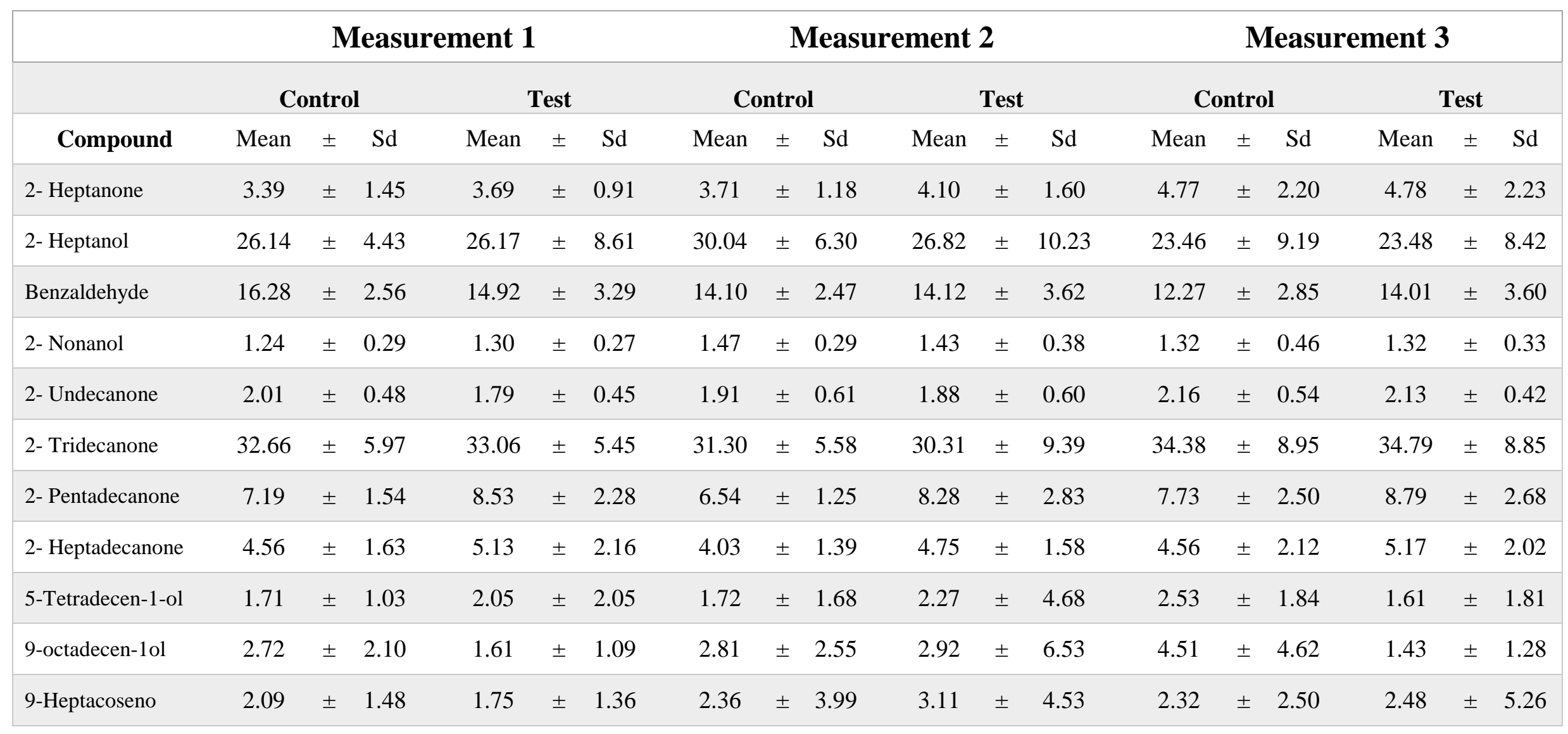




\section{Discussion}

The behavioral tests suggest that $S$. depilis foragers play an important role in male attraction and in the formation of aggregations. Colonies with normal foraging activity attracted significantly more males than colonies without foragers (Fig. 5). The cage structure could have affected the airflow between the colony and the environment and, thus, explain the differences found among groups. However, probably this is not the case for two reasons. First, entrances of stingless bee nests are often concealed (Roubik 2006) and colonies are still able to attract large numbers of males. Second, the number of attracted males increased more than 6 times when we opened the cages (Fig. 7), suggesting that the cage structure per se did not cause the absence of males during the previous 14 days. Therefore, probably the differences in the number of attracted males are related to differences in the foraging activity.

We did not find a change in the chemical profile of foragers that could explain the observed male attraction. More specifically, we did not find a new compound or quantitative differences in the overall chemical profile in foragers from attractive colonies when compared to foragers from unattractive colonies. The absence of a clear change in the chemical profile of foragers belonging to attractive colonies means that we are yet to identify the chemical signal that attracts males from distances as large as $500 \mathrm{~m}$ (Kerr et al. 1962).

Colonies with foraging activity were much more attractive than colonies without active foragers. Consequently, foragers might be responsible for transmitting the sexual signal to males in the surrounding environment. Males may look at flowers for a forager carrying such message, and once they encounter the message, they follow her to the nest (Roubik 1990; Engels et al. 1990). The source of this signal could be either the queen or the workers themselves (Engels et al. 1990). Foragers could carry the sex pheromone produced by queens, that could be easily transmitted to workers during the intranidal interactions between these 
two castes, which occur frequently in stingless bees (Imperatriz-Fonseca and Zucchi 1995). However, this hypothesis would have to accommodate observations that drone aggregations can appear at the new nest, but not at the mother nest, before the arrival of the virgin queen at the new nest (Michener 1946; Kerr et al. 1962; Nogueira-Ferreira and Soares 1998). Alternatively, the chemical profile of the foragers themselves might change, either due the production of new compounds or due to changes in the proportion of existing compounds, because of physiological alterations resulting from the absence of a physogastric queen in the nest. Physiological changes in workers caused by queen removal have been found in stingless bees (Nunes et al. 2014) and other social insects such as honeybees, bumblebees, ants and wasps (Hoover et al. 2003; Holman et al. 2010; Van Oystaeyen et al. 2014) . In both cases, males might use these putative changes in the chemical profile of workers to find attractive virgin queens. However, as the chemical analysis of foragers did not show any variation associated with the attractive status of colonies, these hypotheses remain speculative. An alternative explanation is that workers, while foraging, might be releasing specific compounds deliberately to attract males. In this case, the variation in foragers of attractive colonies would not be in their chemical composition, but in their behavior. Foragers could release higher quantities of compounds they already use for other purposes (e.g. recruitment to food sources) or release specific compounds to attract males. To test these hypotheses, it would be necessary to collect only the compounds foragers are releasing in the environment.

Another possible explanation for the absence of variation in chemical profiles is that the compounds responsible for male attraction are above the analytical capacity of the GC-MS system. This methodology has been very useful for many chemical studies of stingless bees and other social insects (e.g. Nunes et al. 2009; Van Oystaeyen et al. 2014), but also has limitations. Gas chromatography is limited to volatile compounds (or compounds that can be made volatile) and compounds that are stable enough to successfully flow through the column 
(Kitson et al. 1996). It is possible that the attractive signal is comprised of small and high volatile compounds, or large and less volatiles compounds, that cannot be detected by the GCMS. Other analytic techniques can help to elucidate this question and should also be used in further studies.

According Sommeijer et al. (2004), the behavior of workers was important for the formation of drone congregation sites (DCS) in Melipona favosa. Workers were very attractive to males and were seen depositing resin and plant material on the substrate where males aggregate (Sommeijer et al. 2004). Likewise, S. depilis foragers may not rely only on their own compounds, but could use plant material to actively attract males.

Communication between workers and males was also reported in other social insects. Males of the ant Megaponera foetens find the nests where they mate with ergatoid queens by following the pheromone trail laid by workers (Longhurst and Howse 1979). Stingless bees also use pheromone trails to recruit nestmates to food sources (Jarau et al. 2004b; Jarau et al. 2006; Schorkopf et al. 2007; Stangler et al. 2009; Jarau et al. 2010). Foragers produce these pheromones in their labial glands and lay them between the nest and the food source (Jarau et al. 2004; Jarau et al. 2006; Schorkopf et al. 2007; Stangler et al. 2009; Jarau et al. 2010). In S. depilis, foragers chemically mark food sources (Schmidt et al. 2003) and males could follow these pheromone trails and footprints left by foragers to find the nest that has a virgin queen. This would also explain why foraging activity was required to attract males in our study.

The temporal dynamics of aggregation size might give some clue about the features of the attractive signal in stingless bees. Males start to arrive at the entrance of attractive nests two days after queen removal (Fig. 2). The number of males peaked at around 5 to 6 days after queen removal and then decrease steadily (Fig. 2), but a few males could still be seen in front of nests more than one month after mating. So, the sexual signal appears quickly, loses its strength after a few days (probably after copulation), but persists for a long time at a low 
level. The quick start of attraction suggest that the sexual message does not require a long time to be produced and, consequently, probably does not require profound physiological changes in foragers. The persistence of attraction even after mating indicates that the signal could be comprised of less volatile compounds.

When the mating site is the nesting area, females are predicted to be the signaling sex and to communicate using compounds of low volatility, which act only in short-range communication with males (Ayasse et al. 2001). The reason for that is the risk associated with long distance signaling of a nest location, which parasites and predators could exploit (Ayasse et al. 2001). The massive attraction of males to stingless bee nests seems to contradict this prediction. However, the use of foragers to spread the sexual message may provide a way for communicating directly to males the location of a virgin queen. This strategy could reduce the risks of attracting predator or parasites, which are a common threat to stingless bees (Grüter et al. 2016). The queen-produced pheromones would then be used only in a short-range communication, during the nuptial flight.

The available information on sex pheromones produced by stingless bee queens is too limited to draw strong conclusions about their role in long-range communication. Previous studies show that S. postica, S. mexicana and Tetragonisca angustula queens produce compounds that attract males (Engels et al. 1990; Engels et al. 1997; Fierro et al. 2011; Verdugo-Dardon et al. 2011). However, it remains to be tested whether these compounds would still attract males over long distances. In addition to these attractants, other compounds seem important for triggering copulatory behavior (Engels et al. 1997; Fierro et al. 2011).

Thus, the available data demonstrate that queens and males communicate directly, but it remains unclear what explains the long-range attraction of males to nests. Our results suggest a central role of foragers in this long-range attraction. Male-male communication might also be important for the formation of drone congregations in stingless bees (Kerr et al. 1962; 
Engels et al. 1990; Galindo López and Kraus 2009). S. mexicana and S. postica drones use pheromone marks, which are comprised by their cuticular hydrocarbons (see chapter 4), for short distance orientation towards specific sites (Kerr et al. 1962; Galindo López and Kraus 2009; see also chapter 4). Thus, the sexual communication system of stingless bees seems to be complex and relying on interactions between workers, males and queens.

The number of attracted males varied greatly among colonies in both years (Fig. 3). A similar variance was noted in T. angustula drone congregations (Fierro et al. 2011). As we could observe, this difference cannot be explained by foraging traffic (Fig. 8). Such differences among attractive colonies could be linked to a difference in the quality of colonies. The attractive signal may inform males about the quality of a queen (e.g. fecundity or health) or of the whole colony. Alternatively, the differential attraction could be an emergent property of the communication among males. The first males to arrive at attractive colonies might produce signals that will attract more males. Thus, a strong positive feedback is created leading to a phenomenon called "symmetry breaking" (Sumpter 2010a): the more males in a congregation, the more attractive is the congregation. Both hypotheses are tested in chapter 4.

Another interesting result was the temporal variation in chemical profiles. We found a significant temporal difference in leg compounds of foragers collected on different days. Cuticular hydrocarbons are very important cues in nestmate recognition in stingless bees (Nunes et al. 2008) and the implications of such temporal changes for the chemical ecology of S. depilis should be further investigated.

In summary, our results suggest an important role of forager activity in the attraction of males to nests during mating events in S. depilis. We experimentally demonstrated that colonies without foraging activity have a significantly lower capacity to attract males. However, we did not find changes in the chemical profile of foragers related to the attractive status of colonies. Thus, our results suggest foragers as nuptial messengers, but we could not decode 
the message they carry. Our results contribute to the understanding of the mating biology of stingless bees and show that the sexual communication system of these bees is a fascinating and multifaceted process that is likely to involve interactions between queens, workers and males. 
CHAPTER 3

The aggregation pheromone of males 


\begin{abstract}
In stingless bees, aggregations of drones are formed in the surroundings of the virgin queen's colony prior to the mating flight. The pheromonal cues involved in the formation of these drone congregations during reproductive events, however, remain poorly understood. Research has shown that signals transmitted by foragers and queen sex pheromones are involved in the mating communication of these bees. Additionally, there is strong evidence that communication among males plays a role in the establishment of aggregations since males deposit pheromone marks on the substrate where they aggregate. These marks attract males at a short-range and are important for the formation of aggregations. However, the compounds they might use as aggregation pheromones were not yet identified. The aim of this study was to identify the putative aggregation pheromones deposited by males at the aggregation site. To this end, we collected drone markings and analyzed their chemical profile using a gas chromatography and mass spectrometry (GC-MS) system. We also aimed to identify the source of the drone markings by comparing with cuticular extracts and observing the behavior of males in the aggregation. Our results suggest that males actively deposit cuticular hydrocarbons at the aggregation site, which have low volatility and are likely used for short-range orientation only. These results provide additional support for the existence of exchange of information between males during reproduction in stingless bees. However, it still not clear whether the drone marks are signals which evolved to convey a specific information, or if this marks are information unintentionally left at aggregations and used as cues by other males.
\end{abstract}




\section{Introduction}

A common phenomenon in the reproduction of the eusocial stingless bees (Meliponini) is the formation of large drone aggregations in front of conspecific nests (Michener 1946; Engels 1987; Roubik 1990; Nogueira-Ferreira and Soares 1998; Van Veen and Sommeijer 2000; Cortopassi-Laurino 2007; Galindo López and Kraus 2009; Boongird 2011; Bänziger and Khamyotchai 2014). These aggregations can contain up to 7000 mostly unrelated males (Paxton 2000; Cameron et al. 2004; Kraus et al. 2008; Bänziger and Khamyotchai 2014). Males start to arrive at colonies a few days before the nuptial flight.

Pheromones are thought to play an important role in the coordination of mating activities, but the pheromonal signals involved in the formation of aggregations are poorly understood. The observation that aggregations of males are associated with nests during reproductive events led researchers to hypothesize that compounds released by the virgin queens explain the attraction of drones to colonies (Engels 1987). Compounds produced by virgin queens that attract males were already identified in stingless bee species (Engels et al. 1997; Fierro et al. 2011; Verdugo-Dardon et al. 2011). However, several lines of evidence suggest that virgin queen signals might not be responsible for the formation of drone aggregations nearby stingless bee nests and may be used mainly in short-range communication (see chapter 2). Instead, compounds transmitted by foragers may explain the long-range attraction of drones to colonies (chapter 2). Although it was not possible to identify the signal, foragers are probably informing males about the quality of their colonies (see chapter 4).

Additionally, males seem to produce an aggregation pheromone: they cluster at specific locations and return to the same sites every morning (Kerr et al. 1962; Engels et al. 1990; Galindo López and Kraus 2009). Previous studies have suggested that males mark their 
aggregation sites with pheromones (Kerr et al. 1962; Galindo López and Kraus 2009). However, the components of this putative chemical signal have not yet been identified.

Therefore, by combining behavioral observations of male behavior at the aggregations with chemical analyses, the aim of this chapter to identify the chemical compounds males deposit on the substrate of their aggregation sites, which could potentially be used as an aggregation pheromone.

\section{Methods}

Observation of drone aggregations and drone mark collection

The study was carried out on the campus of the University of São Paulo, Ribeirão Preto. In order to observe the behavior of males, we filmed a Scaptotrigona depilis drone aggregation on two different days and analyzed the videos later. To collect the marks deposited by drones on the substrate, we placed filter papers where males of two different aggregations rested (Fig. 9 and Fig. 10). We also placed control filter papers at places where males were not resting. The filter papers remained in these places, as well as in aggregations, for ten days before the chemical analysis.

\section{Preparation of drone marks and cuticular extracts}

To obtain extracts of the marks left on the substrate by drones, the filter paper was cut into several small pieces and immersed in $500 \mu \mathrm{L}$ of organic solvent (dichloromethane). The filter paper was left in the solvent for 24 hours at room temperature before being analyzed. We followed the same procedure to prepare the extracts of the control filter paper without the drone marks. To obtain the drone cuticular extracts, males were individually immersed in 
$500 \mu \mathrm{L}$ of organic solvent (hexane) for five minutes. Each sample comprised a pool of cuticular extract from ten males. The aim was to obtain concentrated samples of cuticular extracts for further comparison with the drone marks.
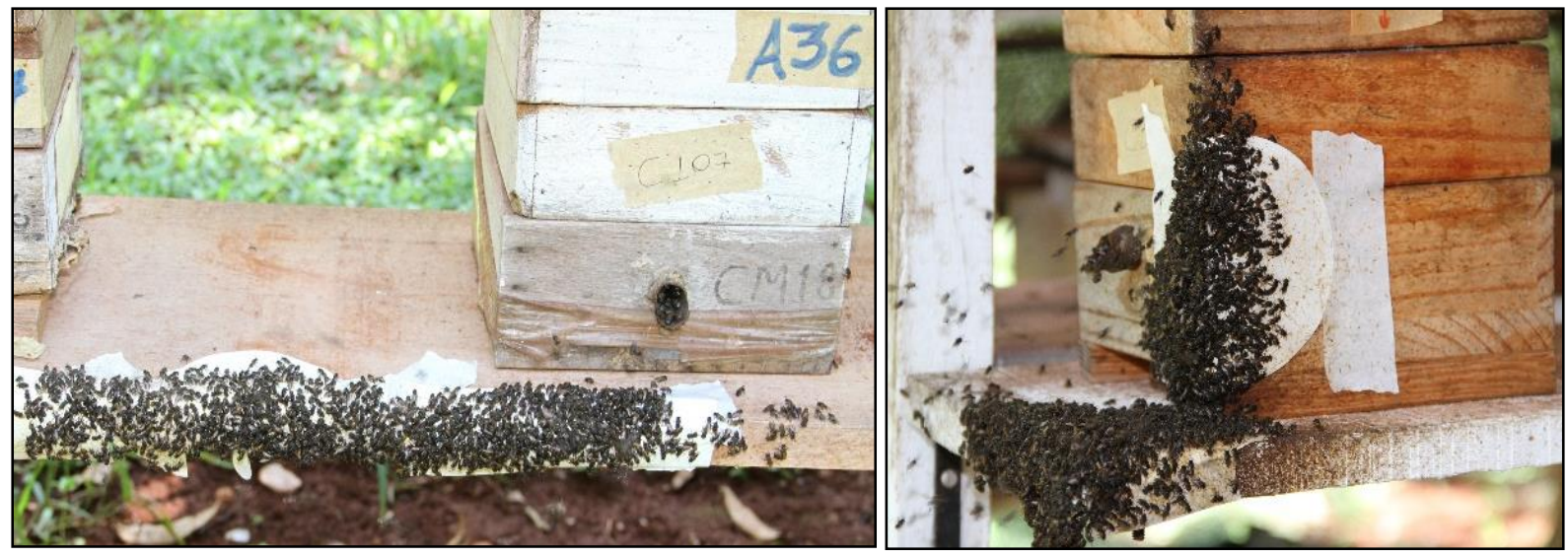

Figure 9. Filter paper placed under males at their aggregation site to collect the drone markings
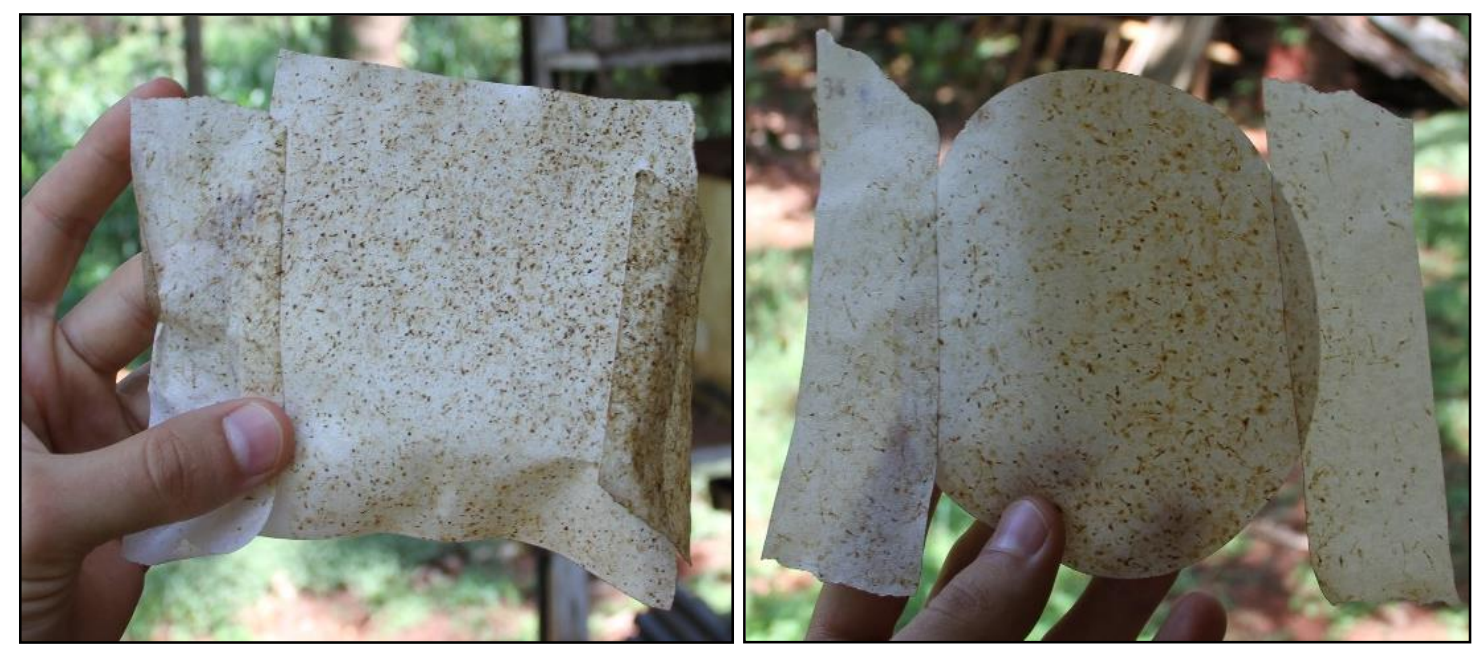

Figure 10. Filter paper after ten days being marked by S. depilis drones. 


\section{Chemical analyses}

Drone marks and cuticular extracts were analyzed using a GC-MS system (SHIMADZU, GCMS-QP2010) equipped with a DB-5 ms capillary column, using helium as the carrier gas at a constant flow rate of $1.0 \mathrm{~mL}$ min-1. $1 \mu \mathrm{L}$ of each sample was injected in the CG-MS system. All samples were injected in the splitless mode. The temperature protocol for the drone marks and cuticular extracts was from $80{ }^{\circ} \mathrm{C}$ to $300{ }^{\circ} \mathrm{C}$ increasing at a rate of $10{ }^{\circ} \mathrm{C} / \mathrm{min}$ and held at $300{ }^{\circ} \mathrm{C}$ for $10 \mathrm{~min}$ at the end. For both group of extracts, the injector inlet temperature was set to $250^{\circ} \mathrm{C}$. The identification of compounds was conducted by comparison with synthetic standard products (Nonanoic acid; Sigma-Aldrich, São Paulo, Brazil), using their retention indices, diagnostic ions, and standard MS databases (NIST 2008).

\section{Behavioral tests}

\section{Olfactometry}

To test the behavioral responses of males we used a four-way olfactometer (Vet et al. 1983). This olfactometer consists of a central arena attached to four concentric arms. A continuous charcoal filtered airflow is created in each arm by an air pump connected to a hole in the center of the arena. One arm of the olfactometer receives the treatment, while the other three receive only pure air (Figs. 11 and 12). The insect is placed in the center of the arena and its behavior is filmed for posterior analysis (Fig. 12).

The four-way olfactometer has several advantages compared to Y-shaped olfactometers since it offers more complex choice tests and also provides more statistical power (Vet et al., 1983). 


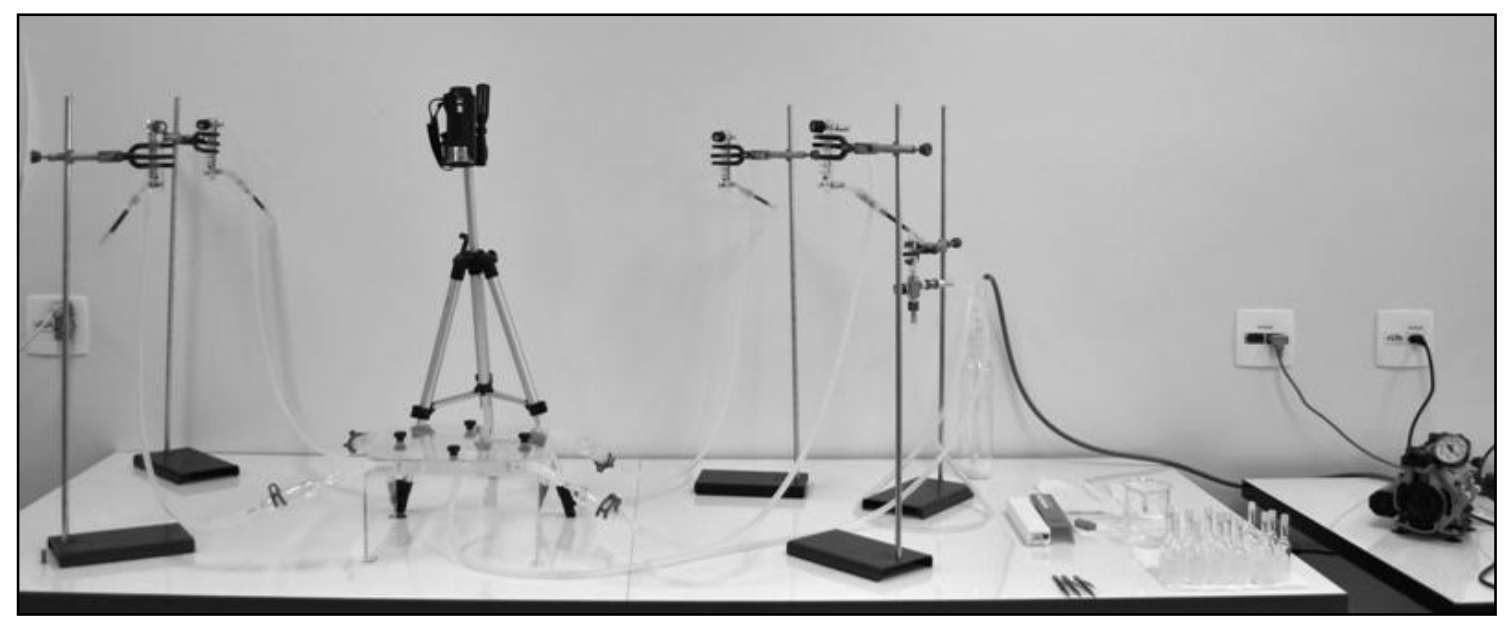

Figure 11. The four-way olfactometer used for the behavioral experiments.

The aim of this experiment was to test if the drone marks, as well as the volatile compound found in the marks (i.e. nonanoic acid, see results), attract $S$. depilis males. Thus, the experimental groups were: (i) filter paper with drone marks; (ii) nonanoic acid; and (iii) dichloromethane (solvent control). To measure the attractiveness, we recorded the time individuals spent in each arm of the olfactometer. We started to record the time as soon as the male crossed the pre-determined dotted line (Fig. 12). Ten males were used in each treatment.

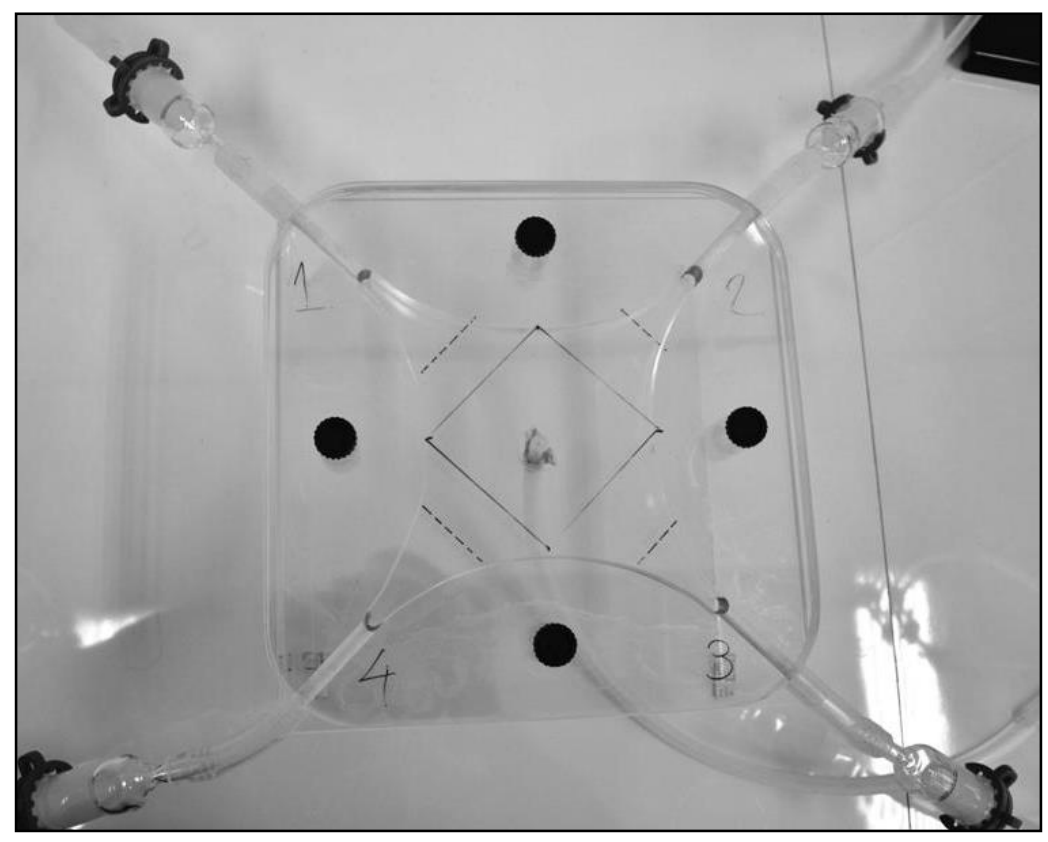

Figure 12. The olfactometer arena, showing the four arms. The dotted line was used as a threshold to determine the choice of an individual to a given arm. 


\section{Experimental procedure}

Before starting the experiment, the airflow rate of each arm was adjusted using dry ice. Moreover, before each trial, males were introduced individually into the arena and kept inside the olfactometer for five minutes to get used to the setup. Then the treatment was placed in the glass flask attached to one of the arms (Fig. 12) and the airflow was activated. At this point, we filmed the behavior of males for ten minutes. After the end of each trial, the olfactometer was cleaned with neutral detergent and alcohol. In addition, the glass flask containing the treatment was replaced by a clean flask which were washed with organic solvent. After cleaning the olfactometer and before starting the next trial, the airflow was activated for ten minutes, aiming to remove any possible remaining compounds. To avoid any position bias we randomly allocated the treatment to an arm for each trial.

\section{Results}

\section{General observations}

The observation of drone behavior at aggregations showed that males constantly rub their legs over their entire body (heads, thorax and abdomen), but more frequently over their abdomen. This was the most typical behavior of males while resting. Males were also often seen exposing their glossa, apparently dehydrating nectar (Fig. 13). No aggressive interactions among males were observed. Workers of other species of bees (e.g. Apis mellifera and Frieseomelitta varia) were observed visiting the drone aggregation (Fig. 14). 


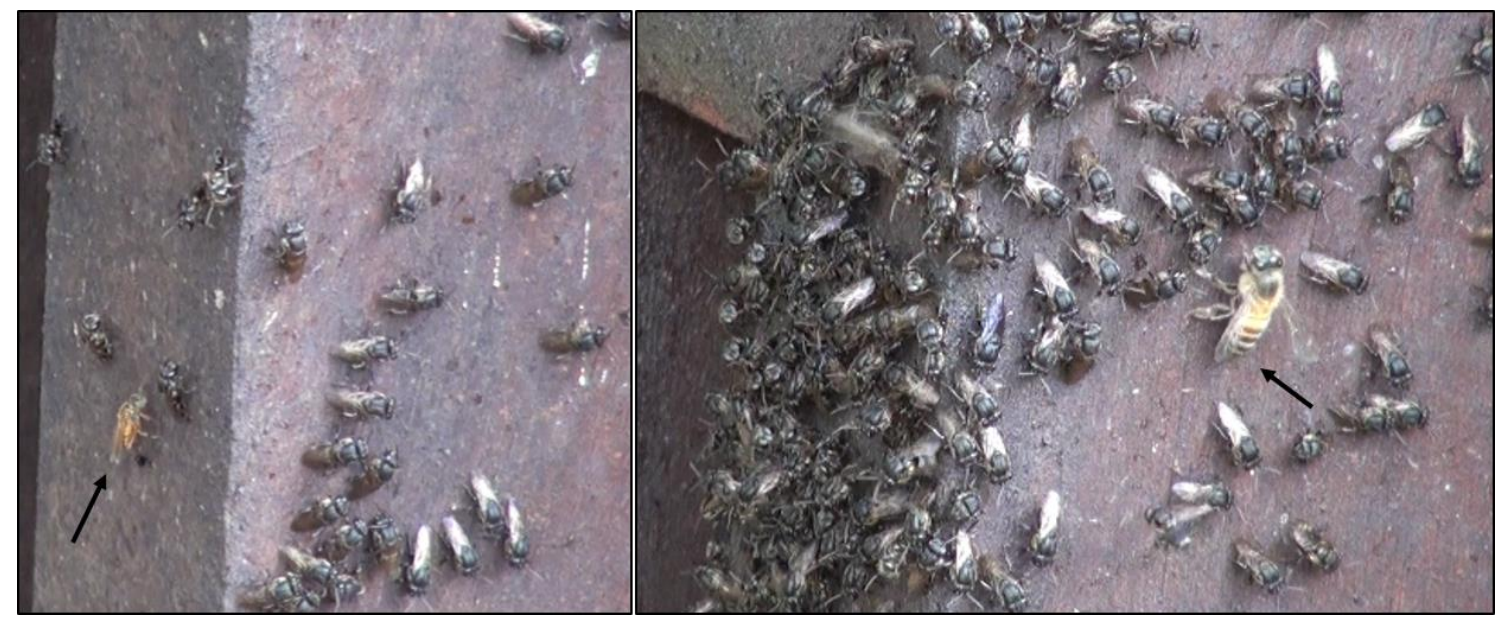

Figure 13. Foragers of $F$. varia (left) and A. mellifera (right), indicated by the arrows, visiting male aggregations.

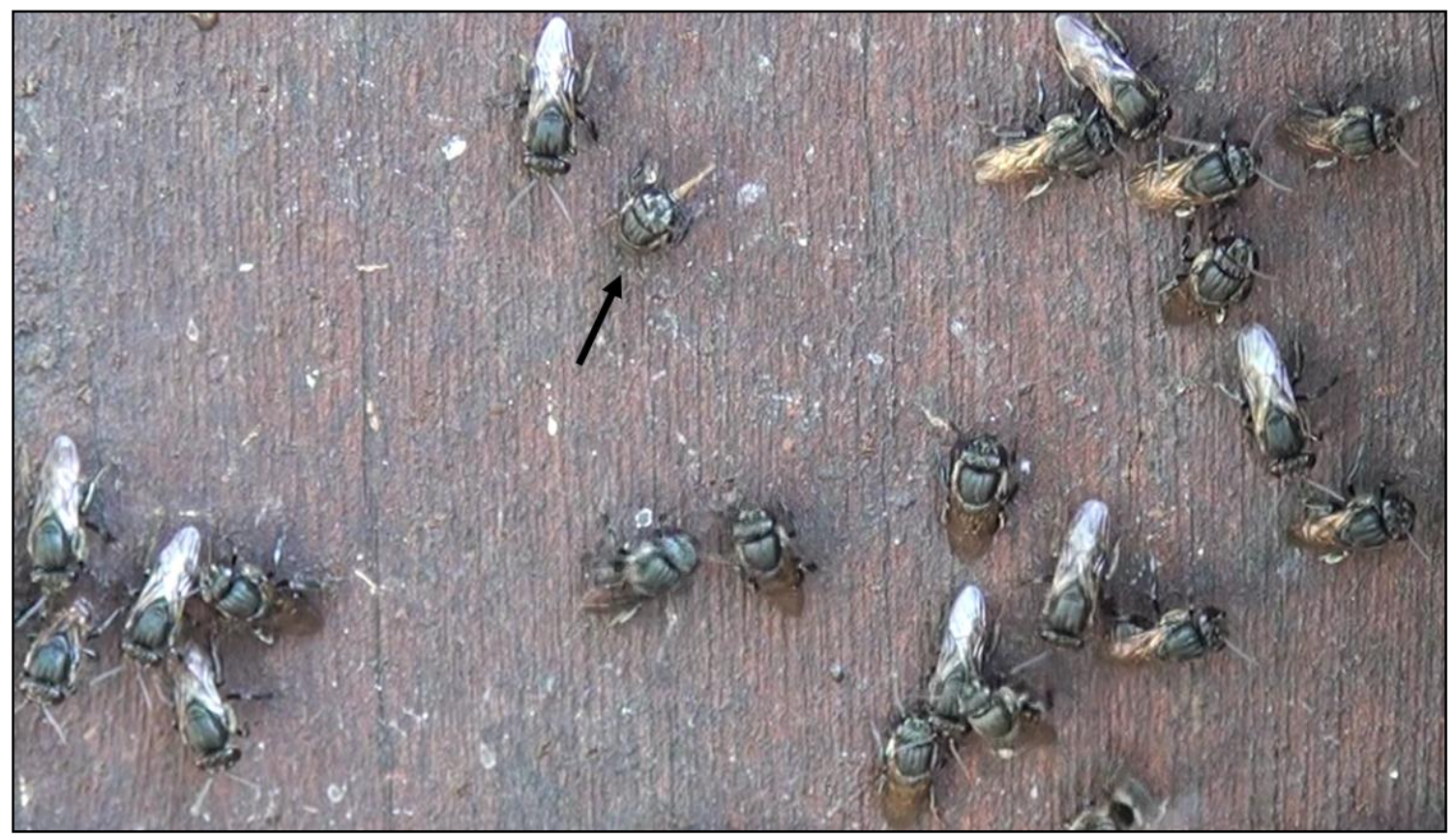

Figure 14. S. depilis males perching in an aggregation. The arrow indicates a male exposing his glossa, probably dehydrating nectar. 
Chemical profile of drone marks and drone cuticular hydrocarbons

The drone extracts comprised a total of twenty-four compounds (Table 9). Most of the compounds found in these extracts were hydrocarbons and the major compound was the Pentacosane, comprising about $30 \%$ of the total extract content. Additionally, a carboxylic acid, the nonanoic acid, was also found (Table 9). The chemical profile of the drone cuticular extracts was very similar to the extract of the marks (Figs. 15 and 16). Only two compounds were not shared by both extracts, the Nonanoic acid and the 9-Octadecen-1-ol. Thus, a total of twenty-two compounds were found in the cuticular extracts and most of them were hydrocarbons (Table 9). The major compounds of cuticular extracts were the same found in the extract of marks (i.e. Pentacosane) and the 9-heptacosene, comprising together $40 \%$ of the total cuticular extract content (Table 9).

\section{Behavioral tests}

Unfortunately, we could not evaluate the behavioral response of males to the tested compounds. When males were introduced inside the olfactometer they became very agitated, running quickly throughout the whole apparatus. Sometimes, when trying to fly they fell upside down, which made them even more excited. In this context, it was difficult to reliably measure the response of males to any treatment. Therefore, as the olfactometer seemed to offer a too artificial situation for the males, we decide not to use the results of this behavioral tests. 
Table 9. Relative concentration (\%) of drone marks and cuticular compounds of S. depilis workers. Data of both colonies were pooled; SD: standard deviation.





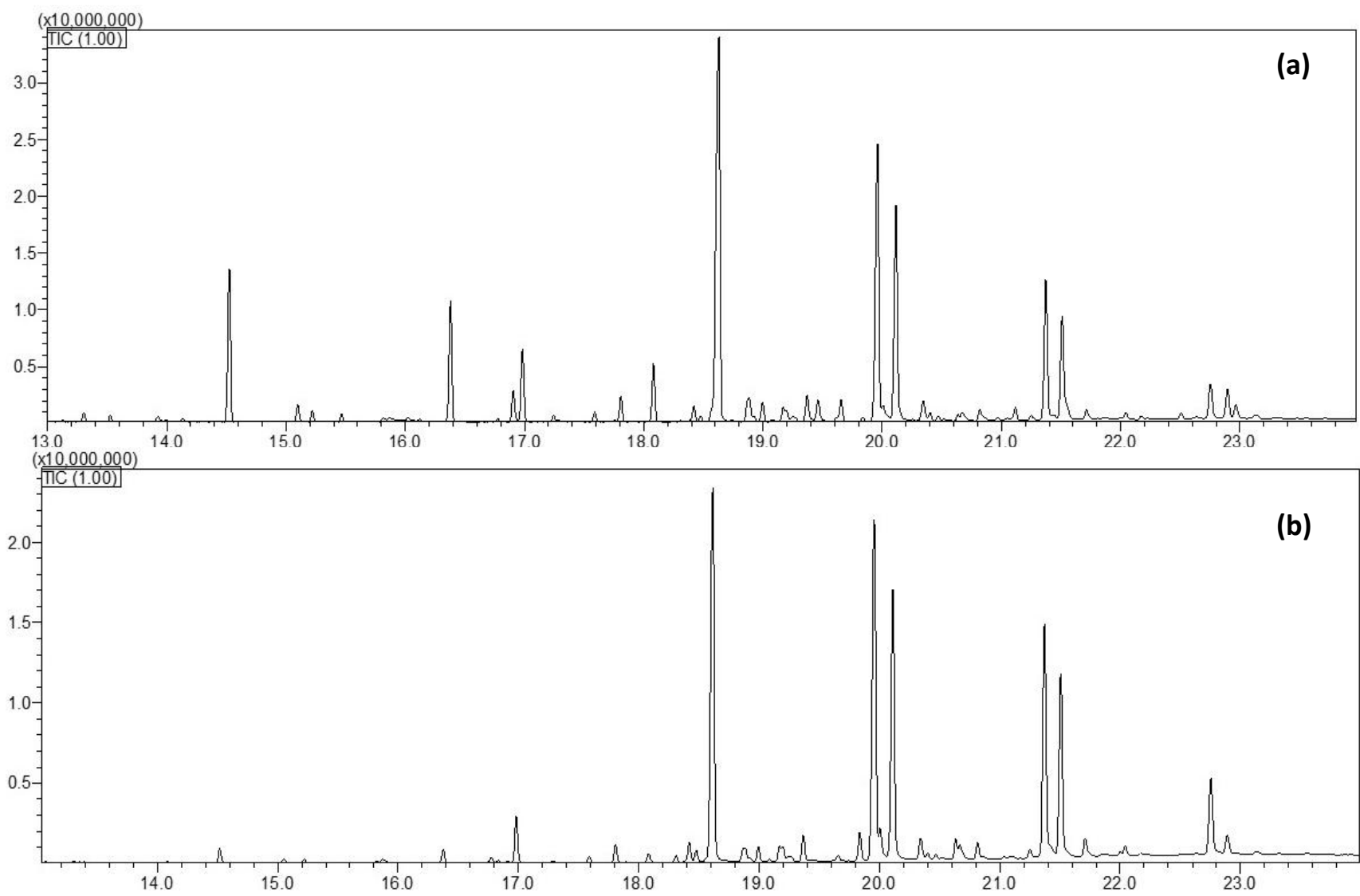

Figure 16. Chromatograms of drone marks (top) and drone cuticular extract (bottom) of S. depilis.

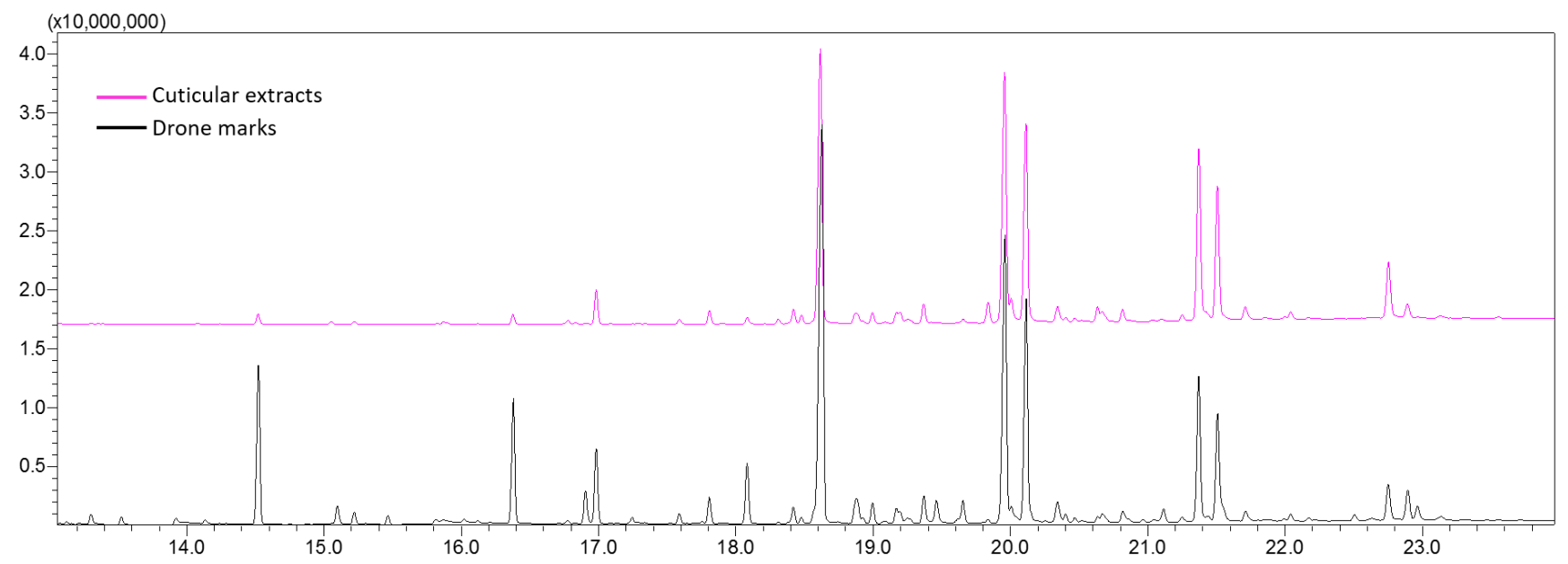

Figure 15. Chromatograms showing the comparison of cuticular and drone marks extracts. 


\section{Discussion}

Our results suggest that males deposit their cuticular hydrocarbons on the substrate where they aggregate. Almost all compounds found in the cuticular extracts of males were also found on the substrate. The behavioral observation of males constantly rubbing their legs over their entire body suggests that they are actively depositing such compounds in the substrate. A similar behavior of drones in aggregations was reported for Tetragonisca angustula (Nogueira-Ferreira and Soares 1998). Cuticular hydrocarbons are compounds with low volatility and probably remain on the substrate for several days. Stingless bee males arrive at the aggregation site early in the morning and leave in the afternoon (Roubik 1990; Van Veen et al. 1997; Nogueira-Ferreira and Soares 1998; Galindo López and Kraus 2009). Thus, these chemical marks may be used for short distance orientation towards the aggregation site in the subsequent day. Drones of two congeneric species, S. mexicana and S. postica, seems also seem to be attracted to chemical marks left at their aggregation site and the attractiveness of such marks rapidly decreases at a relatively close range $(50 \mathrm{~cm}$ : S. mexicana, Galindo López and Kraus 2009; $250 \mathrm{~cm}$ : S. postica, Kerr et al., 1962), reinforcing the idea that low volatility compounds comprise the short-range aggregation pheromone of stingless bees. Hydrocarbons are also found to be used as aggregation pheromones of a beetle species (Wheeler and Cardé 2014).

The marks deposited by males on the substrate could have evolved to convey a specific information (i.e., a signal; Dall et al. 2005) to others males as well as to virgin queens. However, male-produced signals that attract other males seems unlikely to evolve in $S$. depilis. Given the elevated competition faced by males at aggregations, attracting more males to aggregations would only reduce their individual chances of successfully reproduce. To explain the evolution of this apparent cooperative signaling with individual-selectionist arguments, researchers have proposed that males may parasitize the chemical marks laid by 
other males or that a composite signal of several males can attract more females and, thus, increase the absolute number of mates each male has access (Ayasse et al. 2001). This latter argument does not seem to hold for stingless bees since each aggregation attracts only one female. On the other hand, this information might be produced inadvertently by males, like footprints. In this case, drone marks could convey a discrete information (i.e., social cue; Dall et al. 2005), such as the spatial location of the aggregation site, or provide a continuous information, e.g. about the quality of a specific colony (i.e., public information; Dall et al. 2005). The available data do not allow us to conclude which of these cases better explain the exchange of information between $S$. depilis males. The potential benefits of using such information for stingless bee males may be to increase the efficiency of nest localization and to reduce the risks of predation, which is a common threat for Meliponini drones (Brown 1997; Cortopassi-Laurino 2007; Koedam et al. 2009; Koedam et al. 2011).

The exchange of information between males seems to be a common phenomenon in corbiculate bees. In Euglossinni (orchid bees) the fragrances collected from orchid flowers are released during courtship display attracting conspecific males (Zimmermann et al. 2006). Bumble bees (Bombus) males mark their flying routes with labial gland compounds, which may also attract other males (Goulson 2010; Ayasse and Jarau 2014). Similarly, in honeybees (Apis mellifera), males produce compounds that attract conspecific males (Brandstaetter et al. 2014). Here, we offer additional evidence for the existence of a communication among males during mating in S. depilis.

The compounds produced by stingless bee males might also attract virgin queens, as observed in bumblebees (Goulson 2010; Ayasse and Jarau 2014), since virgin queens in Tetragonisca angustula sometimes fly towards the male aggregation (Nogueira-Ferreira and Soares 1998). However, as males aggregate close to the nest and quickly follow the virgin queen as soon as she leaves the nest for the nuptial flight (Van Veen and Sommeijer 2000), it 
seems unlikely that the attraction of virgin queens to males is necessary. Thus, male produced compounds probably act exclusively among males.

Interestingly, $S$. depilis drone aggregation attracted not only conspecific males but also foragers of other species (Fig. 14). Kerr et al. (1962) also reported that honeybee foragers visited drone aggregations of S. postica and licked the legs of some males. This is intriguing since apparently there is no resource at drone aggregations that could be useful for foragers. A possible explanation for this attraction is that males carry compounds that are common attractants for several species (Kerr et al. 1962), such as flower produced compounds. Thus, these compounds may mislead foragers or males that are looking for food. We found small quantities of a volatile compound in the drone marks, the nonanoic acid, that can also be found among the volatiles produced by flowers (e.g. Nogueira et al. 2001) and may explain the attraction of foragers and males of other species. This indicates that males use not only low volatile hydrocarbons to communicate, but also a volatile component.

Unfortunately, we were not able to measure the behavioral response of males to their pheromone markings. The olfactometer seemed to be a too artificial apparatus to test this behavior of stingless bees. We based the choice of this method on previous studies, which successfully measured stingless bee male behavior with similar olfactometers (Fierro et al. 2011; Verdugo-Dardon et al. 2011). However, our tests showed that this method is inappropriate to reliable measure the behavior of $S$. depilis males.

The behavior of males in aggregations was similar to what was previously described for other stingless bee species and we did not observe aggressive interactions among males(Roubik 1990). Moreover, we frequently observed males exposing their glossa, apparently dehydrating nectar, which was also reported for several other species (Van Veen et al. 1997; CortopassiLaurino 2007). 
In summary, our results suggest that males of $S$. depilis mark the substrate at their aggregation site with cuticular hydrocarbons. These compounds have low volatility and are probably used only for short-range orientation. Nevertheless, the use of more volatile compounds cannot be ruled out. Thus, our results provide additional support for the existence of an exchange of information among stingless bees males during the reproduction of stingless bees. However, it still not clear whether the drone marks are signals which evolved to convey a specific information, or if this marks are information unintentionally left at aggregations and used as cues by other males. 


\section{CHAPTER 4}

\section{Differential attraction of males: symmetry breaking or colony quality?}




\section{Abstract}

During reproduction aggregations of males are formed in the surroundings of stingless bee colonies before the virgin queen nuptial flight. The mechanisms underlying the formation of drone aggregation in stingless bees, however, are poorly understood. These aggregations appear to be the outcome of interactions between queens, males and workers. Previous studies have observed considerable variation in the number of males attracted to colonies. This variation could be linked with differences in the quality and/or quantity of the sexual signal that is being emitted from colonies. Alternatively, this variation could be the result of a positive feedback created by the communication among males. The latter explanation would predict that differences in temporal sequence of discovery of attractive colonies will lead to differences in the number of attracted males, given that even small differences in the initial number of males would rapidly amplify the aggregation size due to strong effects of the pheromone on male choice behavior. Here, we tested whether the size of drone aggregations is more likely to be explained by communication among males or by the quality and quantity of the sexual signal. We evaluated the effects of temporal differences in the attractiveness of colonies, colony biomass and queen egg-laying rate on the number of attracted males. Our results show that the number of attracted males is positively correlated with colony biomass, suggesting that differences in colony quality could explain the differential attraction of drones. Whereas, the positive feedback created by male-male communication, as well as queen egg-laying rate, showed no effect on the number of attracted males. These results offer new insights into stingless bee mating biology and provide significant steps towards a better understanding of the factors involved in this complex phenomenon. Finally, we discuss the possibilities and constraints for male mate choice in stingless bees. 


\section{Introduction}

The strategies males use to find and secure mates are an important aspect of the mating behavior of bees. Males of this group actively search for females at their nest, at flowers or at non-resource based landmarks (Alcock 1978; Alcock 1980; Eickwort and Ginsberg 1980; Paxton 2005). Ecological factors, such as the spatiotemporal distribution of receptive females, are thought to shape the evolution of male mate seeking tactics of bees (Alcock 1978; Paxton 2005).

In the large and diverse group of the eusocial stingless bees (Meliponini), the most common strategy adopted by males during reproductive events is to form large congregations in front of the virgin queen's nest and wait for the mating flight (Michener 1946; Engels 1987; Roubik 1990; Nogueira-Ferreira and Soares 1998; Cameron et al. 2004; Cortopassi-Laurino 2007; Galindo López and Kraus 2009; Boongird and Michener 2010; Fierro et al. 2011; Bänziger and Khamyotchai 2014). These aggregations are formed a few days before the nuptial flight and end soon after copulation (Kerr et al. 1962; Nogueira-Ferreira and Soares 1998). The mechanism males use to find the nests having virgin queens are poorly understood. The massive attraction of males to such nests suggests the existence of a strong sexual signal. Research suggests that the build-up of male aggregations is probably an outcome of interactions between males, queens and workers (chapter 2, Engels et al. 1997; Galindo López and Kraus 2009; Fierro et al. 2011; Verdugo-Dardon et al. 2011).

A notable pattern that has emerged from previous observations is that there is considerable variation in the number of attracted males among colonies (chapter 2; Fierro et al. 2011). For example, in Scaptotrigona depilis colonies attracted from 20 to 880 males (chapter 2). The source of this variation remains unknown, nonetheless differences in the quantity or in the quality of the signal coming from attractive colonies could be linked with such differential attraction. Alternatively, this variation could be an emergent property of the communication 
among males. In S. mexicana, for example, males are attracted to conspecific males, as well as to the marks they deposit on the aggregation site (Galindo López and Kraus 2009). In this case, the first males to arrive at attractive colonies might initiate the production of the signals, which will attract more males, creating a positive feedback. Strong positive feedback could lead to a phenomenon called "symmetry breaking", whereby even small differences in the number of males rapidly amplify due to strong effects of the pheromone on male choice behavior (Sumpter 2010b). Hence, differences in the temporal sequence of discovery of attractive colonies by males may lead to strong differences in the number of attracted males, regardless of the quality of colonies. A similar phenomenon was observed in ants during recruitment to food sources (Beckers et al. 1990).

The aim of this chapter was to investigate the mechanism involved in the differential attraction of males to reproducing stingless bee colonies. To understand the factors affecting the number of attracted males, we tested two non-mutually exclusive hypotheses. Firstly, we tested if the putative communication mechanism among males generates a positive feedback, which results in more males being attracted to the colonies that became attractive earlier. Secondly, we tested if the number of attracted males increases with the quality of colonies, measured either as (i) the colony biomass or (ii) rate of new brood cells production.

\section{Methods}

Bees and study site

Eight colonies of the stingless bee $S$. depilis were used. All colonies were kept in wooden boxes during the experiments and were placed in pairs at four different sites on the campus of the University of São Paulo (Fig. 17). Only queenright colonies were used for the experiments. 


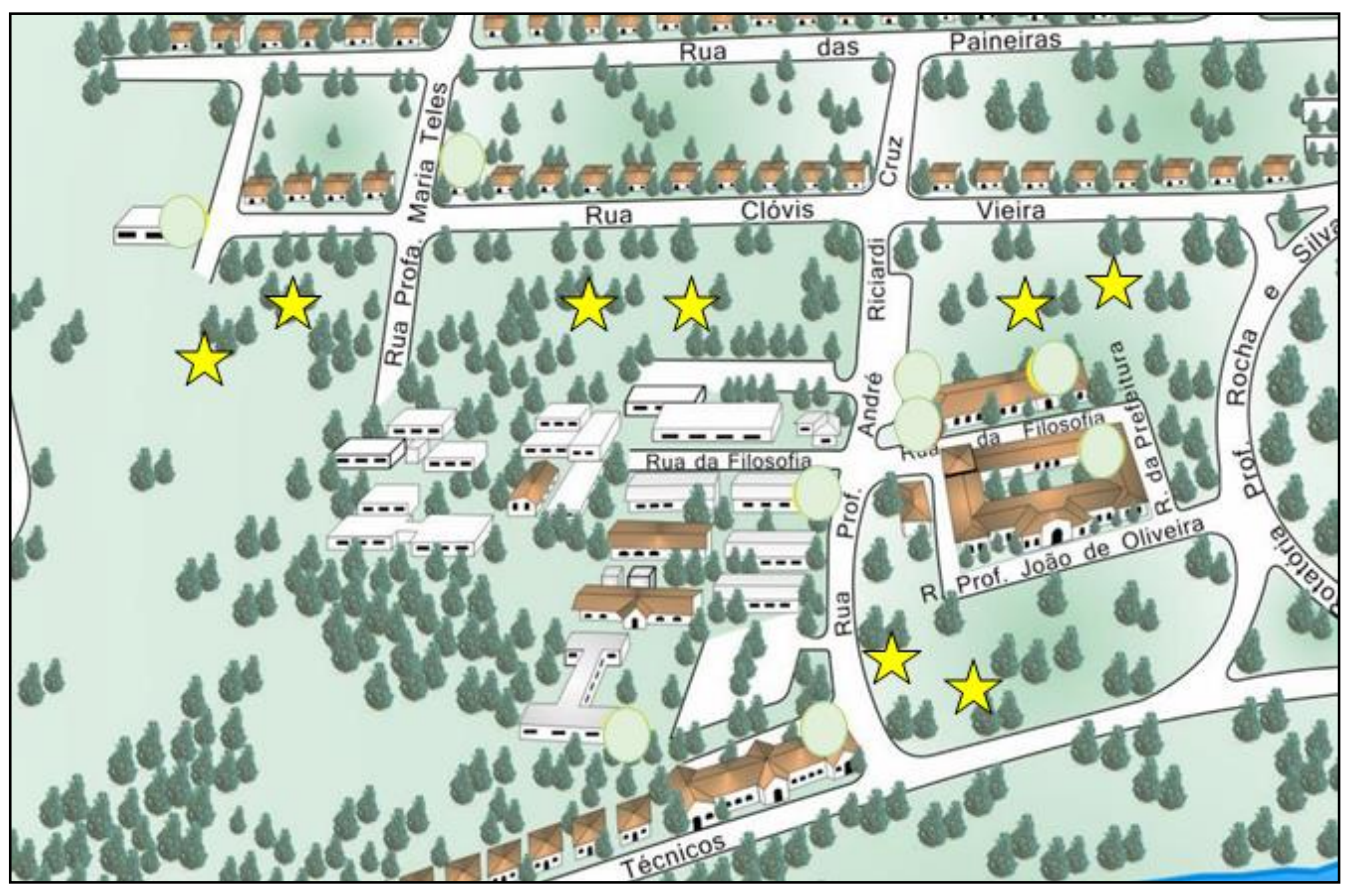

Figure 17. Map of the campus indicating the sites where each pair of colonies (stars) were placed.

\section{Experimental procedure}

We tested two hypotheses to explain the differential attraction of males to S. depilis colonies:

(i) symmetry breaking and (ii) the quality of colonies (see Fig. 18). To test the symmetry breaking hypothesis, one group of colonies became attractive 3 days earlier. We expected that if the differential attraction of drones among colonies was caused by differences in the strength of the male pheromone, early attractive nests would attract more males, since aggregation at these colonies would be already established when the second group of colonies become attractive. To test if the differential attraction of males is linked to the quality of colonies, we measured both the weight of colonies and the number of brood cells that were produced during three days 


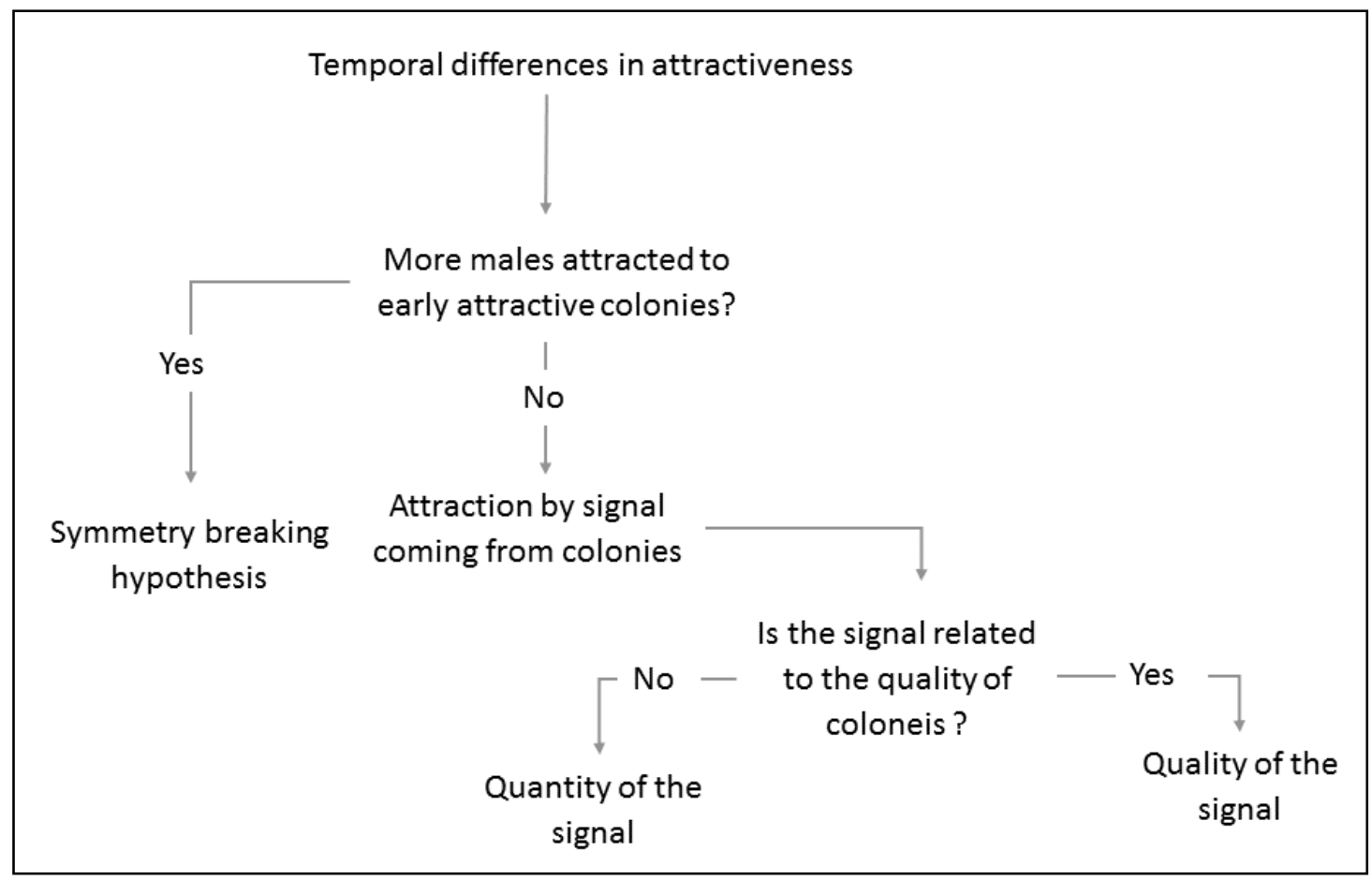

Figure 18. Flow chart of the tested hypotheses to explore the factors involved in the attraction of males.

Before the start of the experiment, all colonies were weighed using a standard scale. We discounted the weight of the wooden box were colonies were kept, by weighing identical empty boxes. To start the experiment, one colony of each pair had their physogastric queen removed (early colonies, $N=4$ ), thereby initiating the reproductive process. S. depilis colonies are headed by one ovipositing queen, but one to several virgin queens are usually present in queenright colonies (Kerr et al. 1962) and one of them will quickly replace the old queen. Afterwards, the number of males arriving at all colonies was recorded every day from (at 13-14h) for fifteen days. To record the number of males, we took pictures of the aggregations and later counted the individuals using standard image editing software. Three days after removing the queens of the first group of colonies, the egg-laying queens of the second group (late colonies, $N=4$ ) were also removed. Based on previous data (see chapter 2) we expected colonies to start attracting males two days after physogastric queen removal. After fifteen days, we checked all colonies for the presence of the newly-mated queens. We 
then counted the number of eggs the mated queens had laid during three days by taking pictures of brood cells and counting the number of new cells produced every day (Fig. 19).

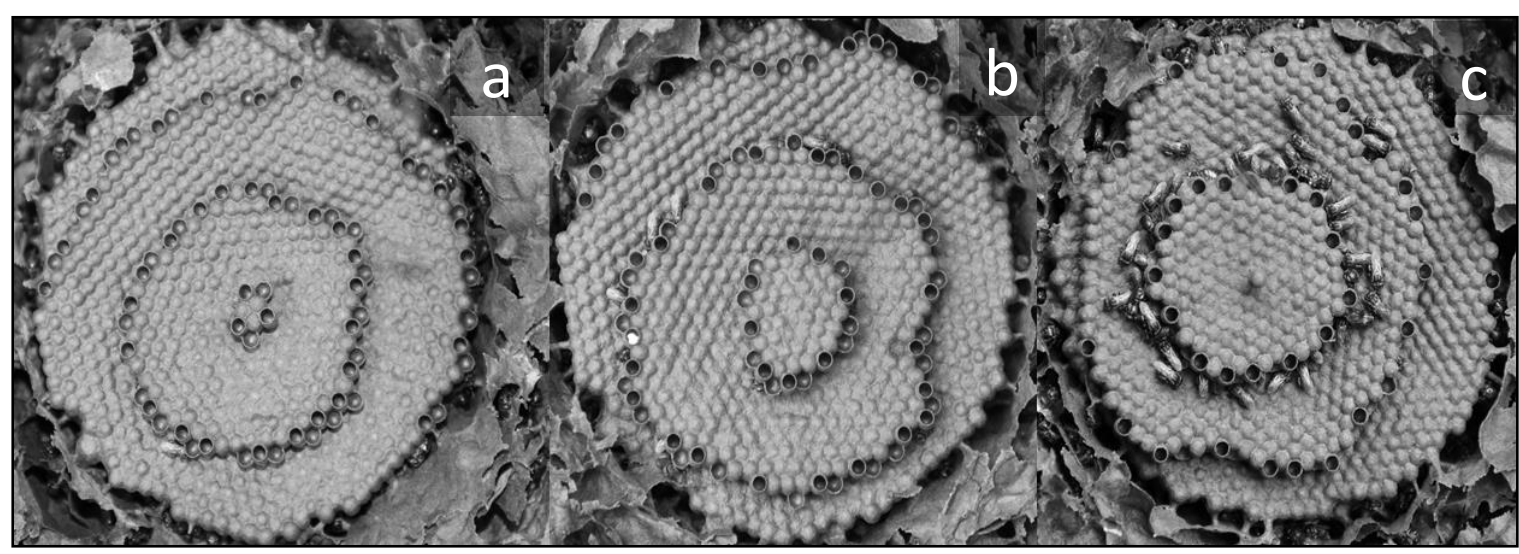

Figure 19. Brood combs of a single colony on three consecutive days (a, b and c). The number of new cells built per day was estimated by comparing pictures of two consecutive days.

\section{Statistical analyses}

All statistical analyses were conducted in R 3.3.2 (R Core Team 2016), using the lme4 package (Bates et al. 2015). To investigate the effects of the temporal sequence of discovery and of the colonies' quality parameters on the number of attracted males, we used generalized mixed-effect models (GLMM). To fit the model, the number of attracted males and the weight of colonies were square-root transformed. To avoid problems caused by zero-inflation, we used the number of males attracted during the peak period (day 5 to day 10) as the dependent variable, whereas fertility (average of eggs laid per queen), colony biomass and treatment (early/late) were included as fixed effects. Colony id was included as random effect to control for non-independence of the data. We also investigated the relationship between biomass and fertility using linear models. 


\section{Results}

Temporal dynamics of male aggregations

Males started to arrive at both groups of colonies two days after the removal of the egg-laying queen (Fig. 20). The number of males peaked at days 5 and 10, and then steadily decreased in both group of colonies, and at day 15 almost no male was observed near any colony. At day 15 all colonies had a new mated egg-laying queen.
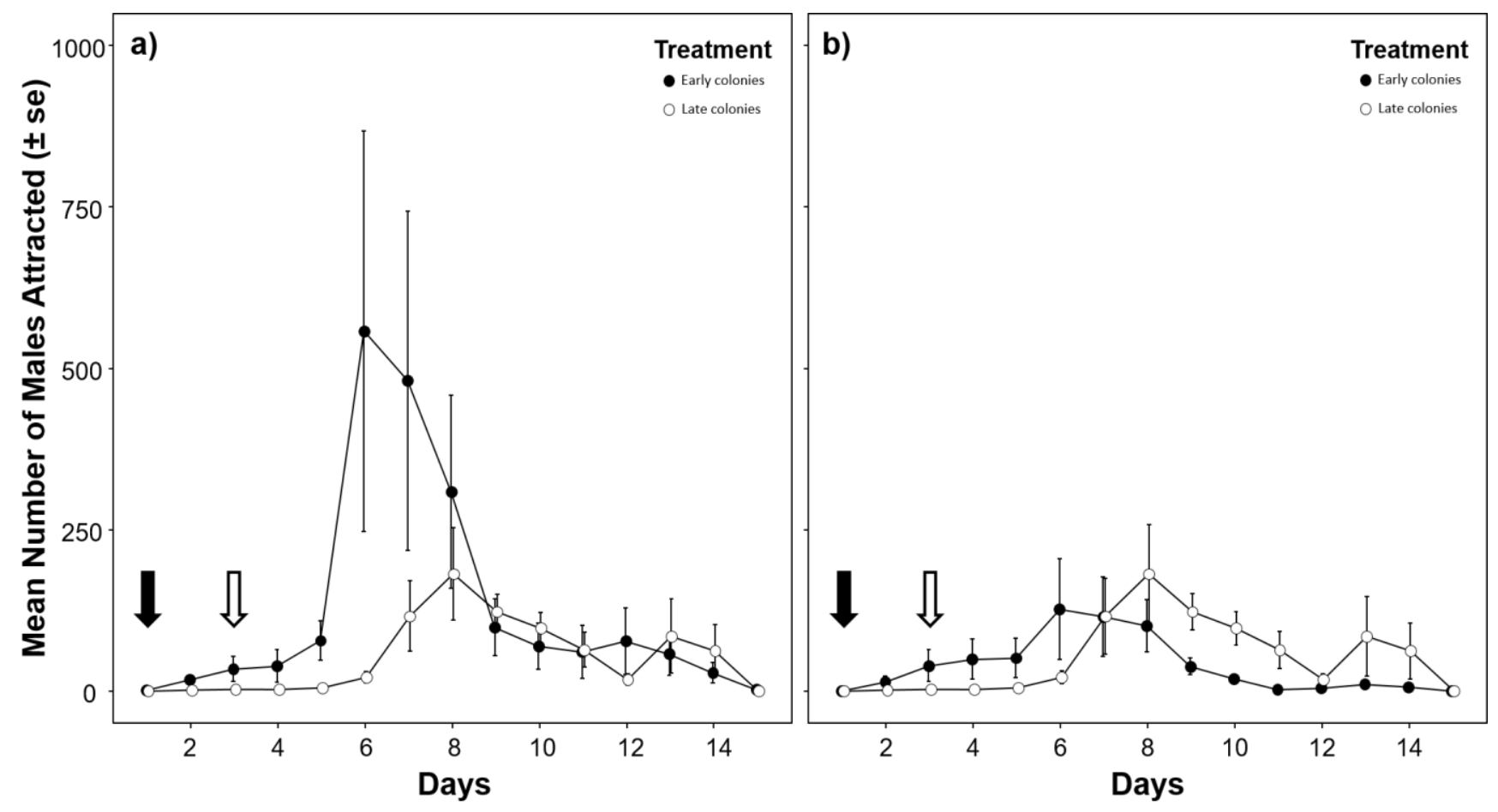

Figure 20. Temporal dynamics of aggregation size in early and late colonies. Black arrows indicate the queen removal in the early colonies while white arrows indicate queen removal in the late colonies. a) All colonies in the experiment. b) Without the outlier colony (E1). 
Effect of temporal sequence of attractiveness on male attraction

As observed previously (see chapter 2), the number of attracted males varied greatly among colonies. The maximum number of males attracted to colonies that became attractive earlier varied from 17 to $1850(127.55 \pm 42.81$; Mean \pm SE), while in the second group of colonies it ranged from 76 to $463(52.20 \pm 12.46$ Mean \pm SE). However, the temporal differences in the attractiveness of colonies did not affect the number of attracted males (GLMM Poison, $\mathrm{z}=$ $1.18, p=0.23$; Fig. 21).

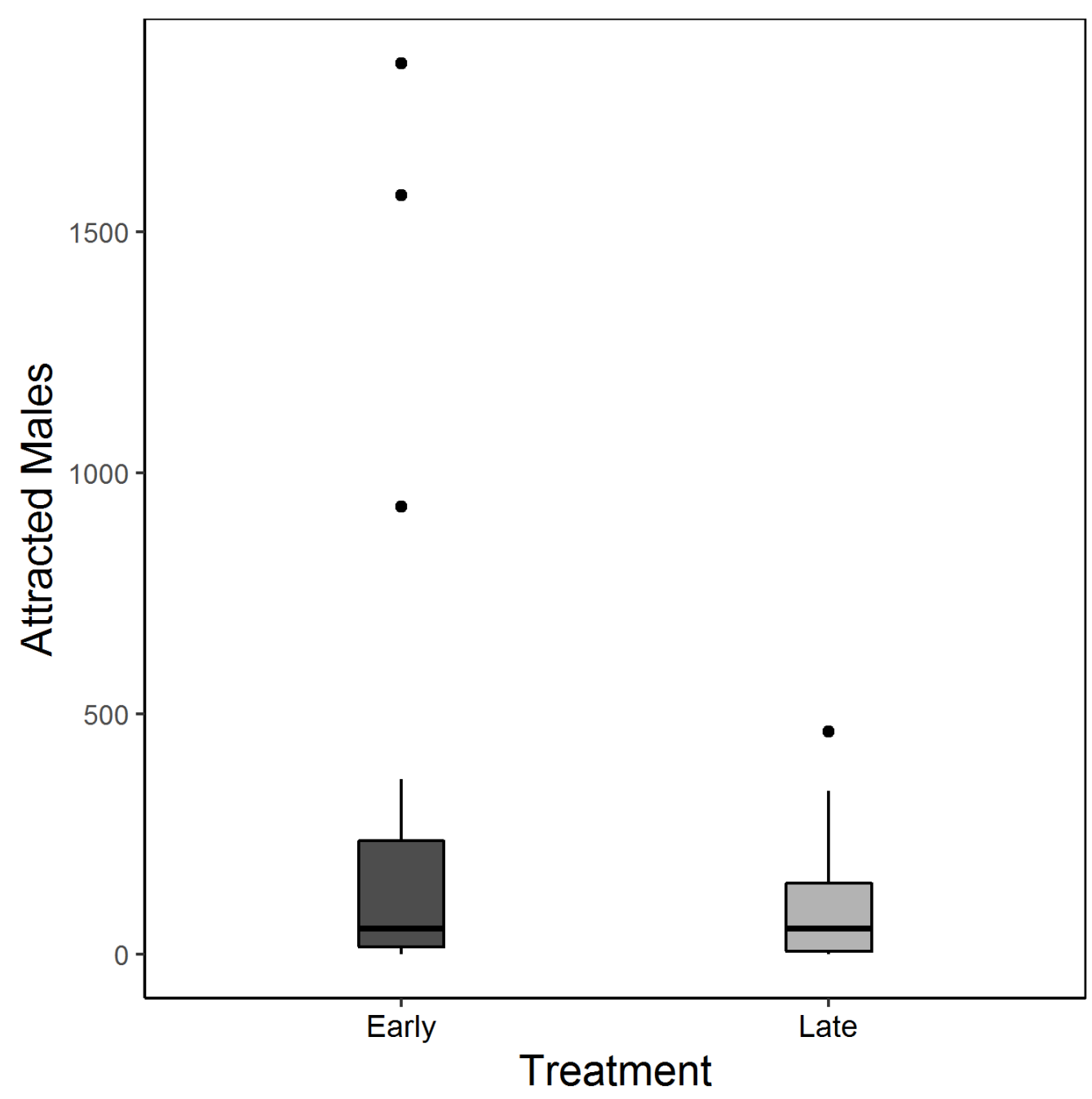

Figure 21. Number of attracted males during the peak period (day 5 to day 10 ) by early and late attractive colonies. Box plots show the median, 25 and $75 \%$ percentiles. Whiskers show all data. 


\section{Effect of quality of colonies}

The number of brood cells produced during three days ranged from 253 to 872 (650 \pm 66.50 ; mean \pm standard error) cells and rate of brood cell production (i.e. number of new cells/day) varied from 84.3 to $290.7(219 \pm 22.16)$. The variation in rate of new brood cells produced was not associated with the number of attracted males (GLMM Poison, $\mathrm{z}=-0.47, p=0.63$ ). The weight of colonies ranged from $1207 \mathrm{~g}$ to $2574 \mathrm{~g}(1821 \pm 176.82 \mathrm{~g})$ and showed a significant positive effect on the number of attracted males (GLMM Poison, $\mathrm{z}=3.36, p<$ 0.001; Fig. 22). We did not find a significant relationship between the colonies biomass and the rate of brood cell production $(\mathrm{LM}, \mathrm{t}=0.75, p=0.47$; Fig. 23 )

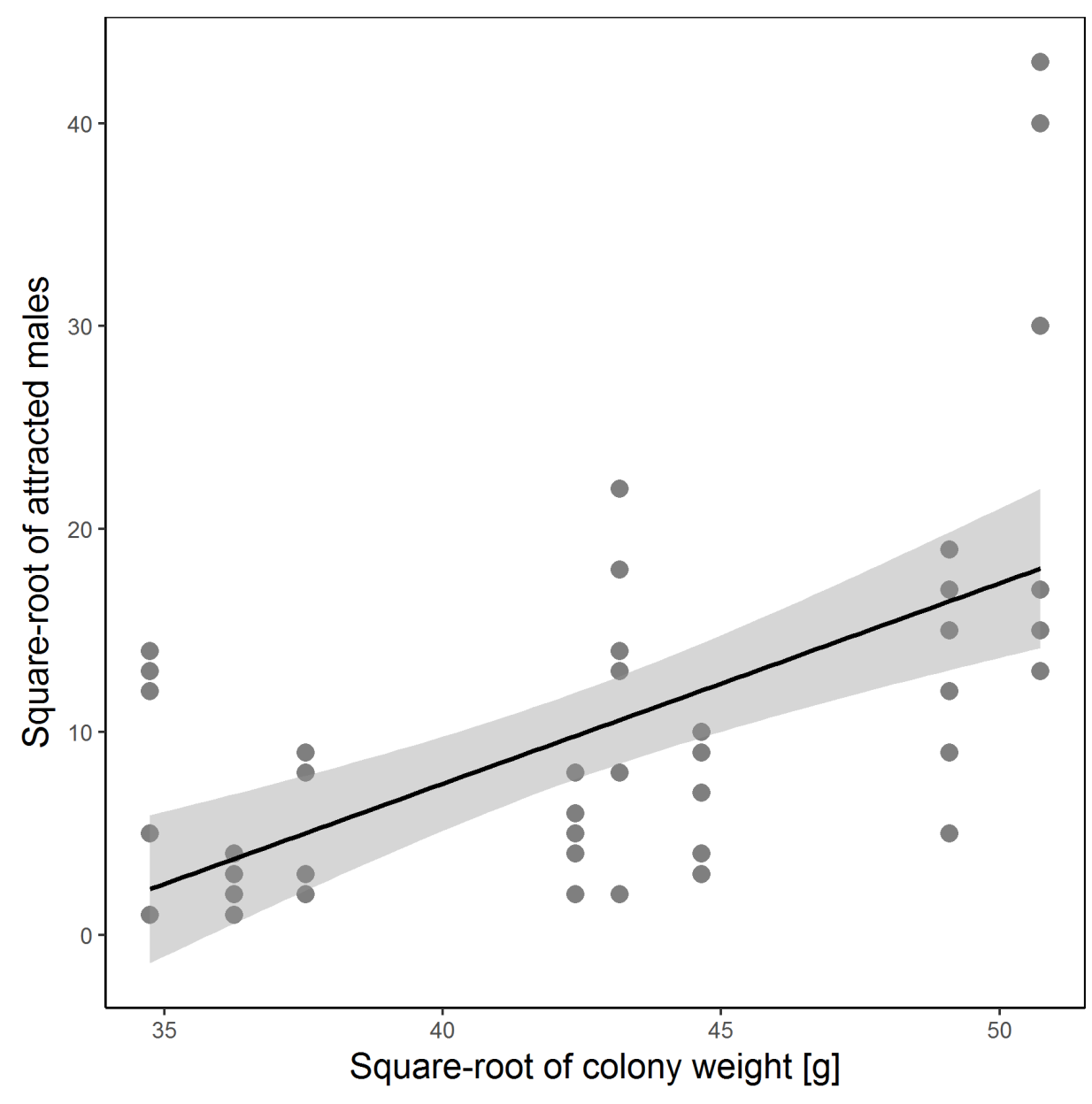

Figure 22. Relationship between biomass of colonies and number of attracted males during the peak period (day 5 to day 10). The solid line is the best fit line for the model. The grey area indicates $95 \%$ confidence interval. 


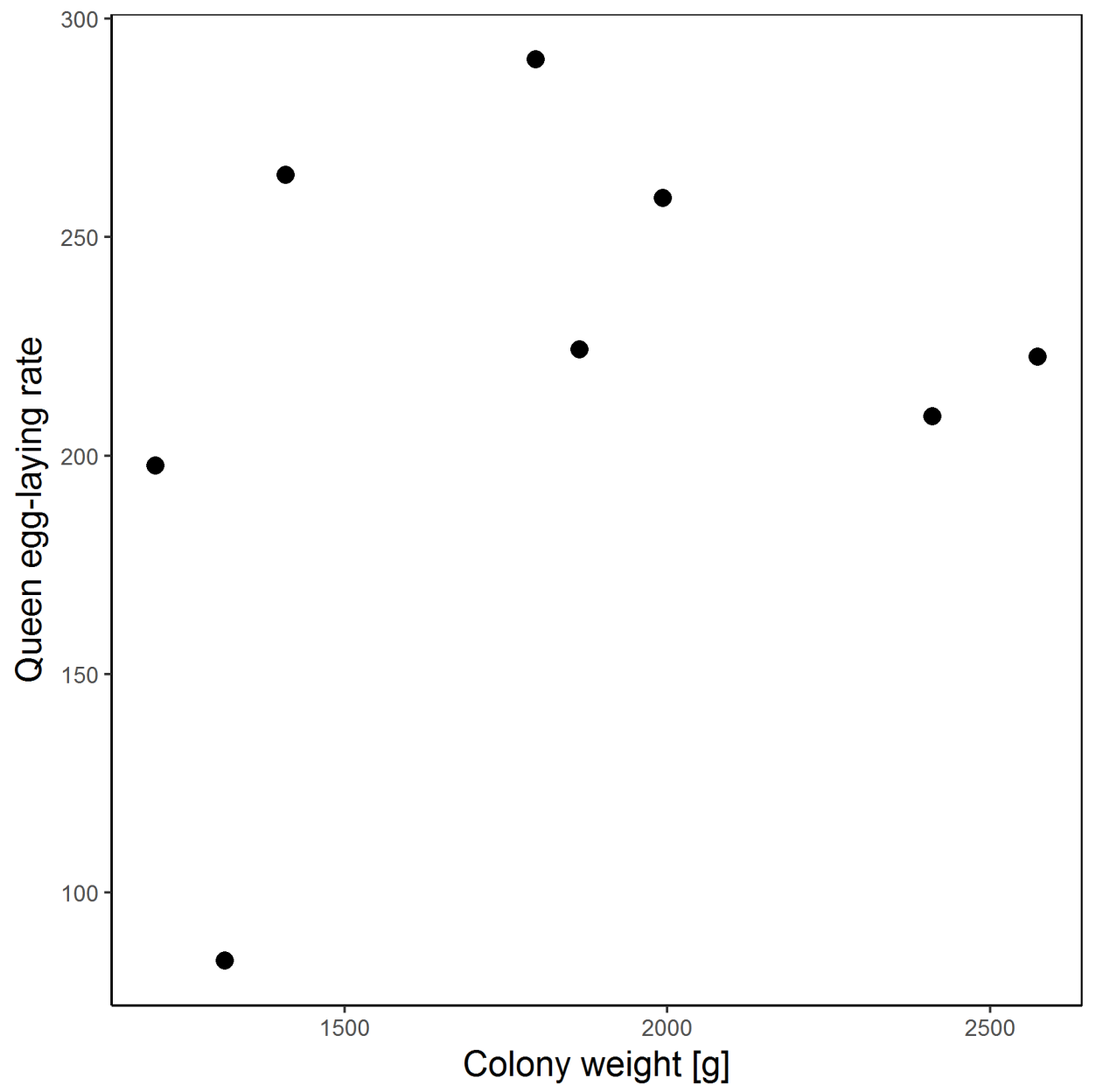

Figure 23. Relationship between biomass of colonies and queen egg-laying rate. 


\section{Discussion}

Our results suggest that differences in the biomass of colonies are strongly associated with differences in their attractiveness to drones. The number of attracted males significantly increased with the weight of colonies (Fig. 22). The data did not support the symmetry breaking hypothesis, as differences in the time colonies became attractive did not significantly affect the number of attracted males. Likewise, the rate of brood cells production did not explain the number of attracted males. These results indicate that the positive feedback generated by male produced signals is unlikely to explain the strong differential attraction of males and suggests that colonies are the source of the sexual signal explaining this variation. Stingless bees males produce compounds that attract conspecific males (Galindo López and Kraus 2009; see also chapter 3), but these compounds may be more important over a shortrange communication.

Thus, differences in the quantity or in the quality of the sexual signal that colonies produce probably explain the variation in the number of males they attract. As we have shown previously (see chapter 2), foragers are an important component of the long-range sexual signaling in S. depilis. Given that differences in the foraging traffic were not associated with the number of attracted males (chapter 2), the observed link between the biomass of colonies and their attractiveness suggest that the information on the colony's quality conveyed by the sexual signal, rather than quantity of the signal, explains the differential attraction of males among colonies. Even though the differences in the biomass were not associated with differences in the rate of brood cell production, it could be related to other aspects of colony's quality (e.g. health). Thus, the message carried by foragers may honestly inform males about the quality of the colony. 
This result raises the question whether males are indeed choosing the colonies. According to sexual selection theory, large male mating investments, either in parental care or in mating effort (i.e. the resources spent in each copulation), that reduce their capacity of subsequent copulations should favor male choosiness (Bonduriansky 2001; Edward and Chapman 2011). If the number of available females exceed the capacity of males to mate with them, rejection of some mates will be favored (Edward and Chapman 2011). Additionally, variation in female quality further favors the evolution of male mate choice, since it is associated with the potential benefits involved in the choice (Bonduriansky 2001; Edward and Chapman 2011). On the other hand, the cost of accessing different females will constrain male choosiness (Bonduriansky 2001; Edward and Chapman 2011).

Male mate investment is extremely high in stingless bees. Although males do not provide parental care, their mating effort is terminal, since they leave their genitalia inside the queen after copulation (Colonello and Hartfelder 2005). Thus, their first copulation precludes their capacity to mate in the future. As our results show there is a considerable variation in colony biomass, which is likely to correlate with female quality. Therefore, the two conditions predicted to favor the evolution of male choosiness exist in stingless bees. However, it is difficult to measure the costs for males of finding and assessing alternative mates. Moreover, stingless bee males, as well as most other social Hymenoptera, have a short life span and, consequently, can mate only during a short temporal window (Boomsma et al. 2005; Velthuis et al. 2005). Additionally, the operational sex ratio is highly male biased, since considerably more males are produced in stingless bees colonies than virgin queens, especially in species that produces queens in royal cells, which results in strong competition among males (SantosFilho et al. 2006). Combined with the fact that most of the produced virgin queens die without mating, the likelihood of finding several receptive females may be low and the opportunity costs of rejecting any mating opportunity might be high. In this case, male mate choice is not 
expected to be strong (Edward and Chapman 2011). Therefore, while the conditions that favor the evolution of male choosiness are present, the constraints involved with choice may select against choosiness.

Further studies are needed to understand how the colony biomass translates into a sexual message for males. Foragers are likely agents transmitting the message to males in the environment (chapter 2), but the precise cues or signals used to attract males remain unknown.

In summary, our results do not support the symmetry breaking hypothesis and favor the hypothesis that signals coming from the colony are responsible for the variation in the number of attracted males. We show for the first time that the biomass of stingless bee colonies is significantly correlated to the differential attraction of males during reproductive events, suggesting that the sexual signal may inform males about the quality of colonies. It is not clear, however, whether males can choose the colonies where to mate with a virgin queen. 


\section{Concluding remarks}

Our results suggest that the mating communication of stingless is comprised of several different components. As shown in chapter 2, foraging activity increased expressively the capacity of colonies to attract males. This suggests that foragers are responsible for transmitting the long-range sexual message for males. Moreover, the message they carry probably honestly inform males about the quality of the colonies, as shown by the link between the number of attracted males and the biomass of colonies (chapter 4). Therefore, the sexual communication of stingless bees comprises a long-range component, which is transmitted by foragers and it is related to the quality of the colony. In addition, short-range components are also important for the whole sequence of mating behavior. One of these components is produced by males. They actively mark their aggregation with their cuticular hydrocarbons (chapter 3), which are probably used as an aggregation pheromone. Queen produced pheromones also seem to comprise the short-range components of stingless bees mating communication. As shown in previous studies, virgin queens produce compounds that attract males and trigger copulation. Several lines of evidence suggest that such compounds are not used in the long-range attraction of males and may be used when queens leave the nest for the nuptial flight.

Our study provides further steps towards a better understanding of the mating communication of stingless bees. At the same time, however, a lot remains to be investigated. For example, we are still to identify the chemical signals used for the long-attraction of males since we could not decode the message transmitted by foragers. Furthermore, the mating communication of Melipona species, which have a completely different behavioral pattern, must also be further investigated. Future studied aiming to fill these gaps will contribute to build the whole picture of sexual communication in this fascinating group of social bees. 


\section{References}

Alcock J (1978) The ecology and evolution of male reproductive behaviour in the bees and wasps. Zool J Linn Soc 64:293-326. doi: 10.1111/j.1096-3642.1978.tb01075.x

Alcock J (2013) Animal Behavior: An Evolutionary Approach. An Evol Approach 522.

Alcock J (1980) Natural Selection and the Mating Systems of Solitary Bees. Sigma Xi, Sci Res Soc 68:146-153.

Alcock J, Eickwort GC, Eickwort KR (1977) The reproductive behavior of Anthidium maculosum (Hymenoptera: Megachilidae) and the evolutionary significance of multiple copulations by females. Behav Ecol Sociobiol 2:385-396. doi: 10.1007/BF00299507

Ayasse M, Engels W, Lübke G, et al (1999) Mating expenditures reduced via female sex pheromone modulation in the primitively eusocial halictine bee, Lasioglossum (Evylaeus) malachurum (Hymenoptera: Halictidae). Behav Ecol Sociobiol 45:95-106. doi: $10.1007 / \mathrm{s} 002650050543$

Ayasse M, Jarau S (2014) Chemical Ecology of Bumble Bees. Annu Rev Entomol 59:299_ 319. doi: 10.1146/annurev-ento-011613-161949

Ayasse M, Paxton RJ, Tengö J (2001) Mating behavior and chemical communication in the order hymenoptera. Annu Rev Entomol 46:31-78. doi: 10.1146/annurev.ento.46.1.31

Baer B (2014) Sexual selection in social insects.

Baer B (2011) The copulation biology of ants ( Hymenoptera : Formicidae ). Myrmecological NewsNews 55-68.

Baer B (2005) Sexual selection in Apis bees. Apidologie 36:187-200. doi: 10.1051/apido:2005013

Baer B (2003) Bumblebees as model organisms to study male sexual selection in social insects. Behav Ecol Sociobiol 54:521-533. doi: 10.1007/s00265-003-0673-5

Bänziger H, Khamyotchai K (2014) An unusually large and persistent male swarm of the stingless bee Tetragonula laeviceps in Thailand (Hymenoptera: Apidae: Meliponini). $\mathrm{J}$ Melittology 32:1-5.

Bateman AJ (1948) Intra-sexual selection in Drosophila. Heredity (Edinb) 2:349-368. doi: 10.1038/hdy.1948.21

Bates D, Mächler M, Bolker BM, Walker SC (2015) Fitting linear mixed-effects models using lme4. J Stat Softw 67:1-48. doi: 10.18637/jss.v067.i01

Beckers R, Deneubourg JL, Goss S, Pasteels JM (1990) Collective decision making through food recruitment. Insectes Soc 37:258-267. doi: 10.1007/BF02224053 
Bonduriansky R (2001) The evolution of male mate choice in insects: a synthesis of ideas and evidence. Biol Rev 76:305-339. doi: 10.1017/s1464793101005693

Boomsma JJ, Baer B, Heinze J (2005) the Evolution of Male Traits in Social Insects. Annu Rev Entomol 50:395-420. doi: 10.1146/annurev.ento.50.071803.130416

Boongird S (2011) Aspects of Culturing, Reproductive Behavior, and Colony Formation in the Stingless Bee Tetragonula fuscobalteata (Hymenoptera: Apidae: Meliponini). J Kansas Entomol Soc 84:190-196. doi: 10.2317/JKES101108.1

Boongird S, Michener CD (2010) Pollen and Propolis Collecting by Male Stingless Bees (Hymenoptera: Apidae). J Kansas Entomol Soc 83:47-50. doi: 10.2317/JKES0810.20.1

Bradbury JW (1981) The evolution of leks. Chiron Press, New York

Brandstaetter AS, Bastin F, Sandoz J-C (2014) Honeybee drones are attracted by groups of consexuals in a walking simulator. J Exp Biol 217:1278-85. doi: 10.1242/jeb.094292

Brown B V (1997) Parasitic phorid flies: a previously unrecognized cost to aggregation behavior of male stingless bees. Biotropica 29:370-372. doi: 10.1111/j.17447429.1997.tb00439.x

Cameron EC, Franck P, Oldroyd BP (2004) Genetic structure of nest aggregations and drone congregations of the southeast Asian stingless bee Trigona collina. Mol Ecol 13:23572364. doi: 10.1111/j.1365-294X.2004.02194.x

Campos LAO, Melo GAR (1990) Physogastric-queen mating in Melipona quadrifasciata Lep. (Hymenoptera, Apidae). Rev. Bras. Genética 13:491-500.

Chinh TX, Sommeijer MJ (2005) Production of sexuals in the stingless bee Trigona ( Lepidotrigona ) ventralis flavibasis Cockerell (Apidae, Meliponini) in northern Vietnam. Apidologie 36:493-503. doi: 10.1051/apido:2005035

Chinhinst TX, Grob GBJ, Meeuwsen FJAJ, Sommeijer MJ (2003) Patterns of male production in the stingless bee Melipona favosa (Apidae, Meliponini). Apidologie 34:161-170. doi: 10.1051/apido:2003008

Clutton-Brock TH, Parker GA (1992) Potential Reproductive Rates and the Operation of Sexual Selection. Q Rev Biol 67:437-456. doi: 10.1086/417793

Colonello NA, Hartfelder K (2005) She's my girl - male accessory gland products and their function in the reproductive biology of social bees. Apidologie 36:231-244. doi: 10.1051/apido:2005012

Cortopassi-Laurino M (2007) Drone Congregations in Meliponini : What Do They Tell Us ? Biosci Journal, Uberlândia 23:153-160.

Cruz-Landim C Da, Moraes RLMS De, Salles HC, Reginato RD (1998) Note on glands present in meliponinae (Hymenoptera, Apidae) bees legs. Rev Bras Zool 15:159-165. doi: 10.1590/S0101-81751998000100014 
da Silva DL, Zucchi R, Kerr WE (1972) Biological and behavioural aspects of the reproduction in some species of Melipona (Hymenoptera, Apidae, Meliponinae). Anim Behav 20:123-132. doi: 10.1016/S0003-3472(72)80182-9

Dall SRX, Giraldeau LA, Olsson O, et al (2005) Information and its use by animals in evolutionary ecology. Trends Ecol Evol 20:187-193. doi: 10.1016/j.tree.2005.01.010

Davies NB, Krebs JR, West S (2012) An Introduction to Behavioural Ecology. An Introd to Behav Ecol 3rd:420. doi: 10.1037/026600

Drosopoulos S, Claridge MF (2006) Insect sounds and communication: physiology, behaviour, ecology and evolution.

Edward DA, Chapman T (2011) The evolution and significance of male mate choice. Trends Ecol Evol 26:647-654. doi: 10.1016/j.tree.2011.07.012

Eickwort GC, Ginsberg HS (1980) Foraging and Mating Behavior in Apoidea. Annu Rev Entomol 25:421-446. doi: 10.1146/annurev.en.25.010180.002225

Eltz T, Brühl CA, Imiyabir Z, Linsenmair KE (2003) Nesting and nest trees of stingless bees (Apidae: Meliponini) in lowland dipterocarp forests in Sabah, Malaysia, with implications for forest management. For Ecol Manage 172:301-313.

Eltz T, Brühl CA, Van der Kaars S, Eduard Linsenmair K (2002) Determinants of stingless bee nest density in lowland dipterocarp forests of Sabah, Malaysia. Oecologia 131:2734. doi: 10.1007/s00442-001-0848-6

Eltz T, Sager A, Lunau K (2005) Juggling with volatiles: exposure of perfumes by displaying male orchid bees. J Comp Physiol A 191:575-581. doi: 10.1007/s00359-005-0603-2

Eltz T, Whitten WM, Roubik DW, Linsenmair KE (1999) Fragrance Collection, Storage, and Accumulation by Individual Male Orchid Bees. J Chem Ecol 25:157-176. doi: 10.1023/A:1020897302355

Emlen ST, Oring LW (1977) Ecology, Sexual Selection, and the Evolution of Mating Syst ; ens. Science (80- ) 197:215-223. doi: 10.1126/science.327542

Engels E, Engels W, Lubke G, et al (1993) Age-Related Patterns of Volatile Cephalic Constituents in Queens of the Neotropical Stingless Bee Scaptotrigona-Postica Latr (Hymenoptera, Apidae). Apidologie 24:539-548. doi: 10.1051/apido:19930601

Engels W (1987) Pheromes and reproduction in Brazilian stingless bees. Mem Inst Oswaldo Cruz 82:35-45.

Engels W, Engels E, Francke W (1997) Ontogeny of cephalic volatile patterns in queens and mating biology of the neotropical stingless bee, Scaptotrigona postica. Invertebr Reprod Dev 31:251-256. doi: 10.1080/07924259.1997.9672583 
Engels W, Engels E, Liibke G, Schroder W (1990) Volatile Cephalic Secretions of Drones, Queens and Workers in Relation to Reproduction in the Stingless Bee, Scaptotrigona postica (Hymenoptera: Apidae: Trigonini). Entomol Gen 15:91-101. doi: 10.1127/entom.gen/15/1990/91

Estoup a., Solignac M, Cornuet J-M (1994) Precise Assessment of the Number of Patrilines and of Genetic Relatedness in Honeybee Colonies. Proc R Soc B Biol Sci 258:1-7. doi: 10.1098/rspb.1994.0133

Fierro MM, Cruz-López L, Sánchez D, et al (2011) Queen volatiles as a modulator of Tetragonisca angustula drone behavior. J Chem Ecol 37:1255-62. doi: 10.1007/s10886011-0034-1

Galindo López JC, Kraus FB (2009) Cherchez la femme? Site choice of drone congregations in the stingless bee Scaptotrigona mexicana. Anim Behav 77:1247-1252. doi:

10.1016/j.anbehav.2009.01.034

Goulson D (2010) Bumblebees: behaviour, ecology, and conservation. Oxford University Press

Grüter C, Keller L (2016) Inter-caste communication in social insects. Curr Opin Neurobiol 38:6-11. doi: 10.1016/j.conb.2016.01.002

Grüter C, von Zuben LG, Segers FHID, Cunningham JP (2016) Warfare in stingless bees. Insectes Soc 1-14. doi: 10.1007/s00040-016-0468-0

Höglund J, Alatalo R V (1995) Leks.

Hölldobler B, Wilson EO (2009) The Superorganism: The Beauty, Elegance, and Strangeness of Insect Societies. W. W. Norton \& Company, Inc. 500, New York

Holman L, Jørgensen CG, Nielsen J, d'Ettorre P (2010) Identification of an ant queen pheromone regulating worker sterility. Proc Biol Sci 277:3793-3800. doi:

$10.1098 /$ rspb.2010.0984

Hoover SER, Keeling CI, Winston ML, Slessor KN (2003) The effect of queen pheromones on worker honey bee ovary development. Naturwissenschaften 90:477-80. doi: $10.1007 / \mathrm{s} 00114-003-0462-\mathrm{z}$

Hrncir M, Jarau S, Zucchi R, Barth FG (2004) On the origin and properties of scent marks deposited at the food source by a stingless bee, Melipona seminigra. Apidologie 35:313. doi: 10.1051/apido:2003069

Hughes WOH, Ratnieks FLW, Oldroyd BP (2008) Multiple paternity or multiple queens: Two routes to greater intracolonial genetic diversity in the eusocial Hymenoptera. J Evol Biol 21:1090-1095. doi: 10.1111/j.1420-9101.2008.01532.x

Imperatriz-Fonseca VL, Zucchi R (1995) Virgin queens in stingless bee (Apidae, Meliponinae) colonies: a review. Apidologie 26:231-244. doi: 10.1051/apido:19950305 
Jaffé R, Pioker-Hara FC, Santos CF dos, et al (2014) Monogamy in large bee societies: A stingless paradox. Naturwissenschaften 101:261-264. doi: 10.1007/s00114-014-1149-3

Jarau S, Dambacher J, Twele R, et al (2010) The trail pheromone of a stingless bee, Trigona corvina (Hymenoptera, Apidae, Meliponini), varies between populations. Chem Senses 35:593-601. doi: 10.1093/chemse/bjq057

Jarau S, Hrncir M, Ayasse M, et al (2004a) A Stingless Bee ( Melipona Seminigra ) Marks Food Sources With A Pheromone From Its Claw Retractor Tendons. 30:793-804.

Jarau S, Hrncir M, Zucchi R, Barth FG (2004b) A stingless bee uses labial gland secretions for scent trail communication ( Trigona recursa Smith 1863). J Comp Physiol A Neuroethol Sens Neural Behav Physiol 190:233-9. doi: 10.1007/s00359-003-0489-9

Jarau S, Schulz CM, Hrncir M, et al (2006) Hexyl decanoate, the first trail pheromone compound identified in a stingless bee, Trigona recursa. J Chem Ecol 32:1555-64. doi: 10.1007/s10886-006-9069-0

Juliani L (1962) O aprisionamento de rainhas virgens em colônias de Trigonini:(Hymenoptera-Apoidea).

Kärcher MH, Menezes C, Alves D a, et al (2013) Factors influencing survival duration and choice of virgin queens in the stingless bee Melipona quadrifasciata. Naturwissenschaften 100:571-80. doi: 10.1007/s00114-013-1053-2

Kerr WE, Zucchi R, Nakadaira JT, Butolo JE (1962) Reproduction in the Social Bees ( Hymenoptera: Apidae ). J New York Entomol Soc 70:265-276.

Kitson F, Larsen B, McEwen C (1996) Gas Chromatography and Mass Spectrometry: a practical guide.

Koedam D, Morgan ED, Nunes TM, et al (2011) Selective preying of the sphecid wasp Trachypus boharti on the meliponine bee Scaptotrigona postica: Potential involvement of caste-specific cuticular hydrocarbons. Physiol Entomol 36:187-193. doi: 10.1111/j.1365-3032.2010.00769.x

Koedam D, Slaa EJ, Biesmeijer JC, Nogueira-Neto P (2009) Unsuccessful attacks dominate a drone-preying wasp's hunting performance near stingless bee nests. Genet Mol Res 8:690-702. doi: 10.4238/vol8-2kerr032

Koeniger N, Koeniger G, Gries M, Tingek S (2005) Drone competition at drone congregation areas in four Apis species 1. Apidologie 36:211-221. doi: 10.1051/apido:2005011

Kraus FB, Weinhold S, Moritz RF a (2008) Genetic structure of drone congregations of the stingless bee Scaptotrigona mexicana. Insectes Soc 55:22-27. doi: 10.1007/s00040-0070966-1

Leonhardt SD, Menzel F, Nehring V, Schmitt T (2016) Ecology and Evolution of Communication in Social Insects. Cell 164:1277-1287. doi: 10.1016/j.cell.2016.01.035 
Lihoreau M, Zimmer C, Rivault C (2007) Kin recognition and incest avoidance in a groupliving insect. Behav Ecol 18:880-887. doi: 10.1093/beheco/arm046

Lloyd JE (1997) Firefly mating ecology, selection and evolution. Mating Syst Insects Arachn 184-192. doi: 10.1007/s00265-004-0861-y

Longhurst C, Howse PE (1979) Some aspects of the biology of the males of Megaponera foetens (Fab.) (Hymenoptera: Formicidae). Insect Soc 26(2):85-91. doi: doi:10.1007/BF02223502

Michener CD (1946) Notes on the Habits of Some Panamanian Stingless Bees (Hymenoptera, Apidæ). J New York Entomol Soc 54:179-197. doi: 10.2307/25005167

Moo-Valle H, Quezada-Euan JJG, Wenseleers T (2001) The effect of food reserves on the production of sexual offspring in the stingless bee Melipona beecheii (Apidae, Meliponini). Insectes Soc 48:398-403. doi: 10.1007/PL00001797

Nogueira-Ferreira FH, Soares AEE (1998) Male aggregations and mating flight in Tetragonisca angustula. Iheringia, Série Zool 84:141-144.

Nogueira PCL, Bittrich V, Shepherd GJ, et al (2001) The ecological and taxonomic importance of flower volatiles of Clusia species (Guttiferae). Phytochemistry 56:443452. doi: 10.1016/S0031-9422(00)00213-2

Nunes TM, Mateus S, Favaris AP, et al (2014) Queen signals in a stingless bee: suppression of worker ovary activation and spatial distribution of active compounds. Sci Rep 4:7449. doi: 10.1038/srep07449

Nunes TM, Nascimento FS, Turatti IC, et al (2008) Nestmate recognition in a stingless bee: does the similarity of chemical cues determine guard acceptance? Anim Behav 75:11651171. doi: 10.1016/j.anbehav.2007.08.028

Nunes TM, Turatti ICC, Lopes NP, Zucchi R (2009) Chemical signals in the stingless bee, Frieseomelitta varia, indicate caste, gender, age, and reproductive status. J Chem Ecol 35:1172-1180. doi: 10.1007/s10886-009-9691-8

Oldroyd BP, Clifton MJ, Wongsiri S, et al (1997) Polyandry in the genus Apis, particularly Apis andreniformis. Behav Ecol Sociobiol 40:17-26. doi: 10.1007/s002650050311

Parker GA, Baker RR, Smith VGF (1972) The origin and evolution of gamete dimorphism and the male-female phenomenon. J Theor Biol 36:529-553. doi: 10.1016/00225193(72)90007-0

Paxton RJ (2000) Genetic structure of colonies and a male aggregation in the stingless bee Scaptotrigona postica, as revealed by microsatellite analysis. Insectes Soc 47:63-69. doi: $10.1007 / \mathrm{s} 000400050010$

Paxton RJ (2005) Male mating behaviour and mating systems of bees: an overview. Apidologie 36:145-156. doi: 10.1051/apido:2005007 
Peters JM, Queller DC, Imperatriz-Fonseca VL, et al (1999) Mate number, kin selection and social conflicts in stingless bees and honeybees. Proc R Soc B Biol Sci 266:379. doi: 10.1098/rspb.1999.0648

Prato M, Soares a. EE (2013) Production of Sexuals and Mating Frequency in the Stingless Bee Tetragonisca angustula (Latreille) (Hymenoptera, Apidae). Neotrop Entomol 42:474-482. doi: 10.1007/s13744-013-0154-0

R Core Team, R Developement Core Team, R Development Core Team R, et al (2016) R: A Language and Environment for Statistical Computing. R Found Stat Comput 1:409. doi: 10.1007/978-3-540-74686-7

Rasmussen C, Cameron S a. (2010) Global stingless bee phylogeny supports ancient divergence, vicariance, and long distance dispersal. Biol J Linn Soc 99:206-232. doi: 10.1111/j.1095-8312.2009.01341.x

Roubik DW (1990) Mate Location and Mate Competition in Males of Stingless Bees (Hymenoptera: Apidae: Meliponinae). Entomol Gen 15:115-120. doi: 10.1127/entom.gen/15/1990/115

Roubik DW (2006) Stingless bee nesting biology. Apidologie 37:124-143.

Sakagami, S. F. \& Laroca S (1963) Additional Observations on the Habits of the Cleptobiotic Stingless Bees, the Genus Lestrimelitta Friese (Hymenoptera, Apoidea). J Fac Sci Hokkaido Univer 15:319-399.

Santos-Filho P de S, Alves DDA, Eterovic A, et al (2006) Numerical investment in sex and caste by stingless bees (Apidae: Meliponini): a comparative analysis. Apidologie 37:207-221. doi: 10.1051/apido:2006015

Santos CF, Menezes C, Vollet-Neto A, Imperatriz-Fonseca VL (2014) Congregation sites and sleeping roost of male stingless bees (Hymenoptera: Apidae: Meliponini). Sociobiology 61:115-118. doi: 10.13102/sociobiology.v61i1.115-118

Schmidt VM, Zucchi R, Barth FG (2003) A stingless bee marks the feeding site in addition to the scent path ( Scaptotrigona aff. depilis ). Apidologie 34:237-248. doi: 10.1051/apido:2003021

Schorkopf DLP (2016) Male meliponine bees (Scaptotrigona aff. depilis) produce alarm pheromones to which workers respond with fight and males with flight. J Comp Physiol A. doi: 10.1007/s00359-016-1109-9

Schorkopf DLP, Jarau S, Francke W, et al (2007) Spitting out information: Trigona bees deposit saliva to signal resource locations. Proc Biol Sci 274:895-8. doi: $10.1098 / \mathrm{rspb} .2006 .3766$

Shelly TE, Whittier TS (1997) Lek behavior of insects. In: The Evolution of Mating Systems in Insects and Arachnids. pp 273-293 
Simmons LW, Alcock J, Reeder a (2003) The role of cuticular hydrocarbons in male attraction and repulsion by female Dawson's burrowing bee, Amegilla dawsoni. Anim Behav 66:677-685. doi: 10.1006/anbe.2003.2240

Sivinski JM, Petersson E (1997) Mate choice and species isolation in swarming insects. In: The Evolution of Mating Systems in Insects and Arachnids. pp 294-309

Slessor KN, Winston ML, Le Conte Y (2005) Pheromone communication in the honeybee (Apis mellifera L.). J Chem Ecol 31:2731-45. doi: 10.1007/s10886-005-7623-9

Sommeijer MJ, Bruijn LLM De (1995) Drone congregations apart from the nest in Melipona favosa. Insectes Soc 42:123-127. doi: 10.1007/BF01242448

Sommeijer MJ, Bruijn LLM De, Meeuwsen FJ a. J (2003) Reproductive behaviour of stingless bees : solitary gynes of Melipona favosa ( Hymenoptera : Apidae, Meliponini ) can penetrate existing nests. Entomol Ber 63:31-35.

Sommeijer MJ, De Bruijn LLM, Meeuwsen F (2004) Behaviour of males, gynes and workers at drone congregation sites of the stingless bee Melipona favosa (Apidae: Meliponini). Entomol Berichten-Nederlandsche Entomol Vereenigung 64:10-15.

Stangler ES, Jarau S, Hrncir M, et al (2009) Identification of trail pheromone compounds from the labial glands of the stingless bee Geotrigona mombuca. Chemoecology 19:1319. doi: 10.1007/s00049-009-0003-0

Strassmann J (2001) The rarity of multiple mating by females in the social Hymenoptera. Insectes Soc 48:1-13. doi: 10.1007/PL00001737

Sumpter DJT (2010a) Collective Animal Behaviour. pp 217-243

Sumpter DJT (2010b) Collective animal behavior. Princeton University Press

Trhlin M, Rajchard J (2011) Chemical communication in the honeybee (Apis mellifera L.): a review. Vet Med (Praha) 6:265-273.

Van Oystaeyen A, Oliveira RC, Holman L, et al (2014) Conserved Class of Queen Pheromones Stops Social Insect Workers from Reproducing. Science (80- ) 343:287290. doi: 10.1126/science. 1244899

van Veen JW, Sommeijer MJ (2000) Observations on gynes and drones around nuptial flights in the stingless bees Tetragonisca angustula and Melipona beecheii (Hymenoptera, Apidae, Meliponinae). Apidologie 31:47-54. doi: 10.1051/apido:2000105

Van Veen JW, Sommeijer MJ (2000) Colony reproduction in Tetragonisca angustula (Apidae, Meliponini). Insectes Soc 47:70-75. doi: 10.1007/s000400050011

Van Veen JW, Sommeijer MJ, Meeuwsen F (1997) Behaviour of drones in Melipona (Apidae, Meliponinae). Insectes Soc 44:435-447. doi: 10.1007/s000400050063 
Veen JW van, Arce HGA, Sommeijer MJ (2004) Production of queens and drones in Melipona beecheii (Meliponini) in relation to colony development and resource availability. Proc Netherlands Entomol Soc Meet 15:35-39.

Velthuis HHW, Koedam D, Imperatriz-Fonseca VL (2005) The males of Melipona and other stingless bees, and their mothers. Apidologie 36:169-185. doi: 10.1051/apido:2005014

Verdugo-Dardon M, Cruz-Lopez L, Malo EA, et al (2011) Olfactory attraction of Scaptotrigona mexicana drones to their virgin queen volatiles. Apidologie 42:543-550. doi: $10.1007 / \mathrm{s} 13592-011-0042-8$

Vet LEM, Lenteren JC van, Heymans M, Meelis E (1983) An airflow olfactometer for measuring olfactory responses of hymenopterous parasitoids and other small insects. Physiol Entomol 8:97-106. doi: 10.1111/j.1365-3032.1983.tb00338.x

Wheeler C a., Cardé RT (2014) Following in Their Footprints: Cuticular Hydrocarbons as Overwintering Aggregation Site Markers in Hippodamia convergens. J Chem Ecol 40:418-428. doi: 10.1007/s10886-014-0409-1

Wilson EOO, Hodobler B, Hölldobler B (1990) The ants.

Wyatt TD (2003) Pheromones and Animal Behaviour. Cambridge University Press

Zimmermann Y, Roubik DW, Eltz T (2006) Species-specific attraction to pheromonal analogues in orchid bees. Behav Ecol Sociobiol 60:833-843. doi: 10.1007/s00265-0060227-8 


\title{
Appendix
}

\section{Appendix 1 - Project developed during the internship at the University of}

\section{Lausanne (Switzerland).}

The evolution of foraging strategies in stingless bees (Hymenoptera: Apidae: Meliponini): what is the role of competition?

Proponent: Lucas Garcia von Zuben

Supervisor: Prof. Laurent Keller

Co-supervisor: Prof. Christoph Grueter

\begin{abstract}
The ability to communicate efficiently allows social insects to act in a highly coordinated way. Although relying on information acquired from other members of the group is often a good strategy, is not always profitable to use this social information, since both the production and use of social information have time and energy costs. A well-studieid example of information exchange is recruitment communication to food sources. Theoretical and empirical attempts have been made to understand the ecological contexts where recruitment would be most profitable in the honeybee (Apis mellifera). These studies suggest that communication about food source locations is beneficial in environments with patchy and ephemeral food sources, such as in tropical environments. However, it seems that the benefits of a recruitment system do not only depend on the spatiotemporal distribution of food sources. In the Neotropical stingless bees (Meliponini), some species communicate food locations, while other species do not use recruitment communication, despite the favorable environmental conditions. We hypothesize that competition plays a role in the evolution of recruitment systems: competition shortens the time food sources are available and, therefore, can explain the absence of recruitment communication in this large group of social bees. In order to test this hypothesis we will develop an agent based simulation model (ABM) of foraging stingless bee colonies in dynamic environments.
\end{abstract}




\section{Introduction}

The ability to perform highly organized tasks is a remarkable feature of social insect colonies. Colonies act in a highly coordinated way even though they often comprise tens of thousands of individuals, and communication plays a fundamental role in the organization of these activities (Hrncir \& Jarau 2009; Grüter \& Leadbeater 2014 Hölldobler \& Wilson 2009).

Among the many tasks that social insects perform in order to survive and reproduce, the collection of food is a very important one. The capacity to gather food efficiently has a great impact on individual and colony fitness (Slaa \& Hughes 2009). Consequently, natural selection for efficient foraging has led to the evolution of a wide range of foraging strategies, which provide high benefits at relatively low costs (Jarau \& Hrncir 2009; Hölldobler \& Wilson 2009). Whenever a forager searches for a food source it needs to take a decision about whether to use social (acquired from other members of the group) or personal (based on previous experience) information, or whether to explore new food sites alone without the use of pre-existing information (Grüter \& Leadbeater 2014). Since individuals will often deliberately or incidentally provide social information to other members of the group about profitable food sources (Grüter \& Leadbeater 2014), other colony members are often an important source of information for the discovery of high quality food sources.

An important and well-studied example of information exchange in insect societies is recruitment communication. This kind of communication is characterized by the increase in the number of individuals at a food source, but recruitment can also occur in the context of nest building or excavation and nest site selection (Dussutour \& Beekman 2009). Social insects have evolved numerous recruitment mechanisms, which can be grouped in two categories: direct and indirect recruitment (Dussutour \& Beekman 2009).

Direct recruitment occurs when one individual (signal producer) transmit the message directly to another individual (signal receiver). Examples include the famous waggle dance performed by honey bee foragers (Apis spp.) to transmit spatial information about food sources inside the nest (von Frisch 1967; Dussutour \& Beekman 2009) or tandem-running in ants (Hölldobler \& Wilson 1990). This kind of recruitment is highly efficient in dynamic environments, since foragers will stop transmitting information about a particular food source when it is no longer profitable, and colonies can rapidly re-allocate foragers to new food sources if the environment changes (Dussutour \& Beekman 2009). 
By contrast, indirect communication occurs when signal producer and signal receiver are not physically in contact with each other (Dussutour \& Beekman 2009). In this case, information is transmitted through signals left in the environment. Generally, this social information is encoded as chemical signals (pheromones), e.g. deposited on the substrate between the nest and the foraging site. The trail pheromones utilized by ants and stingless bees (Meliponini) are examples of indirect recruitment (Dussutour \& Beekman 2009; Jarau 2009). This kind of recruitment is more resilient to losses of individuals, but it less efficient in dynamical environments, since the trail pheromone can outlast the food source (Dussutour \& Beekman 2009).

While using social information is often a good strategy, it is not always profitable to use this kind of information (Leadbeater \& Chittka 2009; Grüter \& Leadbeater 2014). Both the production and the use of social information have time and an energy costs, so in some conditions it will be better to explore the world individually or use personal information acquired in the past (Leadbeater \& Chittka 2009; Grüter \& Leadbeater 2014). While little is known about the adaptive significance of social information in most social insects, both empirical and theoretical attempts have been made to understand the contexts in which social information is beneficial in honeybees (Apis mellifera) (Beekman \& Lew, 2007; Dornhaus, 2006; Anna Dornhaus \& Chittka, 2004; Sherman \& Visscher, 2002; Schürch \& Grüter, submitted). These studies investigated the role of ecological factors, such as the spatial distribution and availability of food sources, on the profitability of waggle dance communication.

The dances performed by workers encode both the direction and the distance of food sources. Surprisingly, these studies suggest that the waggle dance communication is beneficial only in certain ecological situations. Dornhaus \& Chittka (2004), for example, found that spatial dance information improved colony foraging success only in a tropical environment, but not in two different European temperate habitats. In general, the availability and spatial distribution of food sources has been shown to play an important role: recruitment communication was most profitable in environments with patchily distributed (non-random) food sources (Beekman \& Lew, 2007; A Dornhaus, 2006; Anna Dornhaus \& Chittka, 2004; Sherman \& Visscher, 2002; Schürch \& Grüter, unpublished data). Furthermore, in environments with clustered or ephemeral food sources, such as in the tropical habitat studied by Dornhaus \& Chittka (2004), the pay-off of social information was highest, presumably because communication allowed workers to locate profitable, but hard to find food sources 
(Sherman \& Visscher 2002; Dornhaus \& Chittka 2004). By contrast, in environments with a large number of food sources, the costs of communicating appear to outweigh its' benefits, therefore favoring a solitary foraging strategy (Sherman \& Visscher 2002; Dornhaus \& Chittka 2004). Combined, these empirical and theoretical results suggest that communication is important only in particular ecological contexts.

However, the ecological factors analyzed so far (availability and distribution of food sources) are not sufficient to fully explain the evolution of recruitment mechanisms in social insects. The absence of this kind of communication in many species of the Neotropical group of stingless bees (Meliponini) suggests that the spatiotemporal distribution of food sources is not the only factor shaping the evolution of social information use. With more than 600 described species, stingless bees are the largest group of highly eusocial bees (Rasmussen \& Cameron 2010). They inhabit tropical habitats around the world and show a great diversity in their behaviour and ecology (Lindauer \& Kerr 1960; Jarau 2009; Hrncir 2009; Hrncir \& MaiaSilva; Roubik 2006). This diversity is also reflected in the variety of feeding strategies adopted by different species. The strategies are described based mainly on three traits: recruitment ability (solitary or group foraging), individual aggressiveness (present or absent) and local enhancement in heterospecific encounters (attraction or avoidance) (Hrncir \& MaiaSilva 2013). When recruitment occurs the mechanism used to communicate about food sources is mostly indirect recruitment, i.e. bees use pheromones to mark food sources and the trails between the nest and the foraging site (Jarau et al. 2004; Schorkopf et al. 2007; Barth et al. 2008; Stangler et al. 2009; Jarau 2009). Local enhancement and inhibition are not related to recruitment ability, since it is present in both solitary and group foraging and the reaction to heterospecifics seems to be dependent on the body size and aggressiveness of foragers (Slaa \& Hughes 2009).

This diversity of foraging strategies is puzzling given the evidence from honeybee studies that spatial communication is beneficial in tropical habitats (Sherman \& Visscher 2002; Dornhaus \& Chittka 2004). Up to $90 \%$ of the food sources collected by Neotropical stingless bees is provided by mass flowering plants, which are clustered and ephemeral resources (Hrncir 2009; Hrncir \& Maia-Silva 2013). So why do foragers of some species, but not those of others communicate about food source locations if communication is inherently beneficial in such tropical habitats?

One possible explanation for solitary foraging strategies is competition between stingless bee species. Competition for food sources is an important factor in the foraging ecology of these 
social bees, since the foraging range of different stingless bees species and colonies often overlap (Johnson \& Hubbell 1974; Biesmeijer et al. 1999). Three strategies to deal with competition have been identified in Meliponi: "competition winners", "competition avoiders" and "competition indifference" (Hrncir 2009). "Competition winners" represents a strategy whereby a group of bees quickly monopolizes a food source and aggressively repels heterospecifics as well as non-nestmate conspecifics (Hrncir 2009). Mechanisms of mass recruitment are often observed in these species and a potential cost of this strategy is a reduced ability to find new foraging sites (Hrncir 2009). The "competition avoiders" are bees that change the foraging site as soon as they are chased away by competition winners (Hrncir 2009). In these species, recruitment mechanisms often have little or no location specificity and foragers rely on general information about food sites (e.g. flower odors). An advantage of this strategy might be a better ability to discover new food sources (Hrncir 2009). In the "competition indifference" strategy, foragers of different species collect food at the same places without having physical contact with other bees (Hrncir 2009).

The observed patterns suggest that stingless bee foraging methods have evolved in a highly competitive environment where the benefits of a recruitment system might not only depend on the spatiotemporal distribution of food sources, but also on the strategies of competitors. We hypothesize that competition could explain the absence of recruitment communication in some species. Since some bees will be easily chased way by more aggressive species, food sources will be more short-lived and unstable for these "competition avoiders". Therefore, communication might not be profitable for bees that cannot monopolize resources, e.g. due to their small size. Researchers have speculated that competition could shape recruitment systems and communication in stingless bees (e.g. Nieh 2004), but so far this remains an unexplored hypothesis (Nieh 2004; Beekman \& Lew 2007). In order to test our hypothesis that interspecific competition affects the benefits of communication we will develop an agent based simulation model (ABM) of foraging stingless bee colonies in dynamic environments.

\section{Agent based models (ABM's)}

ABM's have become increasingly popular in biology because they enable researchers to build models where individual agents and their interactions are directly represented and can be observed. They allow researchers to perform simulations in highly controllable environments and study general patterns that emerge as a result of interactions between agents or between 
agents and their environment. One advantage of agent based models compared to most mathematical models is that agents can be heterogeneous in their strategies and abilities. ABM's are also becoming more popular to study insect foraging and colony organisation (Dornhaus et al. 2006; Beekman \& Lew 2008; Johnson 2009; Johnson et al. 2011; Grüter et al. 2012, 2013).

\section{Methods}

We will develop an agent based simulation model to understand the factors that might explain the absence of social information use in the Meliponini group. In particular, we test if interspecific competition reduces the benefits of communication. Additionally, we will consider other important factors, e.g. the spatial distribution, quality and availability of food sources.

We will use the free software NetLogo (Wilensky 1999) to develop the model. NetLogo is a relatively new, powerful and easy to use software that has been used recently to model social insect behaviour (e.g. Johnson 2009; Johnson et al. 2011; Grüter et al. 2012; Gruter et al. 2013). The processing power of a laptop computer is sufficient to run the simulations.

\section{The model}

We will develop a spatially-explicit model of interacting agents. In the model different colonies of agents will occupy randomized locations in a two-dimensional grid that also contains various food patches of variable sizes and qualities. The model runs in discrete time steps that correspond to real time. We explore two scenarios: In the first, our focal colonies will follow a "competitor avoidance" strategy, i.e. colonies will abandon a food source if they encounter "competition winners". In the second scenario, focal colonies will only abandon food sources if they are outnumbered at food sources. The second scenario allows colonies to respond in a more fine-tuned manner to competition. We will test the foraging success of focal colonies with and without communication in environments with and without competitors. Recruitment strength and costs will be manipulated to explore their effects. Competitors will vary in number and recruitment system. Additionally, we will vary the number of food patches, their quality, variance and longevity. The values used to parameterise the model will be taken from the stingless bee and honeybee literature. Additionally, we will 
perform a sensitivity analysis to explore whether the main findings are robust to changes of parameter values.

\section{Statistical analyses}

Due to the stochastic nature of simulations, we will run a minimum of 50 simulations for each combination of parameters. Results can then be analyzed using standard statistical tests, such as ANOVA's (Sokal \& Rohlf 1995).

\section{References}

Barth, F. G., Hrncir, M. \& Jarau, S. 2008. Signals and cues in the recruitment behavior of stingless bees (Meliponini). Journal of comparative physiology. A, Neuroethology, sensory, neural, and behavioral physiology, 194, 313-27.

Beekman, M. \& Lew, J. B. 2007. Foraging in honeybees--when does it pay to dance? Behavioral Ecology, 19,

Biesmeijer, J. C., Richter, J. A. P., Smeets, M. A. J. P. \& Sommeijer, M. J. 1999. Niche differentiation in nectar-collecting stingless bees: the influence of morphology, floral choice and interference competition. Ecological Entomology, 24, 380-388.

Dornhaus, A. 2006. Benefits of recruitment in honey bees: effects of ecology and colony size in an individual-based model. Behavioral Ecology, 17,

Dornhaus, A. \& Chittka, L. 2004. Why do honey bees dance? Behavioral Ecology and Sociobiology, 55,

Dussutour, A. \& Beekman, M. 2009. How to Tell Your Mates. In: Food Exploitation By Social Insects, Contemporary Topics in Entomology pp. 115-134. CRC Press.

Gruter, C., Schuch, R. \& Farina, W. 2013. Task-partitioning in insect societies: Non-random direct material transfers affect both colony efficiency and information flow. Journal of theoretical biology, 327, 23-33.

Grüter, C. \& Leadbeater, E. 2014. Insights from insects about adaptive social information use. Trends in ecology \& evolution, 29, 177-184.

Grüter, C., Schürch, R., Czaczkes, T., Taylor, K., Durance, T., Jones, S. \& Ratnieks, F. 2012. Negative feedback enables fast and flexible collective decision-making in ants. PloS one, 7,

Hrncir, M. 2009. Mobilizing the Foraging Force. In: Food Exploitation By Social Insects, Contemporary Topics in Entomology pp. 199-221. CRC Press. 
Hrncir, M. \& Jarau, S. 2009. Introduction. In: Food Exploitation By Social Insects, Contemporary Topics in Entomology pp. 1-5. CRC Press.

Hrncir, M. \& Maia-Silva, C. 2013. On the Diversity of Foraging-Related Traits in Stingless Bees. In: Pot-Honey SE - 13, (Ed. by P. Vit, S. R. M. Pedro, \& D. Roubik), pp. 201-215. Springer New York.

Jarau, S. 2009. Chemical Communication during Food Exploitation in Stingless Bees. In: Food Exploitation By Social Insects, Contemporary Topics in Entomology pp. 223-249. CRC Press.

Jarau, S., Hrncir, M., Zucchi, R. \& Barth, F. G. 2004. A stingless bee uses labial gland secretions for scent trail communication ( Trigona recursa Smith 1863). Journal of comparative physiology. A, Neuroethology, sensory, neural, and behavioral physiology, 190, 233-9.

Johnson, B. 2009. A self-organizing model for task allocation via frequent task quitting and random walks in the honeybee. The American naturalist, 174, 537-547.

Johnson, L. K. \& Hubbell, S. P. 1974. Aggression and competition among stingless bees: field studies. Ecology, 120-127.

Johnson, B., van Wilgenburg, E. \& Tsutsui, N. 2011. Nestmate recognition in social insects: overcoming physiological constraints with collective decision making. Behavioral ecology and sociobiology, 65, 935-944.

Leadbeater, E. \& Chittka, L. 2009. Social Information Use in Foraging Insects. In: Food Exploitation By Social Insects, Contemporary Topics in Entomology pp. 135-146. CRC Press.

Nieh, J. C. 2004. Recruitment communication in stingless bees (Hymenoptera, Apidae, Meliponini). Apidologie, 35, 159-182.

Roubik, D. W. 2006. Stingless bee nesting biology. Apidologie, 37, 124-143.

Schorkopf, D. L. P., Jarau, S., Francke, W., Twele, R., Zucchi, R., Hrncir, M., Schmidt, V. M., Ayasse, M. \& Barth, F. G. 2007. Spitting out information: Trigona bees deposit saliva to signal resource locations. Proceedings. Biological sciences / The Royal Society, 274, 895-8.

Sherman, G. \& Visscher, P. 2002. Honeybee colonies achieve fitness through dancing. Nature, 419, 920-922.

Slaa, E. J. \& Hughes, W. H. 2009. Local Enhancement, Local Inhibition, Eavesdropping, and the Parasitism of Social Insect Communication. In: Food Exploitation By Social Insects, Contemporary Topics in Entomology pp. 147-164. CRC Press.

Stangler, E. S., Jarau, S., Hrncir, M., Zucchi, R. \& Ayasse, M. 2009. Identification of trail pheromone compounds from the labial glands of the stingless bee Geotrigona mombuca. Chemoecology, 19, 13-19. 